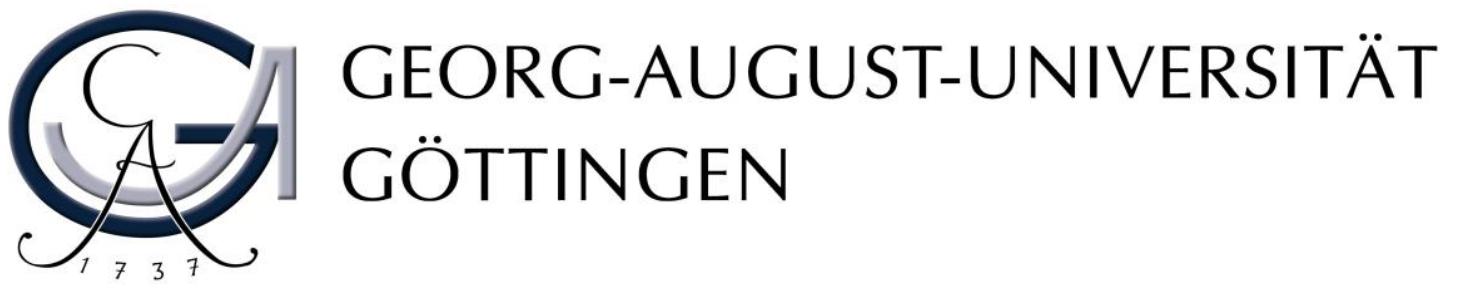

\title{
ISOLATION AND CHARACTERISATION OF SYNAPTIC VESICLES FROM MOUSE BRAIN
}

\author{
Dissertation \\ for the award of the degree \\ "Doctor rerum naturalium" \\ Division of Mathematics and Natural Sciences \\ of the Georg-August-University Göttingen, \\ submitted by \\ Saheeb Ahmed
}

from Sargodha, Pakistan

Göttingen 2010 
Member of the Thesis Committee:

Prof. Dr. Reinhard Jahn (Referee)

Department of Neurobiology

Max-Planck-Institute for biophysical Chemistry, Göttingen

\section{Prof. Dr. Nils Brose (Referee)}

Department of Molecular Biology

Max-Planck-Institute for experimental Medicine, Göttingen

Date of oral examination: November $2^{\text {nd }} 2010$. 
I hereby declare that the Ph.D. thesis entitled "Isolation and Characterisation of synaptic vesicles from mouse brain" has been written independently and with no other sources and aids than quoted.

Saheeb Ahmed

Göttingen, September $20^{\text {th }} 2010$. 
"In the name of Allah, the Gracious, the Merciful.

All praise belongs to Allah, Lord of all the worlds,

The Gracious, the Merciful,

Master of the Day of Judgment.

Thee alone do we worship and Thee alone do we implore for help.

Guide us in the right path -

The path of those on whom Thou hast bestowed Thy blessings, those who have not incurred Thy displeasure, and those who have not gone astray."

The Holy Quran

Chapter 1, Verse 1:7 


\title{
Table of Contents
}

\begin{abstract}
\end{abstract}
1. Introduction

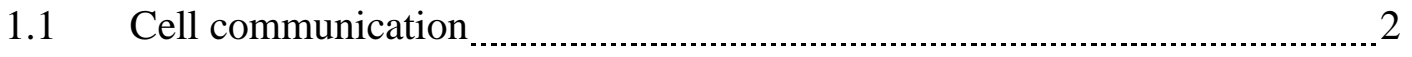

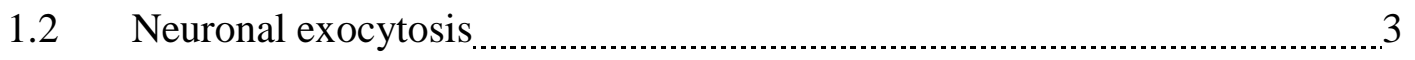

1.3 Synaptic vesicles $\quad 7$.

1.4 Synaptic vesicle isolation procedure (history) ….......................................... 11

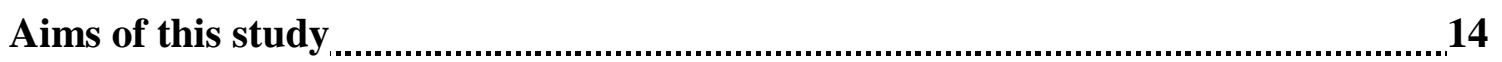

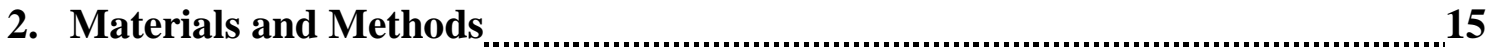

2.1 Materials 15

2.1.1 Antibodies $\ldots \ldots$

2.1.2 Buffers 18

2.1.3 Chemicals

2.1.4 Centrifuges $\quad 23$

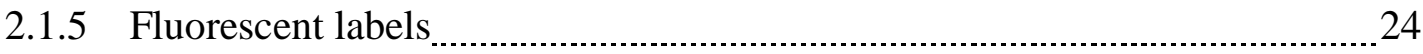

2.1.6 Gelsystems _ _

2.1 .7 Instruments $\quad \ldots \ldots \ldots$

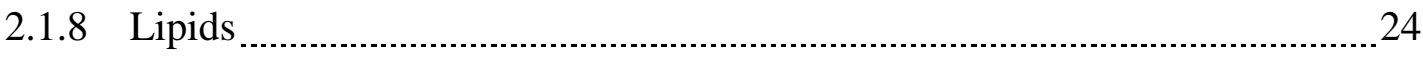

2.1 .9 Rotors $\quad 25$

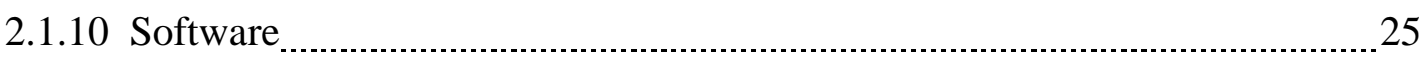

2.1 .11 Others

2.2 Methods

2.2.1 Purification of synaptic vesicles from mouse brain _ _ _ . . 27

2.2.2 Determination of protein concentration $\ldots$

2.2.3 Preparing and running SDS-PAGE mini gels _......................................... 27

2.2.4 Immunoblotting 28 
2.2.5 Electron microscopy (negative staining, cryo and Immunogold labelling) _...29

2.2.6 Monitoring acidification of synaptic vesicles 29

2.2.7 Neurotransmitter uptake 30

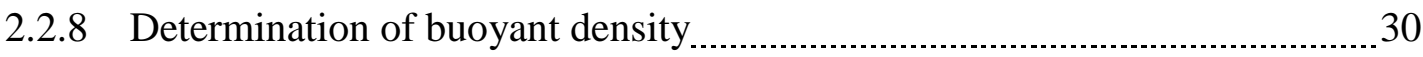

2.2.9 Proteoliposome synthesis 31

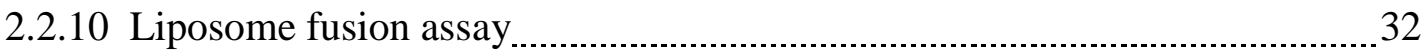

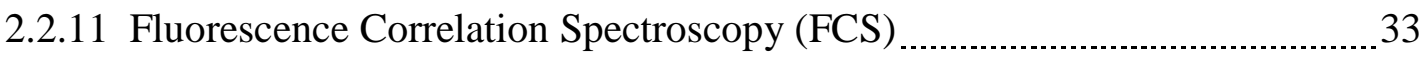

2.2.12 Lipid analysis

3. Results

3.1 Establishment of a new protocol for isolation of synaptic vesicles from small samples

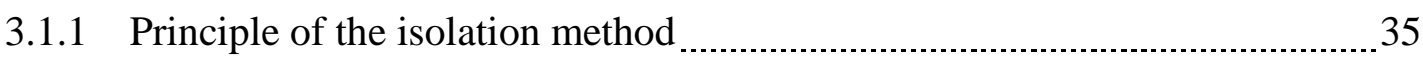

3.1.2 Optimisation of the isolation procedure 38

3.2 Biochemical and morphological characterisation of synaptic vesicles _........ 40

3.2.1 Distribution of SV proteins and marker proteins for other compartments $\quad 40$

3.2.2 Characterisation of synaptic vesicle fractions by electron microscopy _........ 43

3.3 Quantitative analysis of physical parameters

3.3.1 Size determination by cryo EM 46

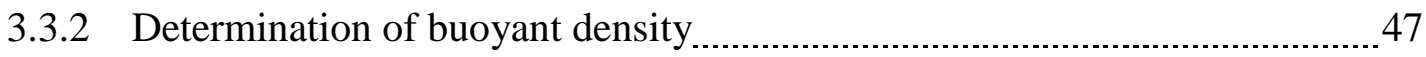

3.3.3 Vesicle counting by FCS and derivation of vesicular mass _........................ 48

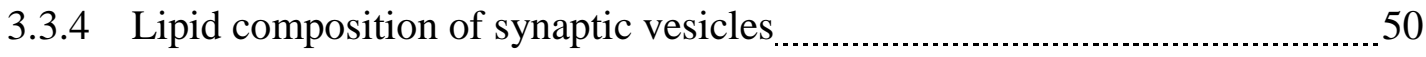

3.4 Functional characterisation of synaptic vesicles _..................................... 51

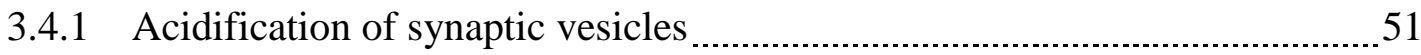

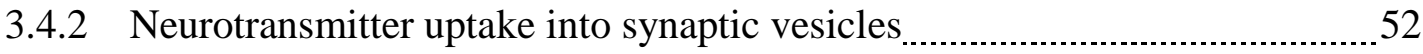

3.4.3 SNARE mediated fusion $\ldots \ldots \ldots$

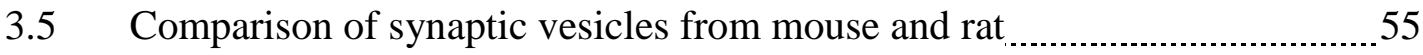

3.5.1 Distribution of SV and other marker proteins of rat synaptic vesicles _........ 55

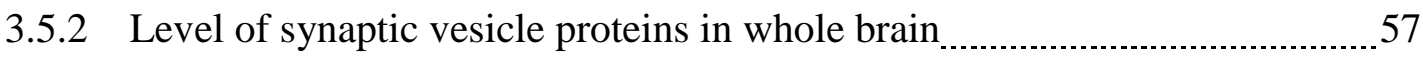

3.5.3 Quantitaion of major SV proteins on mouse and rat vesicles _..................... 59 
3.5.4 Quantitative analysis of physical parameters and lipids of rat synaptic vesicles 61

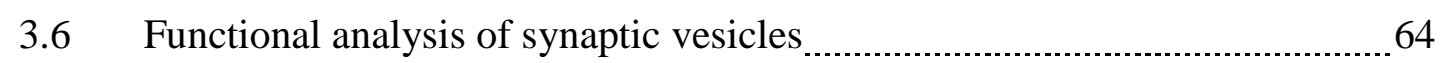

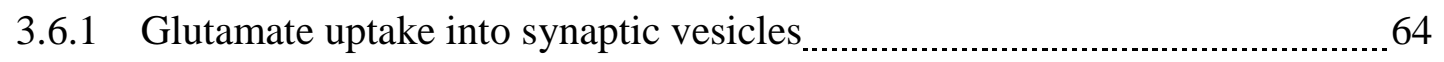

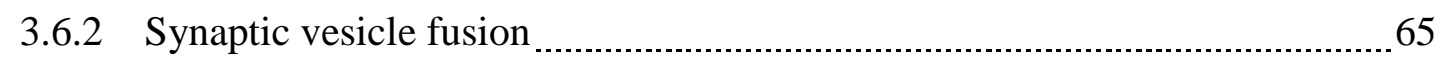

3.7 Analysis of subcellular fractions from Rab-GDI 1 KO mice $\ldots \ldots \ldots \ldots \ldots \ldots \ldots \ldots \ldots . . . . . . . . . . . . . .67$

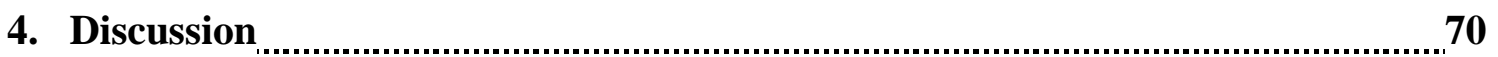

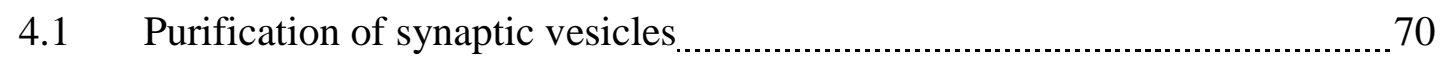

4.2 SNARE mediated fusion, structural integrity and functionality of synaptic vesicles

4.3 Distinctions and similarities between mouse and rat 75

4.4 Effects of Rab-GDI1 deletion on Rab-GTPases _.................................... 76

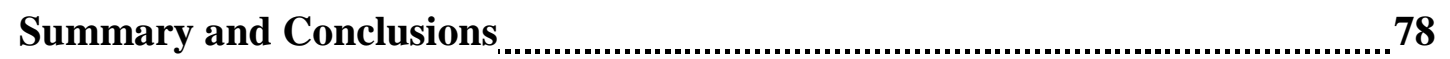

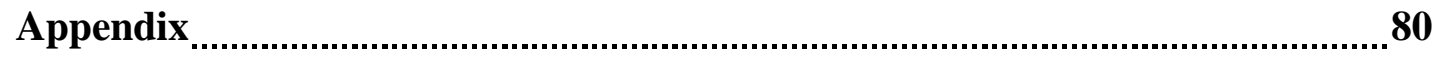

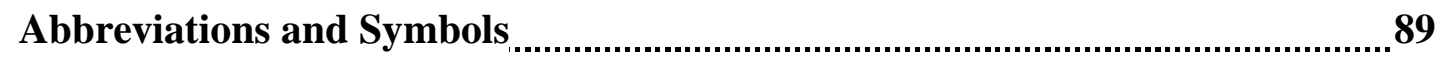

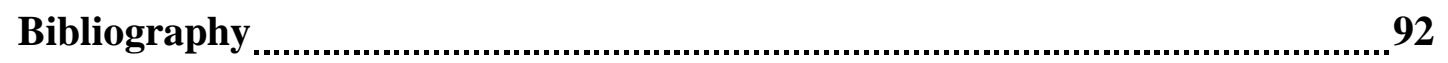

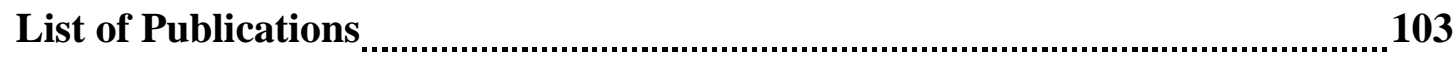

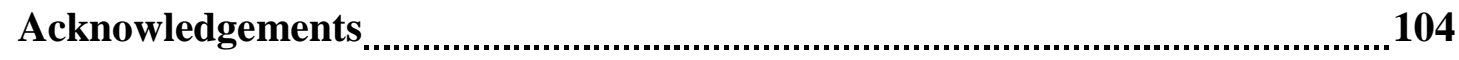

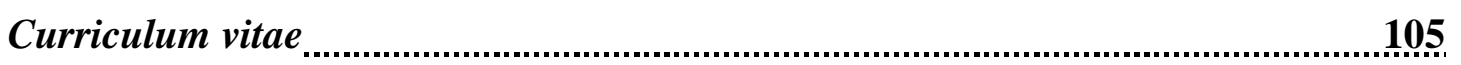




\section{List of Figures}

Figure 1. Illustration of synaptic vesicle cycle

Figure 2. Structure of SNARE core-complex

Figure 3. SNARE mediated exocytosis $\quad$ S 6

Figure 4. Molecular model of a synaptic vesicle $\quad 10$

Figure 5. Flow schematic illustrating the basic steps in synaptic vesicle purification

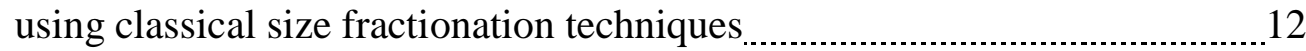

Figure 6. Images of pellets and supernatants obtained during synaptic vesicle

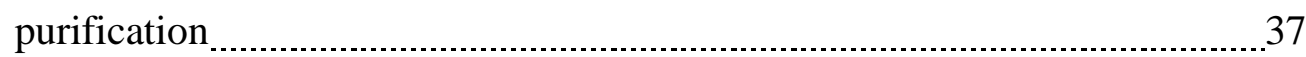

Figure 7. Optimisation of the sucrose cushion step 38

Figure 8. Separation by SDS-PAGE of subfractions taken during the isolation of synaptic vesicles

Figure 9. Effects of size exclusion chromatography on synaptic vesicle purity assessed by electron microscopy.

Figure 10. Size distribution of synaptic vesicles, determined by cryo electron microscopy. 46

Figure 11. Determination of buoyant density of synaptic vesicles using iodixanol density gradients

Figure 12. Determination of synaptic vesicle concentration by Fluorescence Correlation Spectroscopy 49

Figure 13. Quantitative measurements of synaptic vesicle lipids _...............................50

Figure 14. Glutamate induced acidification of synaptic vesicles _................................ 51

Figure 15. Glutamate uptake into synaptic vesicles ................................................ 52

Figure 16. SNARE mediated fusion of synaptic vesicles with liposomes _..................... 54

Figure 17. Protein profile of subfractions from rat synaptic vesicle preparation _...........56

Figure 18. Synaptophysin and synaptobrevin level in brain homogenates _....................58

Figure 19. Quantitative comparison of major synaptic vesicle proteins from mouse and rat 60 
Figure 20. Physical and biochemical characterisation of rat synaptic vesicles _............. 62

Figure 21. Glutamate uptake by two synaptic vesicle populations _............................... 64

Figure 22. Mouse and rat synaptic vesicle fusion with liposomes _................................66

Figure 23. Electron micrograph of synaptic vesicles from Gdil-deficient mice _............ 67

Figure 24. Synaptic vesicles from knock-out mice retain their functionality _................. 68

Figure 25. Subcellular distribution of Rab GTPases and synaptic vesicle proteins .........69

Appendix Figure 1. Level of synaptic vesicle proteins in brain homogenate _................... 80

Appendix Figure 2. Quantitative analysis of Rab-GTPases in LP2, LS2

and SV fractions 


\section{List of Tables}

Table 1. Primary antibodies used in establishment of SV isolation protocol _............. 15

Table 2. Primary antibodies used for Rab-GTPases screening _. 18

Table 3. Composition of one $10 \%$ SDS-PAGE mini gel _ _ _ 28

Table 4. Quantification of synaptic vesicle enrichment during the isolation procedure

Table 5. Physical parameters of mouse and rat synaptic vesicles $\quad$ _................................

Appendix Table 1. Epitope sequences for antibody binding _. 82

Appendix Table 2. Summary of proteins identified by mass spectrometry in purified mouse synaptic vesicles 


\begin{abstract}
All eukaryotic cells exhibit a constant turnover of membrane components via trafficking of vesicles between subcellular compartments. A classical example of a dynamic membrane delimited organelle exhibiting a high degree of complexity in terms of structure and function is the synaptic vesicle (SV), which participates in the release of neurotransmitter from neurons. Biochemical analysis of purified SVs was instrumental in the identification and understanding of proteins involved in exocytotic membrane fusion and neurotransmitter uptake. Numerous protocols have been established detailing the isolation of SVs from brain. Protocols resulting in highly purified vesicles often have extremely low yields compared to the starting material required. Here I describe an improved protocol for the small-scale isolation of synaptic vesicles from mouse and rat brain. The procedure relies on standard fractionation techniques, including differential centrifugation, rate-zonal centrifugation and size-exclusion chromatography. The protocol has been optimised to minimize vesicle loss and increase yield during preparation while maintaining a high degree of purity. The protocol can be completed in a very short time compared to classical protocols. Immunoblotting and electron micrographs showed high purity, enrichment profile of one of the most abundant vesicle protein synapotphysin revealed maximum enrichment in the final SV fraction. This opens the possibility to purify SVs from genetically modified mice to further explore the biochemistry of the neurotransmitter release process. Therefore, I purified SVs from Rab-GDI knock-out mice to ensure the applicability of this new protocol. Furthermore, I carried out the biochemical and morphological characterisation of mouse SVs and compared them to rat SVs. To determine any differences of SVs between these two species, physical parameters were analysed like diameter, mass and density. I found that SVs from mouse and rat are relatively similar except for minor differences in their physical parameters, protein and lipid compositions. To characterise the role of SNARE proteins in membrane fusion and to check for the fusogenic properties of the purified vesicles, in-vitro fusion assays were performed with liposomes containing syntaxin 1 and SNAP-25 and glutamate uptake as a general function was monitored.
\end{abstract}




\section{Introduction}

\subsection{Cell communication}

The principle of cell-cell communication is that a cell delivers a signal to a target cell which leads to a response. This communication can take place in various types, e.g. via direct cell contact through surface bound signalling and receptor molecules, or indirect through diffusion of signal molecules from the signalling cell to the target cell. In the case of synaptic transmission, these signal molecules are stored in synaptic vesicles (SVs) (Heuser et al., 1979), which are small membrane bound structures that can fuse with the target plasma membrane. Upon fusion of these secretory vesicles with the plasma membrane, signal molecules are released and recognised by receptor proteins on the target cell which triggers a specific response. Communication between neurons takes place at specialised junctions at the termini of axons between the pre- and post-synapse. In this process, a neuron sends electrical impulses along the axon with a speed of up to $100 \mathrm{~m} / \mathrm{s}$ (Nicholls et al., 1992). Upon reaching the presynaptic nerve terminal, this electrical signal is converted into a chemical form. The electrical impulse stimulates the nerve terminal, which leads to the release of neurotransmitter into the synaptic cleft (exocytosis). The synaptic cleft is a very narrow gab between the pre- and the post-synapse and the released neurotransmitter diffuses across this synaptic cleft in less than $1 \mathrm{~ms}$ and binds to receptors on the postsynapse. This binding triggers a series of physiological changes in the postneuron which constitutes the signal. To maintain the activity and integrity of a synapse, synaptic vesicles need to be recycled and this proceeds by clathrin mediated endocytosis, followed by refilling with neurotransmitter to prepare them for a new round of exocytosis after arrival of another electrical impulse. 


\subsection{Neuronal exocytosis}

The functional unit of neurotransmitter release are synaptic vesicles. When an action potential arrives at the synaptic terminal, the plasma membrane is depolarised which leads to the opening of voltage-gated $\mathrm{Ca}^{2+}$ channels in the plasma membrane. Influx of calcium leads to raise intracellular $\mathrm{Ca}^{2+}$ concentration and triggers the fusion (exocytosis) of synaptic vesicles (SVs) with the plasma membrane. Once a vesicle reaches the presynaptic membrane, it undergoes a series of protein - protein and protein - lipid interactions leading to fusion competence (Jahn et al., 2003). To maintain synapse activity and integrity, SVs are recycled from the presynaptic plasma membrane primarily by the clathrin-mediated endocytotic pathway (Granseth et al., 2006) (Fig. 1). Synaptic vesicles are subsequently processed in the early endosomes which then leads to the formation of a fusion competent vesicle for subsequent rounds of exocytosis (Südhof, 2004).

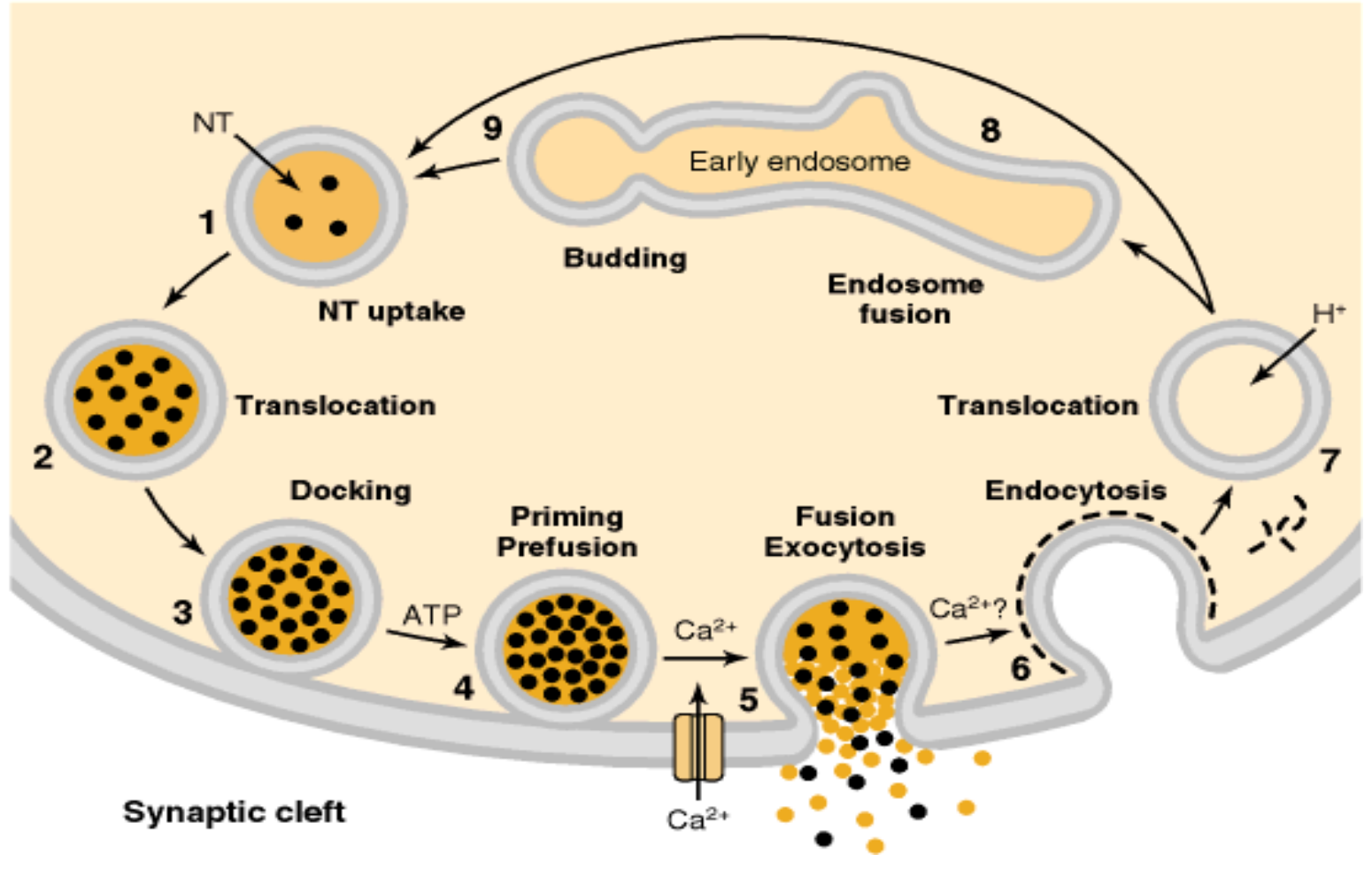

Figure 1. Illustration of synaptic vesicle cycle (Südhof, 1995). The pathway of SVs in the nerve terminal is divides into 9 stages. 1: Synaptic vesicles are filled with neurotransmitter by an active transport through neurotransmitter transporters. 2: Filled SVs are translocated to the active zone where they undergo sequential steps of 3. docking and 4. priming and prefusion to the target membrane. 5: Exocytosis of vesicles takes 
place upon $\mathrm{Ca}^{2+}$ influx through voltage-gated $\mathrm{Ca}^{2+}$ channels. 6: Scission occurs mediated by dynamin, vesicles are then coated with clathrin and undergo clathrin-mediated endocytosis. 7: After disassembly of the clathrin coat, acidification of vesicles takes place via proton pump activity and transported to 8: early endosomes, intermediate sorting compartment followed by 9: regeneration by budding from endosomes. Although some vesicles can by-pass endosomal processing and can go directly from step 7 to step 1 .

Synaptic vesicles have been used as a classical example to illustrate the physico-chemical properties of a membrane trafficking organelle. Detailed analysis of the protein composition of rat SVs revealed (Takamori et al., 2006) the presence of numerous integral membrane proteins among which the SNARE family (soluble NSF attachment protein receptor where NSF stands for $N$-ethyl-maleimide-sensitive fusion protein) are the predominant proteins. Membrane fusion is mediated and regulated by various factors among which SNARE proteins are thought to constitute the basic fusion machinery (Brunger, 2001; Chen \& Scheller, 2001; Jahn et al., 2003; Rizo \& Südhof, 2002). SNARE proteins are found in all intracellular organelles and mediate fusion events in the secretory pathway (Chen \& Scheller, 2001; Kavalali, 2002). The major proteins of the SNARE family that plays an essential role in fusion especially during neuronal exocytosis are synaptobrevin (Syb), SNAP-25 and syntaxin 1 (Syx 1). These SNARE proteins are characterised by the SNARE motif consisting of 60-70 amino acid strech arranged in heptad repates at the C-terminal end (Weimbs et al., 1997) (Fig. 2). Synaptobrevin and syntaxin 1 each have one SNARE motif, whereas SNAP-25 contains two SNARE motifs. Syntaxin 1 and SNAP-25 are mainly located in the presynaptic plasma membrane (Duman et al., 2003) whereas synaptobrevin is expressed with $\sim 70$ copies in an average SV membrane (Takamori et al., 2006). SNARE proteins undergo conformational changes during SV cycle (Fig. 3) with structural interaction between SVs and the presynaptic membrane. Interaction of SNARE proteins leads to core complex formation and drives fusion. After completion of fusion core complexes are disassembled (Söllner et al., 1993) and undergo a cycle (Fig. 1). SNAREs forming the core complex have been categorised into Qa - (syntaxin), Qb - (SNAP), Qc - (SNAP) and R-SNAREs (synaptobrevin) (Fasshauer et al., 1998; Bock et al., 2001). The Qa-,b-,c- SNAREs form an acceptor 
complex prior to fusion (Fiebig et al., 1999; Fasshauer et al., 2004) and interact with the Nterminal region of the R-SNARE that leads to formation of a loose trans-SNARE complex.

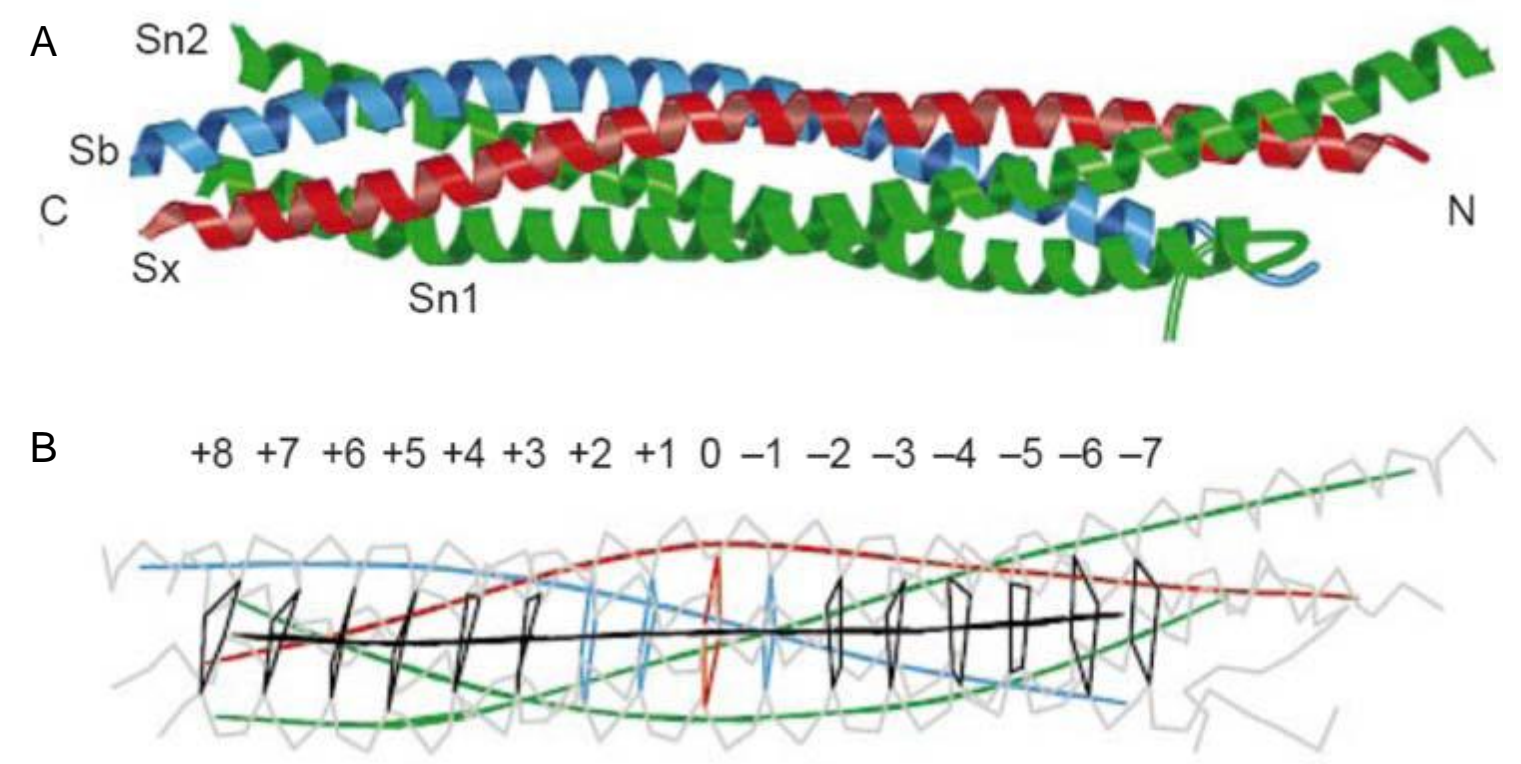

Figure 2. Structure of SNARE core-complex (Sutton et al., 1998). (A) Crystal structure of the synaptic core-complex. Helices of synaptobrevin 2 (sb, blue), C-terminal and N-terminal part of SNAP-25 (Sn1 and $\mathrm{Sn} 2$ green), syntaxin 1A (sx, red) are shown. (B) The layers structure of the synaptic core-complex from layers -7 to +8 ; 0 layer in red, $-1,+1,+2$ in blue and all other layers in back are illustrated.

The process of SNARE assembly starts from the $\mathrm{N}$-terminal to the C-terminal end of the SNARE motif and is described as "zippering" (Hanson et al., 1997). This so called zippering results in a structural transition of the loose trans-SNARE complex to a tight trans-SNARE complex and identified by the formation of four $\alpha$-helical bundles (Fig. 3). The states between loose and tight trans-SNARE complexes are thought to be reversible and reach equilibrium (Xu et al., 1999). The bilayers of the target and vesicular membranes merge the trans-SNARE complex into cis-complex which results in release of vesicle content. The cis-complex is disassembled by NSF and $\alpha$-SNAP to provide free SNARE molecules to participate in new formation of acceptor complexes for subsequent rounds of fusion (Söllner et al., 1993). In vitro studies on SNARE mediated fusion have been based on interaction between recombinant proteins, which not mimic the physiological mechanisms in a complex cellular environment. Synaptic vesicle fusion and neurotransmitter release shows a high degree of complexity which cannot be explained in 
précised detail using soluble recombinant proteins. But it can provide an insight into SNARE mediated fusion using artificial liposomes reconstituted with SNARE proteins.

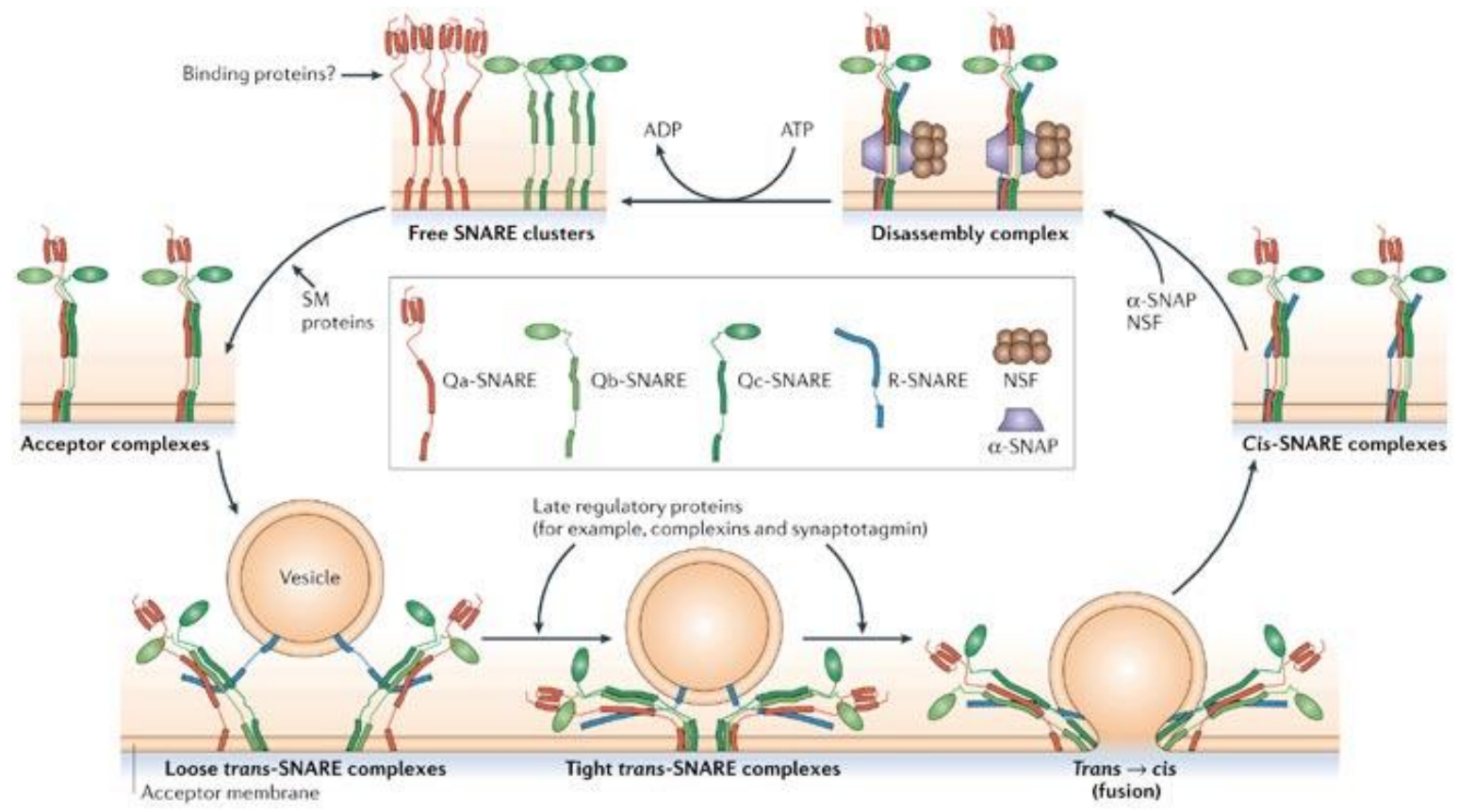

Figure 3. SNARE mediated exocytosis (Jahn \& Scheller., 2006). The Q-SNARE proteins (syntaxin 1 and SNAP-25) are located on the acceptor membrane as free clusters which are assembled into acceptor complexes by SM proteins (Sec1/Munc18-related proteins). The interaction of these acceptor complexes with vesicular R-SNARE (synaptobrevin) leads to formation of a loose trans-SNARE complex. This interaction is initiated by nucleation of the complex on the N-terminal region of the SNARE motif of the R-SNARE (synaptobrevin) followed by "zippering" of the SNARE motifs from N-terminal to C-terminal region forming a tight tans-SNARE complex. A "fusion pore" is formed across the bilayers through which neurotransmitters are released into the synaptic cleft. The transition states between loose and tight trans-SNARE complexes are regulated by proteins like complexin and synaptotagmin. The tight trans-SNARE complex is merged into the cis-complex during fusion and is disassembled by NSF (N-ethylmaleimide-sensitive factor) and $\alpha$-SNAP (soluble NSF attachment protein) and can form new acceptor complexes for subsequent rounds of fusion. 


\subsection{Synaptic vesicles}

Synaptic vesicles (SVs) are essential and characteristic organelles in the presynaptic terminal of chemical synapses. Synaptic vesicles are made of lipid bilayer in which proteins of different functions are inserted. Purified SVs have a protein:phoshoplipid ratio of 2:1 with a lipid composition of $(36 \%$ phosphatidylcholine (PC), $23 \%$ phosphatidylethanolamine (PE), 12\% phosphatidylserine (PS), 19\% phosphatidylinositol (PI) and 40\% cholesterol (Benfenati et al., 1989; Takamori et al., 2006). They are among the smallest trafficking organelles of mammalian cells and are highly abundant in brain tissue with approximately $5 \%$ of total protein content of mammalian central nervous system tissue. Because of the size of SVs they can not visualised by light microscopy. Synaptic vesicles were first discovered by high-resolution electron microscopy in the 50ies of the last century using fixed and embedded brain sections (Sjöstrand 1953; Palay \& Palade 1954; De Robertis \& Bennett 1954; Del Castillo and Katz 1955). It has been suggested that these vesicles might be the basis of transmitter release (Del Castillo and Katz 1955) and experiments have been demonstrated SV depletion on stimulation (Ceccarelli et al., 1973; Zimmermann \& Denston 1977). Katz and co-workers showed in a classic experiment that the transmission at the neuromuscular junction is 'quantal. A quantum is thought to correspond to the release of transmitter from one vesicle - the miniature endplate potential. The coordinated release of multiple vesicles during neuronal stimulation gives rise to the end plate potential (Del Castillo and Katz, 1954).

Even after the first morphological description of SVs based on electron micrographs, speculations about their function remained incomplete. Therefore it was necessary to isolate pure SVs for the understanding of their biochemistry and role in neurotransmitter storage and release. The first description for the isolation of SVs from brain extracts is dated back to 1964 (Whittaker et al., 1964). Thus, after the first description for SV purification, a large number of refined procedures were developed for the characterisation. After the first identification of SVs in 1953 to date numerous SV-specific proteins such as synapsin (Ueda et al., 1979; Huttner et al., 1983), synaptophysin (Wiedemann and Franke, 1985; Jahn et al., 1985), synaptotagmin (Matthew et al., 1981; Perin et al., 1990; Brose et al., 1992) were 
identified. Recent studies on SV revealed the complexity of these organelles. Takamori and colleagues provided a molecular model addressing the $\mathrm{SV}$ proteome and physical parameters such as size, shape and density (Takamori et al., 2006). This model and previous work presents novel insights into the structure of membranes, neurotransmitter uptake and storage, and the mechanism of membrane fusion. Synaptic vesicle proteins can be classified into two groups, first: proteins involved in neurotransmitter uptake and storage and second: proteins involved in membrane fusion.

Proteins that are involved in neurotransmitter uptake and storage: A) a vacuolar proton ATPase that creates a $\mathrm{pH}$ gradient and provides the energy to drive transmitter uptake. The V-ATPase is a complex enzyme which has at least 13 subunits (Sun et al., 1987; Adachi et al., 1990; Bowman et al., 1988; Xie \& Stone 1988; Wang et al., 1988; Hirsch et al., 1988; Takamori et al., 2006). B) Ion channels and electron transporters for charge compensation during transmitter uptake. The knowledge about ion channels of SV is still limited, but biochemical and electrophysical experiments have demonstrated the presence of cations and chloride channels (Rahamimoff et al., 1988). It was reported, that the glutamate transporter VGLUT1 represents the major chloride permeation pathway in SVs (Schenck et al., 2009). C) They are distinct neurotransmitter transporter on SVs for monoamines (Johnson, 1988), acetylcholine (Marshall \& Parson 1987), glutamate (Maycox et al 1990; Takamori et al., 2000) and GABA (Fykse \& Fonnum, 1988; Reimer et al., 1998). All transporters differ in their functional transport mechanism but all of them use either the $\mathrm{pH}$ gradient or membrane potential as the driving force.

Proteins involved in membrane fusion: The most abundant proteins involved in membrane fusion on SVs are synaptobrevin 2 (vamp 2) and synaptotagmin 1. Syntaxin 1 and SNAP25 are largely distributed on the presynaptic plasma membrane. Synaptobrevin 2, syntaxin 1 and SNAP-25 forms the core-complex that is essential for SV exocytosis. Synaptobrevin 2 is an integral membrane protein of $13 \mathrm{kDa}$ with a C-terminal transmembrane domain (Trimble et al., 1988; Baumert et al., 1989). It has been fist identified as the target for tetanus toxin and botulinum B toxin, cleavage of synaptobrevin between residue 76 and 77 by these neurotoxins leads to total inhibition of SV fusion (Link et al., 1992; Schiavo et al., 1992; McMahon et al., 1993). Synaptotagmin 1 is an integral 
membrane glycoprotein of $65 \mathrm{kDa}$, it has a N-terminal domain and a conserved cytoplasmic tail that contains two $\mathrm{Ca}^{2+}$ - binding sites (C2-domain). Upon influx of $\mathrm{Ca}^{2+}$ into the presynapse, synaptotagmin binds $\mathrm{Ca}^{2+}$ and triggers exocytosis of SVs. These two C2domains were first identified in cytoplasmic phospholipase $\mathrm{A}_{2}$ as $\mathrm{Ca}^{2+}$ binding sites (Clark et al., 1990; Brose et al., 1992). There are a large number of proteins identified as bona fide SV proteins, which are integral or peripheral membrane proteins, recent studies have been confirmed that many of them are either involved in exo-endocytosis. Another protein family that is believed to play an important role in exocytosis are Rab-GTPases. Rab proteins belong to the ras-related superfamily of small monomeric GTPases. Rab-GTPases are regulatory factors involved in vesicular trafficking in endocytic and secretory pathways where they mainly comprise in vesicle budding, docking and fusion. They can switch between GTP-bound (active) and GDP-bound (inactive) forms through the action of regulatory proteins. GDI (GDP dissociation inhibitor) is one among these regulatory proteins; to maintain the pool of soluble Rab-GDP it retrieves the GDP-bound form from the membrane. (Wu et al., 1996; Schalk et al., 1996). Synaptic vesicles contain several Rabs, the most abundant is Rab3a, which is also highly enriched in purified SVs (Fischer von Mollard et al., 1990). Experiments with synaptosomes have shown Rab3a dissociation from SVs upon stimulation of exocytosis (Fischer von Mollard et al., 1991). The functional role of some proteins like synaptophysin is still unknown or debated. Since SVs were first isolated, research of many groups have broadened our knowledge of the biochemistry and function of neurotransmitter uptake and release but there is still room for further discovery. 

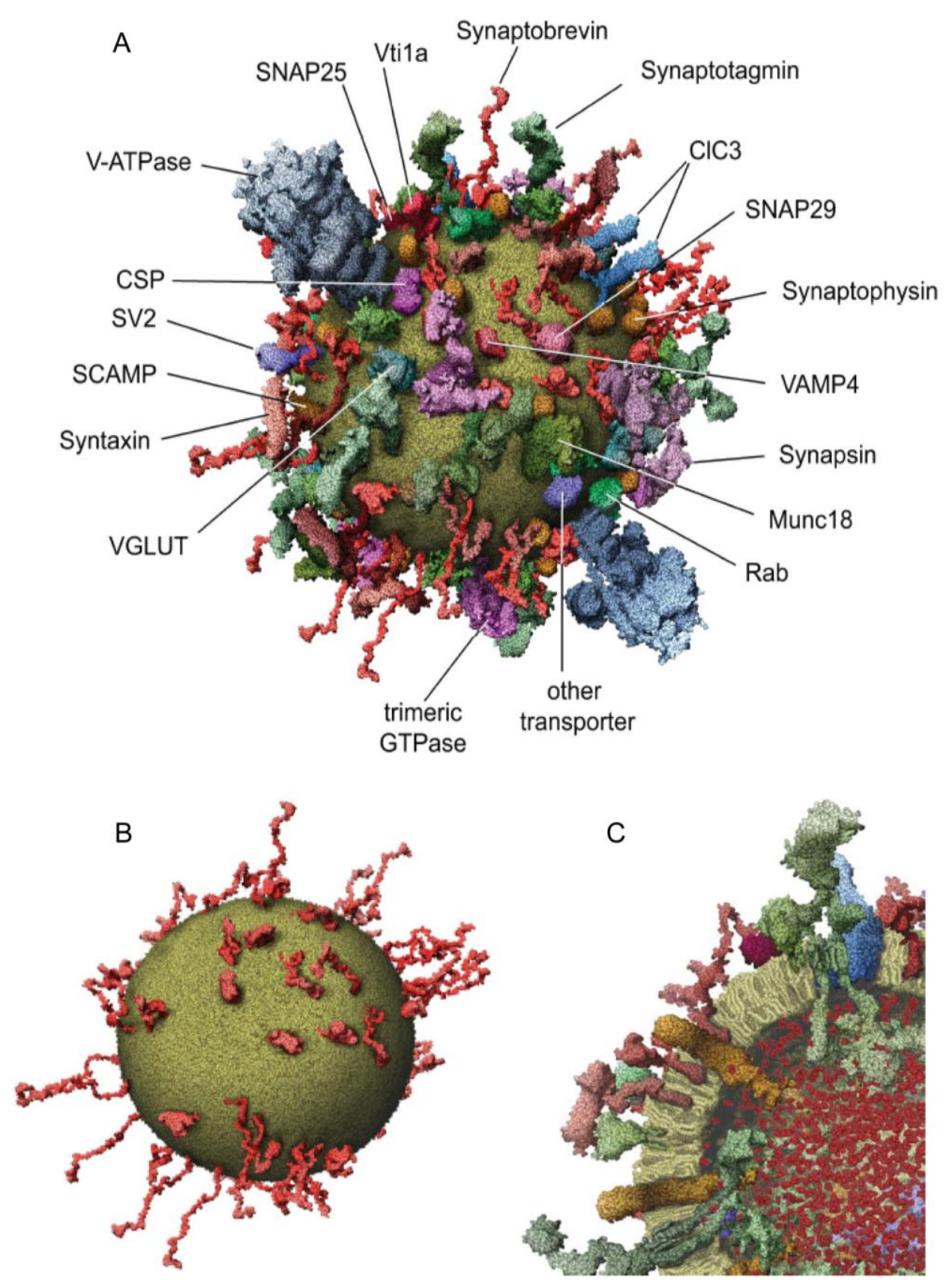

Figure 4. Molecular model of a synaptic vesicle (Takamori et al., 2006). (A) Outside view of a vesicle with various proteins. (B) Surface view of a vesicle, containing synaptobrevin as the most abundant vesicle protein that is randomly distributed. (C) Filled cross-section of a vesicle with neurotransmitters in red. 


\subsection{Synaptic vesicle isolation procedures (history)}

Indeed biochemical characterisation of purified synaptic vesicles (SVs) was instrumental in proving that SVs are the storage organelles for neurotransmitter and play an important role in membrane docking and fusion at the synapse. Protocols for synaptic vesicle isolation from brain homogenates were originally developed in 1960's. Whittaker attempted to isolate SVs from brain cortex in 1957 using "bound acetylcholine" as a marker, but what he actually isolated were synaptosomes containing SVs assessed by electron microscopy. Later on two independently groups purified crude fractions of SVs (De Robertis et al., 1961; Gray \& Whittaker 1960). Several methods have been developed for the isolation of SVs from brain (De Robertis et al., 1963; Whittaker et al., 1964; Lapetina et al., 1967; Kanaseki et al., 1969), but in all cases these SVs were contaminated by synaptosomal plasma membrane, myelin and membranes of the endoplasmic reticulum (Whittaker et al., 1964; Lapetina et al., 1967). In the early days De Robertis and colleague's assessed the purity of isolated SVs by electron micrographs, and later also by enzymatic assays (Morgan et al., 1973). The procedure described by Whittaker and colleagues (Whittaker et al., 1964) formed the basis for the protocols employed today. In that protocol, Whittaker separated SVs from synaptosomes. After homogenisation of the brain in a sucrose buffer, contaminants like membrane fragments, myelin etc. were partially separated from synaptosomes using centrifugation steps with low and moderate g-forces. The main purpose was to isolate relatively clean synaptosomes, from which SVs could be subsequently released. In order to release the SVs from these synaptosomes, he applied either an osmotic-shock with ice cold water or disrupted the synaptosomes by multiple freeze-thaw cycles. The released SVs were then separated from the disrupted membranes by discontinuous sucrose density gradients with a concentration range from $0.2 \mathrm{M}$ to $1.2 \mathrm{M}$. Analysis of the fractions from this gradient with electron microscopy showed small synaptic vesicles between $0.4 \mathrm{M}$ and $0.6 \mathrm{M}$ sucrose along with few large membrane structures as contaminants.

After the first description of a protocol for the isolation of SVs from brain a large number of more or less refined procedures were developed. Most of them date back to the 70ies and 
80ies of the last century; they were developed before sofisticated molecular tools were available for the characterisation of the isolated SVs. One of these protocols was from Nagy and colleagues (Nagy et al., 1976) and was widely regarded as the "gold standard" for highly purified SV preparation. This was followed by similar protocols with minor variations from Huttner and Hell (Huttner et al., 1983; Hell et al., 1988). With the identification of SV-specific proteins, morphological and biochemical homogeneity could be readily assessed, allowing the differentiating of the SVs from other vesicles. The conventional methods for SV isolation employing subcellular fractionation can be divided into two main groups. The first involves the isolation of synaptosomes (pinched-off nerve terminals) that are generated during gentle homogenisation of brain tissue (Gray \& Whittaker, 1962; Nagy et al., 1976; Huttner et al., 1983) (Fig. 5).

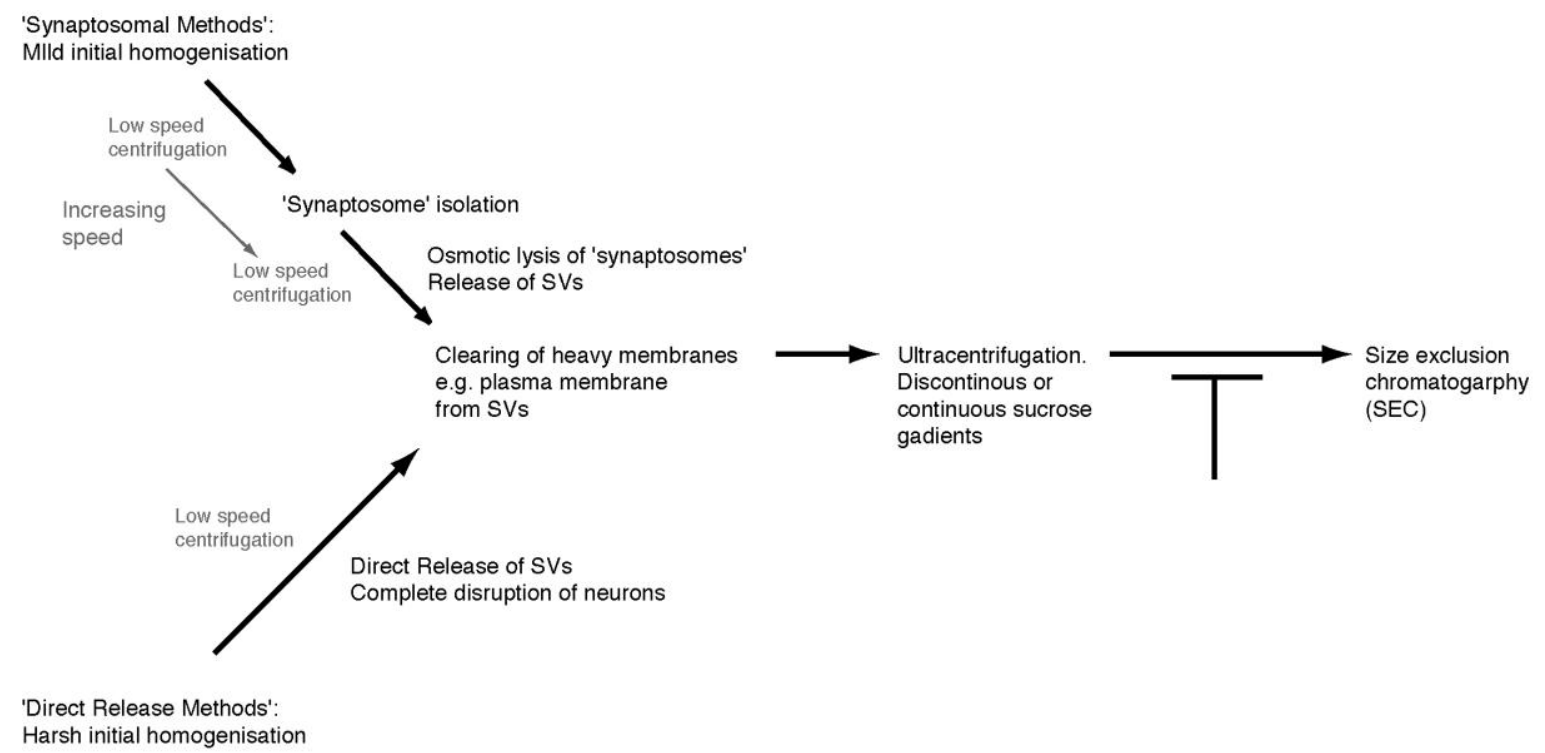

Figure 5. Flow schematic illustrating the basic steps in synaptic vesicle purification using classical size fractionation techniques.

Synaptic vesicles are then released by hypotonic rupture of synaptosomes and are further purified using differential and density gradient centrifugation. One of the disadvantages of this protocol is that during initial homogenisation many nerve terminals are damaged and release some of their SV-content into the supernatant. This results in loss of a fraction of 
the SVs at this stage. The second group of protocols involves direct isolation of SV from brain homogenates. Accordingly, homogenisation conditions can be harsher, and protocols using shock-frozen brains have been described (Hell et al., 1988). These protocols result in higher yield of isolated SVs, but it is more difficult to remove contaminants. In both protocols, the final purification steps usually involve a combination of differential and density gradient centrifugation, in addition to size-exclusion chromatography. Differential centrifugation takes advantage of the fact that vesicles are amongst the smallest organelles known, with high-speed ultracentrifugation being required to pellet them. Therefore, SV containing samples can be pre-centrifuged at relatively high g-forces, pelleting the larger membranes, while leaving the synaptic vesicles free in the supernatant. Density gradients are subsequently carried out as rate-zonal centrifugations, in which SVs migrate as a band that can be collected after it has separated from contaminants. Due to their small and homogeneous size, size-exclusion chromatography using CPG-beads (controlled pore glass beads) (Nagy et al., 1976) and Sephacryl (Stadler \& Whittaker, 1978) was frequently employed as a final purification step for synaptic vesicles, to further remove contaminating membranes and (if needed) any remaining cytosolic proteins. Size exclusion chromatography was first introduced by (Marchbanks, 1968) using columns packed with sephadex G-50 to separate membranes from SVs. Whittaker and colleagues later on used bio-gel agarose and carbowax-coated porous glass bead columns for the final separating step (Whittaker et al., 1972; Zimmermann \& Whittaker, 1974). Morris and co-worker showed that SVs can be separated from membrane fragments and soluble proteins using chromatography on glass beads of controlled pore size (CPG) (Morris, 1973) and this material was used in many classical protocols (Nagy et al., 1976; Huttner et al., 1983; Hell et al., 1988). 


\section{Aims of this study}

Biochemical characterisation of synaptic vesicles ( $\mathrm{SVs}$ ) is instrumental for understanding neurotransmitter storage and membrane fusion, access to transgenic animals with targeted deletions or mutations in SV proteins allows understanding of these events in more detail. However, isolation protocols for SVs from mammalian brain require large amounts of starting material and are time consuming. SV isolated by the novel procedure were to be characterised with respect to purity, structure and function. Therefore, it was the goal of this thesis to establish an isolation protocol for synaptic vesicles from mouse brain with comparatively small amounts of starting material where the yield and purity is optimised. Furthermore a biochemical comparison is carried out between SVs isolated from wildtype and transgenic mice, where the gene for Rab-GDI is deleted. With the limiting amount of starting material from transgenic mice, it is needed to establish a protocol to obtain SV from at least 1 mouse brain resulting in high yield and purity. To achieve this task, existing standard protocols to isolate SVs from rat brains had to be modified in terms of down-scaling and final yield. In line with this work conventional purification methods are applied, using differential and gradient centrifugation steps. For final purification size exclusion chromatography, which separates proteins according to their size is included. After purification of SVs, biochemical and physical characterisation has been done, this includes neurotransmitter uptake, SNARE dependent fusion with membranes, analysis of protein content and membrane lipids. As mentioned above, this protocol gives us access to transgenic mice to hopefully understand membrane fusion, neurotransmitter uptake and storage precisely and in more detail. Another advantage to purify SVs from mouse brain is to compare them with SVs from other species like rats, to determine any differences. 


\section{Materials and Methods}

\subsection{Materials}

\subsubsection{Antibodies}

Table 1. Primary antibodies used in establishment of SV isolation protocol.

\begin{tabular}{|c|c|c|c|c|}
\hline Protein & Supplier & $\begin{array}{c}\text { Catalogue } \\
\text { Number/Type }\end{array}$ & $\begin{array}{c}\text { Apparent } \\
\text { MW } \\
\text { (SDS- } \\
\text { PAGE) } \\
\end{array}$ & Comments \\
\hline Clathrin light chain & $\begin{array}{l}\text { Synaptic } \\
\text { Systems } \\
(\text { SySy) } \\
\end{array}$ & $\begin{array}{l}113011 \\
\text { Monoclonal }\end{array}$ & $\sim 30 \mathrm{kDa}$ & $\begin{array}{l}\text { Key component of the } \\
\text { endocytic clathrin coat. }\end{array}$ \\
\hline Dynamin & SySy & $\begin{array}{l}115002 \\
\text { Polyclonal }\end{array}$ & $\sim 100 \mathrm{kDa}$ & $\begin{array}{l}\text { GTPase involved in } \\
\text { vesicle scission during } \\
\text { endocytosis. }\end{array}$ \\
\hline $\mathrm{ERC} 1 \mathrm{~b} / 2$ & SySy & $\begin{array}{l}143003 \\
\text { Polyclonal }\end{array}$ & $\sim 110 \mathrm{kDa}$ & $\begin{array}{l}\text { Neuronal active zone } \\
\text { protein. }\end{array}$ \\
\hline $\begin{array}{l}\text { Glial fibrillary } \\
\text { acidic } \\
\text { protein (GFAP) }\end{array}$ & AbD Serotec & $\begin{array}{l}46500280 \\
\text { Polyclonal }\end{array}$ & $\sim 50 \mathrm{kDa}$ & Glial cell marker. \\
\hline $\begin{array}{l}\text { Lactate } \\
\text { dehydrogenase } \\
(\mathrm{LDH})\end{array}$ & $\begin{array}{l}\text { Chemicon } \\
\text { (Millipore) }\end{array}$ & $\begin{array}{l}\text { SC-33781 } \\
\text { Monoclonal }\end{array}$ & $\sim 35 \mathrm{kDa}$ & Soluble protein. \\
\hline $\mathrm{mSec} 22$ & $\begin{array}{l}\text { Verrier et al., } \\
2008\end{array}$ & N/A & $\sim 22 \mathrm{kDa}$ & $\begin{array}{l}\text { SNARE protein involved } \\
\text { in ER-Golgi transport. }\end{array}$ \\
\hline Munc-18 & SySy & $\begin{array}{l}116011 \\
\text { Monoclonal }\end{array}$ & $\sim 66 \mathrm{kDa}$ & $\begin{array}{l}\text { Membrane protein } \\
\text { involved in vesicle } \\
\text { docking and fusion. }\end{array}$ \\
\hline mUse1 & $\begin{array}{l}\text { Verrier et al., } \\
2008\end{array}$ & N/A & $\sim 31 \mathrm{kDa}$ & $\begin{array}{l}\text { SNARE protein involved } \\
\text { in ER-Golgi transport. }\end{array}$ \\
\hline $\begin{array}{l}\text { Myelin basic protein } \\
(\mathrm{MBP})\end{array}$ & Dako & $\begin{array}{l}\text { A0623 } \\
\text { Monoclonal }\end{array}$ & $\sim 20 \mathrm{kDa}$ & $\begin{array}{l}\text { Major protein component } \\
\text { of the neuronal myelin } \\
\text { sheath. }\end{array}$ \\
\hline $\mathrm{Na}^{+} / \mathrm{K}^{+}$-ATPase & Abcam & $\begin{array}{l}\text { AB7671 } \\
\text { Monoclonal }\end{array}$ & $\sim 110 \mathrm{kDa}$ & $\begin{array}{l}\mathrm{Na}^{+} / \mathrm{K}^{+} \text {transporter } \\
\text { specific for the plasma } \\
\text { membrane. }\end{array}$ \\
\hline NMDA-R1 & SySy & $\begin{array}{l}114011 \\
\text { Monoclonal }\end{array}$ & $\sim 110 \mathrm{kDa}$ & $\begin{array}{l}\text { Subunit of post-synaptic } \\
\text { NMDA glutamate } \\
\text { receptor. }\end{array}$ \\
\hline
\end{tabular}




\begin{tabular}{|c|c|c|c|c|}
\hline NSF & SySy & $\begin{array}{l}123001 \\
\text { Monoclonal }\end{array}$ & $\sim 68 \mathrm{kDa}$ & $\begin{array}{l}\text { Essential protein involved } \\
\text { in SNARE complex } \\
\text { disassembly. }\end{array}$ \\
\hline PSD-95 & Neuromab & $\begin{array}{l}75-028 \\
\text { Monoclonal }\end{array}$ & $\sim 110 \mathrm{kDa}$ & $\begin{array}{l}\text { Scaffolding protein at the } \\
\text { post-synaptic density. }\end{array}$ \\
\hline $\operatorname{Rab} 3 \mathrm{a}$ & SySy & $\begin{array}{l}107111 \\
\text { Monoclonal }\end{array}$ & $\sim 25 \mathrm{kDa}$ & $\begin{array}{l}\text { Small GTPase associated } \\
\text { with synaptic vesicles. }\end{array}$ \\
\hline Rab 5 & SySy & $\begin{array}{l}108011 \\
\text { Monoclonal }\end{array}$ & $\sim 25 \mathrm{kDa}$ & $\begin{array}{l}\text { Small GTPase associated } \\
\text { with SVs and recycling } \\
\text { endosomes. }\end{array}$ \\
\hline Rab-GDI & SySy & $\begin{array}{l}130001 \\
\text { Monoclonal }\end{array}$ & $\sim 65 \mathrm{kDa}$ & $\begin{array}{l}\text { Regulator of Rab protein } \\
\text { activity. }\end{array}$ \\
\hline Rpt 4 & Abcam & $\begin{array}{l}\text { AB22639 } \\
\text { Monoclonal }\end{array}$ & $\sim 44 \mathrm{kDa}$ & Proteasome component. \\
\hline $\begin{array}{l}\text { Succinate } \\
\text { dehydrogenase } \\
\text { (SDHA) } \\
\end{array}$ & Abcam & $\begin{array}{l}\text { AB14715 } \\
\text { Monoclonal }\end{array}$ & $\sim 70 \mathrm{kDa}$ & Mitochondrial protein. \\
\hline SNAP-25 & SySy & $\begin{array}{l}111111 \\
\text { Monoclonal }\end{array}$ & $\sim 25 \mathrm{kDa}$ & $\begin{array}{l}\text { Plasma membrane } \\
\text { SNARE protein involved } \\
\text { in neuronal exocytosis. }\end{array}$ \\
\hline SNAP-29 & SySy & $\begin{array}{l}111303 \\
\text { Polyclonal }\end{array}$ & $\sim 30 \mathrm{kDa}$ & $\begin{array}{l}\text { Plasma membrane } \\
\text { SNARE protein involved } \\
\text { in neuronal exocytosis. }\end{array}$ \\
\hline SNAP-47 & SySy & $\begin{array}{l}111403 \\
\text { Polyclonal }\end{array}$ & $\sim 50 \mathrm{kDa}$ & $\begin{array}{l}\text { SNARE protein with } \\
\text { unknown function, first } \\
\text { identified on synaptic } \\
\text { vesicles. }\end{array}$ \\
\hline Spliceosome $61 \mathrm{~K}$ & $\begin{array}{l}\text { Marakova et } \\
\text { al., } \\
2002\end{array}$ & N/A & $\sim 55 \mathrm{kDa}$ & $\begin{array}{l}\text { Protein component } \\
\text { of the spliceosome. }\end{array}$ \\
\hline Synaptobrevin 1 & SySy & $\begin{array}{l}104001 \\
\text { Monoclonal }\end{array}$ & $\sim 18 \mathrm{kDa}$ & $\begin{array}{l}\text { Major vesicle protein } \\
\text { involved in fusion. }\end{array}$ \\
\hline Synaptobrevin 2 & SySy & $\begin{array}{l}104211 \\
\text { Monoclonal }\end{array}$ & $\sim 18 \mathrm{kDa}$ & $\begin{array}{l}\text { Vesicular SNARE protein } \\
\text { involved in neuronal } \\
\text { exocytosis. }\end{array}$ \\
\hline Synaptophysin 1 & SySy & $\begin{array}{l}101011 \\
\text { Monoclonal }\end{array}$ & $\sim 38 \mathrm{kDa}$ & $\begin{array}{l}\text { Major synaptic vesicle } \\
\text { membrane protein. } \\
\text { Function unknown. }\end{array}$ \\
\hline $\begin{array}{l}\text { Synaptophysin } 1 \\
\text { G95 }\end{array}$ & $\begin{array}{l}\text { Jahn et al., } \\
1985\end{array}$ & N/A & $\sim 38 \mathrm{kDa}$ & $\begin{array}{l}\text { Major synaptic vesicle } \\
\text { membrane protein. } \\
\text { Function unknown. }\end{array}$ \\
\hline
\end{tabular}




\begin{tabular}{|l|l|l|l|l|}
\hline Synaptotagmin 1 & SySy & $\begin{array}{l}105011 \\
\text { Monoclonal }\end{array}$ & $\sim 60 \mathrm{kDa}$ & $\begin{array}{l}\mathrm{Ca}^{2+} \text {-sensor on synaptic } \\
\text { vesicle. }\end{array}$ \\
\hline Synaptotagmin 1 & SySy & $\begin{array}{l}105221 \\
\text { Monoclonal }\end{array}$ & $\sim 60 \mathrm{kDa}$ & $\begin{array}{l}\mathrm{Ca}^{2+} \text {-sensor on synaptic } \\
\text { vesicle. }\end{array}$ \\
\hline Syntaxin 1A & SySy & $\begin{array}{l}110111 \\
\text { Monoclonal }\end{array}$ & $\sim 36 \mathrm{kDa}$ & $\begin{array}{l}\text { Plasma membrane } \\
\text { SNARE protein involved } \\
\text { in neuronal exocytosis. }\end{array}$ \\
\hline Syntaxin 7 & SySy & $\begin{array}{l}110073 \\
\text { Monoclonal }\end{array}$ & $\sim 36 \mathrm{kDa}$ & $\begin{array}{l}\text { Involved in fusion of late } \\
\text { endosomes and } \\
\text { lysosomes. }\end{array}$ \\
\hline VGAT & SySy & $\begin{array}{l}131103 \\
\text { Polyclonal }\end{array}$ & $\sim 60 \mathrm{kDa}$ & $\begin{array}{l}\text { Vesicular GABA } \\
\text { transporter. }\end{array}$ \\
\hline VGLUT1 & $\begin{array}{l}\text { Takamori et } \\
\text { al., }\end{array}$ & N/A & & $\begin{array}{l}\text { Vesicular glutamate } \\
\text { transporter. }\end{array}$ \\
\hline VGLUT2 & So00 & $\begin{array}{l}135503 \\
\text { Polyclonal }\end{array}$ & $\sim 60 \mathrm{kDa}$ & $\begin{array}{l}\text { Vesicular glutamate } \\
\text { transporter. }\end{array}$ \\
\hline
\end{tabular}


Table 2. Primary antibodies used for Rab-GTPases screening.

\begin{tabular}{|l|l|}
\hline Rab antigen & \multicolumn{1}{|c|}{ Supplier } \\
\hline Rab1b & Santa Cruz Biotechnology, Inc. \\
\hline Rab2 & Santa Cruz Biotechnology, Inc. \\
\hline Rab3b & Schlüter et al., 2002 \\
\hline Rab3c & Synaptic Systems (SySy) \\
\hline Rab3d & SySy \\
\hline Rab4 & Abcam \\
\hline Rab6 & Opdam et al., 2000 \\
\hline Rab10 & Protein Tech Group, Inc. \\
\hline Rab14 & Santa Cruz Biotechnology, Inc. \\
\hline Rab27a & SySy \\
\hline Rab27b & SySy \\
\hline Rab33b & Santa Cruz Biotechnology, Inc. \\
\hline Rab35 & Kouranti et al., 2006 \\
\hline Rab39 & Protein Tech Group, Inc. \\
\hline Rabphilin & SySy \\
\hline
\end{tabular}

Secondary antibodies: Fluorescent labelled Cy3 IgG goat anti-mouse and Cy5 IgG goat anti-rabbit (both from Dianova) were used routinely for quantitative immunoblotting. HRP (horseradish peroxidase) conjugated goat anti-mouse and HRP conjugated goat anti-rabbit (both from Biorad) were used preliminary experiments.

Antibodies were used according to the supplier's recommendations.

\subsubsection{Buffers}

Anode buffer (10x)

2 M Tris- $\mathrm{HCl}, \mathrm{pH} 8.9$

Acidification buffer:

$$
\begin{aligned}
& 0.3 \mathrm{M} \text { sucrose } \\
& 2 \mathrm{mM} \mathrm{MgSO}_{4} \\
& 2 \mathrm{mM} \mathrm{MgCl}_{2} \\
& 10 \mathrm{mM} \mathrm{MOPS} / \mathrm{KOH}, \mathrm{pH} 7.4
\end{aligned}
$$

Blocking solution:

$$
\begin{aligned}
& 5 \%(\mathrm{w} / \mathrm{v}) \text { low fat milk powder } \\
& 0.1 \%(\mathrm{v} / \mathrm{v}) \text { Tween } 20 \\
& \text { in PBS }
\end{aligned}
$$


Blot-transfer buffer:

Cathode buffer (10x):

Column buffer:

Coomassie staining solution:
$200 \mathrm{mM}$ glycine

$25 \mathrm{mM}$ Tris

$0.04 \%(w / v)$ SDS

$20 \% \mathrm{MeOH}$

1 M Tricine

$1 \%(w / v)$ SDS

0.1 M Tris- $\mathrm{HCl}, \mathrm{pH} 7.6$

$0.1 \mathrm{M} \mathrm{KCl}$

$0.2 \%$ Coomassie Brilliant Blue R

$25 \% \mathrm{EtOH}$

$10 \%$ Acetic acid

$65 \% \mathrm{ddH}_{2} \mathrm{O}$

Coomassie destaining solution: $\quad 20 \% \mathrm{EtOH}$

$5 \%$ Acetic acid

$1 \%$ Glycerol

Gel buffer:

3 M Tris- $\mathrm{HCl}, \mathrm{pH} 8.45$

$0.3 \%(w / v)$ SDS

Glutaraldehyde:

$8 \%(\mathrm{v} / \mathrm{v}) \mathrm{GA}$ in PBS

${ }^{3} \mathrm{H}-\mathrm{ATP}$-buffer:

$1 \mu \mathrm{M}{ }^{3} \mathrm{H}$-glutamate

$99 \mu \mathrm{M}$ glutamate

4 mM ATP 
HB-100:

25 mM Hepes- $\mathrm{NaOH}, \mathrm{pH} 7.4$

$100 \mathrm{mM} \mathrm{KCl}$

$1 \mathrm{mM}$ DTT

Hepes:

$1 \mathrm{M}$ Hepes-NaOH, pH 7.4

Homogenisation buffer:

$320 \mathrm{mM}$ sucrose

4 mM HEPES-NaOH, pH 7.4

Homogenisation medium (density): $250 \mathrm{mM}$ sucrose

$1 \mathrm{mM}$ EDTA

10 mM Tris-HCl, $\mathrm{pH} 7.4$

Lowry solution I:

$189 \mathrm{mM} \mathrm{Na}_{2} \mathrm{CO}_{3}$

$68 \mathrm{mM} \mathrm{NaOH}$

$8 \mathrm{mM} \mathrm{Na}_{2}$-Tartrate $* 2 \mathrm{H}_{2} \mathrm{O}$

$1 \%(\mathrm{w} / \mathrm{v}) \mathrm{SDS}$

Lowry solution II:

$250 \mathrm{mM} \mathrm{CuSO}_{4} * 5 \mathrm{H}_{2} \mathrm{O}$

Lowry solution III:

$100 \mathrm{ml}$ Lowry solution I + $1 \mathrm{ml}$ Lowry solution II

Lowry solution IV:

2 N Folin-Ciocalteus-Phenol-Reagent

1:1 diluted with $\mathrm{H}_{2} \mathrm{O}$

NT uptake buffer:

100 mM K-gluconate

20 mM Pipes

$2.5 \mathrm{mM} \mathrm{MgCl}_{2}$

4 mM EGTA, pH 7.0

Paraformaldehyde: $\quad 10 \%(w / v)$ PFA in $100 \mathrm{mM} \mathrm{KPP}$ 
PBS:

$20 \mathrm{mM} \mathrm{Na}_{2} \mathrm{HPO}_{4}$

$150 \mathrm{mM} \mathrm{NaCl}, \mathrm{pH} 7.4$

SDS-Sample buffer:

50 mM Tris- $\mathrm{HCl}, \mathrm{pH} 6.8$

$12 \%(\mathrm{v} / \mathrm{v})$ Glycerol

$4 \%(\mathrm{w} / \mathrm{v}) \mathrm{SDS}$

$2 \%(\mathrm{v} / \mathrm{v}) \beta$-Mercaptoethanol

$0.01 \%$ Serva Blue G

TBS (10x):

200 mM Tris-HCl, pH 7.5

$1.5 \mathrm{M} \mathrm{NaCl}$

Working solution (density):

$250 \mathrm{mM}$ sucrose

6 mM EDTA

60 mM Tris-HCl, $\mathrm{pH} 7.4$

\subsubsection{Chemicals}

Acetic acid, Merck (Darmstadt, Germany)

Acridine Orange, Sigma (Deisenhofen, Germany)

Acrylamide/Bisacrylamide solution, Roth (Karlsruhe, Germany)

Adenosine 5'-triphosphate (ATP), Fluka (Switzerland)

Agarose, Applichem (Darmstadt, Germany)

Albumin bovine serum (BSA), Sigma (Deisenhofen, Germany)

Ammonium acetate, Fluka (Switzerland)

Ammoniumpersulfate (APS), Sigma (Deisenhofen, Germany)

Ammonium chloride, Baker (Houston, USA)

ß-Mercaptoethanol, Sigma (Deisenhofen, Germany)

Bromophenol blue, Sigma (Deisenhofen, Germany)

Bradford-Reagent, Biorad (Richmond, USA)

Calcium chloride dehydrate, Fluka (Switzerland) 
Chloroform, Merck (Darmstadt, Germany)

Coomassie Brilliant Blue G-250, Serva (Heidelberg)

Coomassie Brilliant Blue R-250, Serva (Heidelberg, Germany)

Cooper sulfate, Merck (Darmstadt)

Desoxycholrideacid (DOC), Fluka (Buchs Switzerland)

Dithiothreitol (DTT), Roth (Karlsruhe, Germany)

Dipotassium hydrogen phosphate, Merck (Darmstadt, Germany)

Disodium hydrogen phosphate, Merck (Darmstadt, Germany)

EDTA Titriplex III, Merck (Darmstadt, Germany)

EGTA, Sigma (Deisenhofen, Germany)

Ethanol, Merck (Darmstadt, Germany)

FCCP- Carbonyl cyanide-p-trifluoromethoxyphenylhydrazone, Sigma (Deisenhofen, Germany)

Folin-Ciocalteus-Phenol-Reagent, Merck (Darmstadt)

Glutaraldehyde

Glycerol, Baker (Deventer, Holland)

Glycine, Sigma (Deisenhofen, Germany)

Hepes-(2-hydroxyethyl)piperazine--N'-2-ethanesulphonicacid), GERBU(Gaiberg, Germany)

${ }^{3} \mathrm{H}$-glutamic acid, Hartman Analytic (Braunschweig, Germany)

Hydrochloric acid, Merck (Darmstadt, Germany)

Isopropanol, Merck (Darmstadt, Germany)

L-Glutamic acid monopotassium, Sigma (Deisenhofen, Germany)

Magnesium chloride, Sigma-Aldrich (St. Louis, USA)

Magnesium sulfate, Sigma-Aldrich (St. Louis, USA)

Methanol, Merck (Darmstadt, Germany)

MOPS- 3-(N-morpholino)propanesulfonic acid, Sigma (Deisenhofen, Germany)

N,N,N',N'- Tetramethylethylendiamine (TEMED), Biorad (Richmond, USA)

Paraformaldehyde, Sigma-Aldrich (St. Louis, USA)

Pepstatin A, Peptide Institute Osaka (Japan) 
PIPES, AppliChem (Darmstadt, Germany)

Potassium acetate, Merck (Darmstadt, Germany)

Potassium dihydrogen phosphate, Merck (Darmstadt, Germany)

Potassium gluconate, Sigma (Deisenhofen, Germany)

Potassium hydroxide, Merck (Darmstadt, Germany)

PMSF (paramethyl sulphonyl fluoride), Roth (Karlsruhe, Germany)

Sodium chloride, Merck (Darmstadt, Germany)

Sodiumdodecylsulfate (SDS), Biorad (Richmond, USA)

Sodium hydrogen carbonate, Merck (Darmstadt, Germany)

Sodiumhydroxide, Merck (Darmstadt)

Sucrose, Roth (Karslruhe, Germany)

Trichloressigsäure, Fluka (Buchs, Switzerland)

Tricine, Applichem (Darmstadt, Germany)

Tris (hydroxymethyl)-aminomethane (Tris), Merck (Darmstadt, Germany)

Triton X-100, Merck (Darmstadt, Germany)

Tween 20, Sigma (Deisenhofen)

Ultima Gold, Perkin Elmar (Wiesbaden, Germany)

Urea, Merck (Darmstadt, Germany)

\subsubsection{Centrifuges}

Optima TL-100 Ultracentrifuge, Beckman Coulter (Krefeld, Germany)

Optima L-90K Ultracentrifuge, Beckman Coulter (Krefeld, Germany)

Optima L-70K Ultracentrifuge, Beckman Coulter (Krefeld, Germany)

RC 5C Plus centrifuge, Sorvall (Bad Homburg, Germany)

RC 5B centrifuge, Sorvall (Bad Homburg, Germany)

Fresco 21 Heraeus Tabeltop, Thermo Fischer Scientific (Langenselbold, Germany) 


\subsubsection{Fluorescent labels}

NBD PE, Avanti Polar Lipids Inc. (Alabama, USA)

Lissamine Rhodamine PE, Avanti Polar Lipids Inc. (Alabama, USA)

\subsubsection{Gelsystems}

Electrophoresis chamber Mini-Protean II, Biorad (Richmond, USA)

Power Pac 300, Biorad (Richmond, USA)

Power Pac P25, Biometra (Göttingen, Germany)

\subsubsection{Instruments}

Aminco DW-2000, On-Line Instruments Systems (Bogart, USA)

Fluorescence scanner, FLA-7000 Fujifilm (Japan)

Fluoromax-2, Horiba Jobin Yvon (Edison, NJ, USA)

GeniosPro microplate fluorescence reader, Tecan (Crailsheim, Germany)

Gradient master, Science Services (München, Germany)

Luminescent image analyzer, LAS-1000 Fujifilm (Japan)

Novaspec II, Parmacia Biotech (Freiburg)

Philips CM120 electron microscope

SMART Systems, GE Healthcare (Freiburg)

\subsubsection{Lipids}

All lipids were purchased from Avanti Polar Lipids Inc. (Alabama, USA)

Cholesterol (brain)

L- $\alpha$-Phosphatidylcholine (brain)

Phosphatidylethanolamine (brain)

Phosphatidylserine sodium salt (brain)

Phosphatidylinositol sodium salt (brain) 


\subsubsection{Rotors}

SS 34, Sorvall (Bad Homburg, Germany)

SW 28, Beckman Coulter (Krefeld, Germany)

SW 41, Beckman Coulter (Krefeld, Germany)

Ti 50.2, Beckman Coulter (Krefeld, Germany)

Ti 70.1, Beckman Coulter (Krefeld, Germany)

TLA 100.1, Beckman Coulter (Krefeld, Germany)

\subsubsection{Software's}

Adobe Photoshop 7.0, Adobe Systems (CA, USA)

Aida Image Analyzer, Raytest (Straubenhardt, Germany)

Aminco Upgrade Software DW-2000, On-Line Instruments Systems (Bogart, USA)

Digital Micrograph 3.4, Gatan Inc.

Endnote 9, Thomson

Multi Gauge 3.0, Fujifilm (Japan)

Sigma Plot 9.01, Systat Systems Inc. (USA)

\subsubsection{Others}

$16 \mathrm{ml}$ flanged polycarbonate (non-sealed) tubes with adaptors, Beckman Coulter (Krefeld) Chromatography column (100 cm length $* 1 \mathrm{~cm}$ inner diameter), Biorad (Richmond, USA)

Fraction Collector, GE Healthcare (Freiburg)

Iodixanol (Optiprep), Life Technologies International (NY, USA)

Microsmass QII mass spectrometer (Micromass, Manchester, UK)

Molecular weight protein standards, MBI Fermentas (St. Leon-Rot, Germany)

Motor-driven glass-Teflon homogenisers $1 \mathrm{ml}$ and $17 \mathrm{ml}$, Schütt 24 (Göttingen, Germany)

Nitrocellulose and PVDF membranes, Merck (Darmstadt, Germany)

Peristaltic Pump, Merck (Darmstadt, Germany)

Sephacryl S-1000 Superfine HR, GE Healthcare (Freiburg)

Sephadex G50, GE Healthcare (Freiburg) 
Ti 50.2 and Ti 70.1 sealed polycarbonate tubes, Beckman Coulter (Krefeld) UV Detector Unit, GE Healthcare (Freiburg)

Western Lightning Chemiluminiscence Kit, Perkin Elmer (Wiesbaden, Germany) 


\subsection{Methods}

\subsubsection{Purification of synaptic vesicles from mouse brain}

Synaptic vesicle purification from brain homogenates was described previously by (Nagy et al., 1976; Hell et al., 1988). This new established procedure allows the isolation of SVs from mouse and rat using one brain. The protocol is essentially a hybrid of existing protocols, which has been optimised for yield and purity, and which can be carried out in less than $24 \mathrm{~h}$. Detailed description is found in section 3.1.1.

All animal experiments were carried out in accordance with local animal protection legislation.

\subsubsection{Determination of protein concentration}

Protein concentration was determined according to a modified Lowry-Peterson method that includes solubilisation and precipitation of proteins by TCA (Peterson, 1977). Bovine serum albumin was used as a standard in the range of 0 to $40 \mu \mathrm{g}$. A dilution series of all samples were set up (1:2, 1:5, 1:10 and 1:20). Standards and samples were filled up to $1 \mathrm{ml}$ with $\mathrm{ddH}_{2} \mathrm{O}$ and incubated with $100 \mu \mathrm{l} 0.15 \%$ DOC for 10 at RT. After $72 \%$ TCA was added samples were incubated on ice for $10 \mathrm{~min}$ and centrifuged at $13.000 \mathrm{rpm}$ for 10 min at $4{ }^{\circ} \mathrm{C}$. The resulting pellet was dissolved in $250 \mu 1 \mathrm{ddH}_{2} \mathrm{O}$ and $750 \mu \mathrm{l}$ Lowry solution III and incubated for $30 \mathrm{~min}$ at RT. After adding $75 \mu 1$ Lowry solution IV all samples were incubated for $45 \mathrm{~min}$ at RT, the absorbance at $750 \mathrm{~nm}$ was measured using a photometer (Parmacia Biotech Novaspec II). Microsoft Excel was used to calculate the protein concentration of samples.

\subsubsection{Preparing and running SDS-PAGE mini gels}

For SDS-PAGE gels glass plates, spacers $(0.8 \mathrm{~mm})$ and combs (10 and 15 wells) were mounted into a holder. The components were mixed according to (Tab. 3) (Schägger et al., 1987) $3.4 \mathrm{ml}$ separation gel (10\%) was poured first and filled with $1 \mathrm{ml}$ of the 
collecting gel on top of the separation gel and comb was added. Meanwhile samples were mixed with 5x SDS sample buffer and loaded on the polymerised gel directly or boiled for 5 min at $95^{\circ} \mathrm{C}$. The gel tank was filled with anode and cathode buffer and electrophoresis was carried out at a current of 60 voltage for $15 \mathrm{~min}$ and raised to 120 voltage until the blue front ran out of the gel.

Table 3. Composition of one $10 \%$ SDS-PAGE mini gel

\begin{tabular}{|l|l|l|}
\hline \multicolumn{1}{|c|}{ Component } & \multicolumn{1}{c|}{ Collecting gel } & Separating gel \\
\hline Acrylamide $30 \%$ & $200 \mu \mathrm{l}$ & $1.66 \mathrm{ml}$ \\
\hline Gel buffer & $375 \mu \mathrm{l}$ & $1.68 \mathrm{ml}$ \\
\hline $\mathrm{ddH}_{2} \mathrm{O}$ & $925 \mu \mathrm{l}$ & $570 \mu \mathrm{l}$ \\
\hline $50 \%$ glycerol & - & $1.06 \mathrm{ml}$ \\
\hline TEMED & $2 \mu \mathrm{l}$ & $3 \mu 1$ \\
\hline $10 \%$ APS & $10 \mu \mathrm{l}$ & $25 \mu \mathrm{l}$ \\
\hline
\end{tabular}

\subsubsection{Immunoblotting}

SDS-PAGE gels were blotted in a semi-dry transfer apparatus (Towbin et al., 1989) using nitrocellulose and PVDF membranes (Millipore). Proteins were transferred for 60 min at a current of $50 \mathrm{~mA}$ per membrane. The membrane was subsequently blocked with 5 $\%$ low fat milk solution (blocking solution) for 2 times 10 min followed by incubation with primary antibody for $2 \mathrm{~h}$ or over night. Dilutions of antibodies were according to suppliers instructions. After incubation with primary antibodies and two washing steps, secondary antibody was added (either horseradish peroxidase HRP or fluorescence labelled Cy3, Cy 5) and incubated for at least $2 \mathrm{~h}$. The membrane was washed 3 times 10 min with PBS and developed by enhanced chemiluminescence (ECL) and detected using luminescent image analyzer (LAS-1000 Fujifilm) or fluorescence scanner (FLA-7000 Fujifilm). For quantification Multi Gauge 3.0 software was used. 


\subsubsection{Electron microscopy (negative staining, cryo and Immunogold labelling)}

For negative stain microscopy, synaptic vesicles were applied to a glow discharged carbon coated grid, washed once with $100 \mathrm{mM}$ ammonium acetate and stained with $2 \%$ uranyl acetate (Jahn and Maycox, 1988). For recording dark-field images at various magnifications a CM120 Philips electron microscope equipped with a TemCam 224A slow scan CCD camera (TVIPS, Gauting, Germany) was used.

For cryo-electron microscopy (with modification from Adrian et al., 1984), SVs were applied to perforated carbon coated grids and rapidly frozen in liquid ethane. Images were taken at a magnification of 50,000X on a negative film and a defocus of 2-3 $\mathrm{mm}$ using a Gatan cryostage in a Philips CM120 electron microscope. To measure the diameter of the SVs, recorded images from cryostage were analysed using Digital Micrograph 3.4 software (Gatan, Inc.) (Schütte et al., 2004). The longest and shortest diameter of each vesicle were measured and averaged to produce the mean vesicle diameter. For immunogold labelling (Jahn and Maycox, 1988) purified SVs were applied to perforated plastic grids and fixed with $2 \%$ PFA (paraformaldehyde) and $0.2 \%$ GA (glutaraldehyde) for 10 min, incubated in $0.02 \%$ glycine and BSA/TBS solution for $10 \mathrm{~min}$ and subsequently adding antisynaptophysin G 95 antibody to the solution. After incubation with G 95 antisynaptophysin antibody the grids were washed two times with $0.5 \%$ BSA/TBS solution and incubated with $0.5 \% \mathrm{BSA} / \mathrm{TBS}$ solution containing gold particles for $30 \mathrm{~min}$. After incubation grids were washed four times with $0.5 \%$ BSA/TBS solution and stained with uranyl acetate and recorded with Philips CM 120 electron microscope at a magnification of 27.500X. These experiments were performed in cooperation with Dr. Dietmar Riedel Electron microscopy group MPIbpc Göttingen.

\subsubsection{Monitoring acidification of synaptic vesicle}

Acidification of synaptic vesicles was monitored with the fluorescent dye Acridine Orange (AO) (Maycox et al., 1988). Acridine Orange is usually membrane permeable but is trapped and quenched in an acidic environment as in the vesicular lumen during acidification (Palmgren, 1991). Therefore, AO is used to monitor changes in intra-organelle 
pH. Purified synaptic vesicles $(20 \mu \mathrm{g})$ were resuspended in acidification buffer $(300 \mathrm{mM}$ sucrose, $2 \mathrm{mM} \mathrm{MgSO}_{4}, 2 \mathrm{mM} \mathrm{MgCl}_{2}$ and $10 \mathrm{mM} \mathrm{MOPS/KOH}, \mathrm{pH}$ 7.4) and equilibrated in Aminco dual beam spectrophotometer at $32^{\circ} \mathrm{C}$. After preincubation for 5 min Acridine Orange ethanol) (final concentration $10 \mu \mathrm{M}$ ) and ATP (final concentration $2 \mathrm{mM}$ ) were added from $1 \mathrm{mM} \mathrm{AO}$ in $30 \%(\mathrm{v} / \mathrm{v})$ and $120 \mathrm{mM}$ ATP KOH, pH > 6.5 stock solutions, followed by rapid mixing. Additionally potassium glutamate (final concentration $1 \mathrm{mM}$ ), $\mathrm{KCl}$ (final concentration $150 \mathrm{mM}$ ) and ammonium sulfate (final concentration $50 \mu \mathrm{M}$ ) were added from $1 \mathrm{M}, 3 \mathrm{M}$ and $4 \mathrm{M}$ solutions, respectively. Change of fluorescence was measured at wavelength $492 \mathrm{~nm}$ and $530 \mathrm{~nm}$ as the reference wavelength.

\subsubsection{Neurotransmitter uptake}

Glutamate uptake by synaptic vesicles was performed with modifications described by (Maycox et al., 1988). 20 $\mathrm{g}$ of Synaptic vesicles were resuspended in uptake buffer (100 mM K-gluconate, $20 \mathrm{mM}$ Pipes, $2.5 \mathrm{mM} \mathrm{MgCl}_{2}, 4 \mathrm{mM}$ EGTA, $\mathrm{pH}$ 7.0) incubated in ${ }^{3} \mathrm{H}$ ATP-buffer $\left(0.5 \mu \mathrm{M}{ }^{3} \mathrm{H}\right.$-glutamate, $45,5 \mu \mathrm{M}$ glutamate and $4 \mathrm{mM}$ ATP as final concentrations) for $10 \mathrm{~min}$ at $25^{\circ} \mathrm{C}$. The reaction was stopped by adding $400 \mu \mathrm{l}$ ice cold $\mathrm{K}$ gluconate buffer and centrifuged for $10 \mathrm{~min}$ at $436,000 \mathrm{~g}_{\max }$ in TLA 100.1 rotor. The small pellet was washed three times with $400 \mu \mathrm{l}$ ice cold K-gluconate buffer and dissolved in 200 $\mu 10.4 \%$ Triton X-100 by incubating for $10 \mathrm{~min}$ at room temperature and $10 \mathrm{~min}$ at $40^{\circ} \mathrm{C}$. $100 \mu 1$ of dissolved pellet was added to $4 \mathrm{ml}$ Ultima Gold liquid scintillation cocktail (Perkin Elmar) and uptake was measured in a liquid scintillation analyzer Tri-CARB 2100 TR (Packard). For uptake inhibition ${ }^{3} \mathrm{H}-\mathrm{ATP}-$ buffer containing $30 \mu \mathrm{M}$ FCCP was used.

\subsubsection{Determination of buoyant density}

To prepare the density gradients $5.5 \mathrm{ml}$ of 5\% Iodixanol (Optiptep, Life Technologies International, Grand Island, NY, USA), diluted in the density range of 1.04 $1.22 \mathrm{~g} / \mathrm{ml}$ into $250 \mathrm{mM}$ sucrose, $6 \mathrm{mM}$ EDTA, $60 \mathrm{mM}$ Tris-HCL, $\mathrm{pH}$ 7.4, were mixed with $5.5 \mathrm{ml}$ of $36 \%$ Iodixanol in a gradient mixer. $100 \mu \mathrm{g}$ of freshly purified synaptic vesicles were diluted to a volume of $200 \mu \mathrm{l}$ in homogenisation medium ( $250 \mathrm{mM}$ sucrose, $1 \mathrm{mM}$ 
EDTA, $10 \mathrm{mM}$ Tris-HCL, $\mathrm{pH}$ 7.4) layered on top of the gradient and centrifuged for 5 hours at $180,000 \mathrm{~g}_{\max }$ in a SW 41 rotor. After centrifugation, $500 \mu$ fractions were collected manually from top of the gradient and analyzed for protein content, refractive index and vesicle proteins by immunoblotting

\subsubsection{Proteoliposome synthesis}

For proteoliposome reconstitution lipid micelles were prepared (Avanti Polar Lipids) using phosphatidylcholine, phosphatidylethanolamine, phosphatidylserine, phosphatidylinositol and cholesterol in the molar ratio of 5:2:1:1:1 under Argon. This lipid composition is equivalent to the physiological levels in synaptic vesicle membranes (Takamori et al., 2006). Phosphatidylethanolamine was conjugated to the fluorescent pairs NBD (N-7-nitro-2,1,3-benzoxadiazole-4-yl) and rhodamine at a molar percentage $1.5 \%$ of the total lipid concentration. Lipids were solubilised in chloroform/methanol at a 2:1 (v/v) ratio. The lipid mixtures were dried under a stream of $\mathrm{N}_{2}$ and resuspended in $\mathrm{HB} 100$ buffer (25 mM Hepes- $\mathrm{NaOH}, \mathrm{pH} 7.4,100 \mathrm{mM} \mathrm{KCl}, 1 \mathrm{mM}$ DTT) containing $5 \%$ sodium cholate, to a final concentration of $13.5 \mathrm{mM}$. For reconstitution of liposomes, a lipid/protein ratio of 100:1 in $120 \mu \mathrm{l}$ was used. To incorporate the Q-SNARE syntaxin/SNAP-25 into liposomes, they were mixed at a molar ratio of 1:1.5 and incubated for $1 \mathrm{~h}$ to form a binary complex. Labelled lipids and the complex were injected onto a Sephadex G50 column mounted in the SMART machine (GE Healthcare) layered with HB-100 buffer and proteoliposomes were

formed. Recombinant syntaxin/SNAP-25 was provided by Dr. Matthew Holt Dept. of Neurobiology MPIbpc Göttingen. 


\subsubsection{Liposome fusion assay}

Liposome fusion reactions were performed as described in previous studies (Weber et al., 1998; Holt et al., 2008). A FRET based lipid-mixing assay was used to monitor SNARE mediated fusion of synaptic vesicles with liposomes. FRET occurs between the dyes NBD and Rhodamine, which were coupled to lipids used in the liposome preparation. FRET decrease resulting in a measurable increase in NBD fluorescence.

Protein ( $20 \mu \mathrm{g}$ of synaptic vesicles) were mixed with lipid ( $2.5 \mu \mathrm{g}$ labelled liposomes) in a quartz cuvette with a total volume of $75 \mu \mathrm{l}$ and placed in Fluoromax-2 spectrometer (Horiba Jobin Yvon, Edison, NJ, USA). The FRET signal was measured at wavelengths of $460 \mathrm{~nm}$ excitation and $538 \mathrm{~nm}$ emission. The slit width of the excitation and emission wavelengths were adjusted to 2 and $5 \mathrm{~nm}$ and the integration time was set to $1 \mathrm{~s}$. Fluorescence measurements were taken once every $15 \mathrm{~s}$ for $30 \mathrm{~min}$. After the end of the reaction, liposomes were completely solubilised by $20 \%$ (w/v) Triton X-100 detergent, resulting in maximal spatial separation of NBD and Rhodamine. Initial fluorescence intensity was taken as zero and the relative fluorescence was expressed as a percentage of the maximal NBD signal upon detergent treatment. To ensure fusion is SNARE dependent, synaptic vesicles were incubated with protein free liposomes in the same manner as mentioned above. To inhibit fusion, synaptic vesicles were treated with $7.5 \mu 1$ tetanus toxin of a 1:500 dilution (TeNT $205 \mu \mathrm{M}$ stock) for $2 \mathrm{~h}$ at $37^{\circ} \mathrm{C}$, and then liposomes were added and measured. Tetanus toxin light chain selectively cleaves synaptobrevin between residue 76 and 77. Furthermore for competitive SNARE inhibition a soluble fragment of vesicular SNARE synaptobrevin $(1-96,(662 \mu \mathrm{M}))$ or syntaxin/SNAP-25 were added to liposomes and incubated for $60 \mathrm{~min}$ at $37^{\circ} \mathrm{C}$, synaptic vesicles were added to the mixture and fluorescence was recorded. Tetanus toxin, recombinant synaptobrevin fragment (1-96) and syntaxin/SNAP-25 was provided by Dr. Matthew Holt Dept. of Neurobiology MPIbpc Göttingen. 


\subsubsection{Fluorescence Correlation Spectroscopy (FCS)}

Freshly purified synaptic vesicles were labelled with $5 \mu \mathrm{M}$ membrane dye FM1-43. A Titanium-sapphire laser $(800 \mathrm{~nm}, 87 \mathrm{MHz})$ for two-photon excitation was coupled to an Axiomat inverse microscope (Zeiss, Germany). The laser beam was expanded using a lens system, reflected to the top of the microscope with a dichroic mirror (715 DSCPXR, AHF, Germany) and focused with a UPlanSApo 60x/1.2w water immersion objective (Olympus, Germany). The emitted photons passed through the objective and the dichroic mirror. Scattered light from excitation beam was blocked by a short pass filter (E700SP2, AHF, Germany).The emission was collimated using a second lens system, filtered with a band pass filter (HQ 645/75, AHF, Germany) and collected by an avalanche photodiode (APD) (SPCM-AQR-13, Perkin-Elmer, Canada). The TTL-Signals from the APD were analyzed using a 4-channel router (PRT 400, PicoQuant GmbH, Germany) and TCSPC card (TimeHarp200, PicoQuant GmbH, Germany) and saved in TTTR format (time-tagged timeresolved) for further analysis (Cypionka et al., 2009). This experiment was performed by Wensi Gao Dept. of Neurobiology MPIbpc Göttingen.

\subsubsection{Lipid analysis}

Lipid analysis was carried out using the method described by Bligh and Dyer (Bligh and Dyer, 1959) and quantitative analysis was performed according to Brügger (Brüger et al., 1997; Brügger et al., 2000).

Briefly, samples were resuspended in $5 \mathrm{mM}$ ammonium acetate in methanol after solvent evaporation. Nano-ESI-MS analysis was carried out on a Micromass QII triple-stage quadrupol mass sprectrometer (Micromass, Manchester, UK). As the collision gas Argon was used $\left(2.5 * 10^{-3}\right.$ millibar pressure) and cone voltage was set to $30 \mathrm{~V}$. A parent ion scanning was used for phopshatidylcholine and sphingomyelin detection with $\mathrm{m} / \mathrm{z}$ value of 184 for fragment ion, collision energy was set to $32 \mathrm{eV}$. Phosphatidylethanolamine, phosphatidylserine and phosphatidylinositol were quantified by neutral loss scanning for a neutral loss of m/z 141, 185 and 277 at collision energy of $25 \mathrm{eV}$ and $30 \mathrm{eV}$. Standards of phosphatidylethanolamine and phosphatidylserine were synthesised as described by 
(Koivusalo et al., 2001). For cholesterol quantification d6-cholesterol standard was used (Cambridge Isotope Laboratories Inc. MA, USA) with a cone voltage of $50 \mathrm{~V}$ and collision energy of $130 \mathrm{eV}$ for a fragment ion with $\mathrm{m} / \mathrm{z}$ of 80 . This experiment was performed by $D r$. Britta Brügger Biochemistry Centre Heidelberg University, Heidelberg. 


\section{Results}

\subsection{Establishment of a new protocol for isolation of synaptic vesicles from small samples}

\subsubsection{Principle of the isolation method}

Synaptic vesicle purification from brain homogenates were described previously by (Nagy et al., 1976; Hell et al., 1988) using extent starting material with an enrichment of SVs of $\sim 25$ fold over the homogenate. As mentioned in section 1.4 these protocols isolate SVs either indirectly from synaptosomes (Nagy et al., 1976) that are generated during gentle homogenisation or directly from homogenates using shock-frozen brains (Hell et al., 1988). Here, I developed a procedure that is essentially a hybrid of existing protocols and has several advantages over these earlier protocols. First it allows the isolation of SVs from mouse or rat using only one brain, second it has been optimised for both yield and purity, and can be carried out in less than $24 \mathrm{~h}$. Synaptic vesicles are relative homogeneously distributed in the brain. Therefore, to isolate SVs from crude brain homogenate, subcellular fractionation techniques are required which separate SVs based on their size, shape and density. These techniques usually consist of differential centrifugation, rate-zonal centrifugation and size exclusion chromatography. Application of these techniques has been shown previously for the purification of SVs from rat brain.

The protocol developed here starts with initial mild homogenisation of brain to reduce fragmentation and vesiculation of large membranes, and results in release of SVs from damaged nerve terminals (Fig 6A). Differential centrifugation steps at moderate g-forces are subsequently applied to separate large cell fragments and nuclei from free vesicles and pinched-off nerve terminals (synaptosomes). Synaptosomes are then pelleted by centrifugation; the resulting supernatant S2, which because it is contaminated with cell fragments such as microsomes, small myelin fragments and also soluble proteins, is usually discarded in the classical protocol, (Nagy et al., 1976) actually contains the majority of SVs (Jahn et al., 1985) which are released during initial homogenisation, and is stored to 
combine later with SVs released from synaptosomes. Synaptic vesicles enclosed in synaptosomes are released with a hypo-osmotic shock and centrifugation at intermediate gforce pellets large components, leaving SV and small particles in the supernatant (LS1). To increase the final yield of SVs, the lysate supernatant LS1 and S2 are combined. Combining these two fractions also increases the level of contamination and significantly lowers the purity. To remove all large membraneous contaminations (mostly mitochondria, junctional complex and myelin) combined fractions LS1 and S2 are centrifuged. In addition a further purification step, a simplified rate-zonal sucrose density step gradient is used. The resulting supernatant of LS1 and S2 (CS1) is layered on a sucrose cushion and rate-zonal centrifugation is applied to separate SVs from protein particles such as ribosomes and proteasomes, which otherwise would co-sediment with SVs. Following rate-zonal centrifugation, the fractions containing SVs are collected and an enriched SV fraction is then obtained by high-speed centrifugation. This enriched SV fraction is still contaminated with membrane fragments and cytosolic proteins. To free SVs from these contaminants, size exclusion chromatography on Sephacryl S-1000 is used. The elution chromatogram produces two absorption maxima, the first contains larger membrane fragments and SVs are present in the second peak (Fig 6B). The fractions from the second peak are pooled and centrifuged at high-speed; pure SVs are visible as a clear translucent pellet on the wall of the tube. With respect to purity, the final fraction compares well to the 'classical' procedure originally developed by Nagy and with modifications by Hell (Nagy et al., 1976; Hell et al., 1988). Although unfortunately, it was not possible to completely free the final synaptic vesicle fraction from transport vesicles that share similar physical properties, such as those involved in the traffic between the endoplasmic reticulum and the Golgi apparatus, which are also released during the initial homogenisation. 


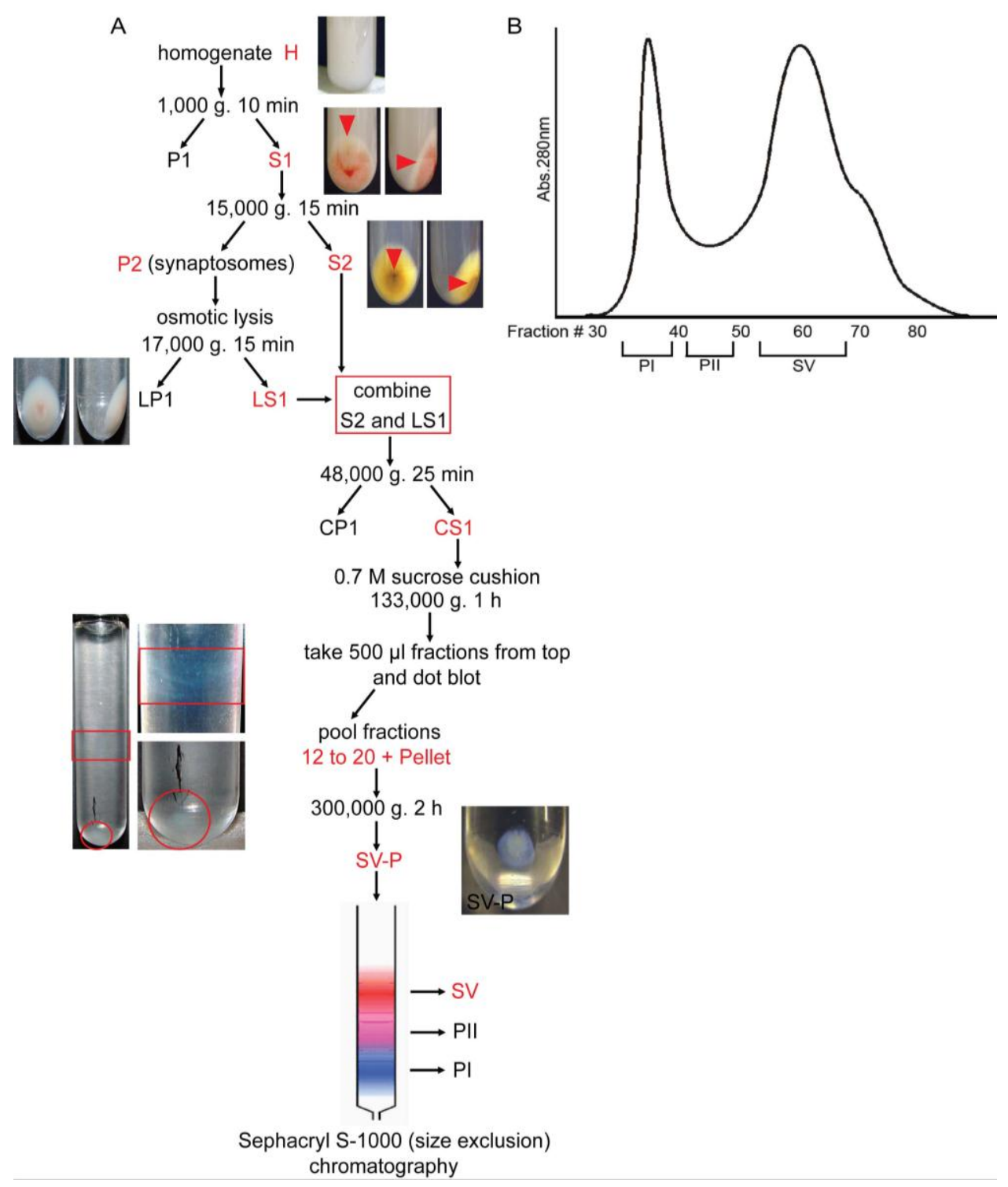

Figure 6. Images of pellets and supernatants obtained during synaptic vesicle purification. (A) Flow diagram of synaptic vesicle purification, illustrating pellets and supernatants formed at each stage. Careful handling of pellets and supernatants is essential to avoid contamination in the final synaptic vesicle fraction. After centrifugation of the sucrose cushion, synaptic vesicles are enriched in the white band and pellet (red boxed region and red circles). (B) Elution profile of the Sephacryl S-1000 column monitored at wavelength $280 \mathrm{~nm}$. The elution profile consists of two peaks and a middle section. PI, PII and SV brackets on the chromatogram indicate fractions pooled following elution from the column. 


\subsubsection{Optimisation of the isolation procedure}

To separate SVs from contaminants such as ribosomes and protasomes, which otherwise co-sediment with SVs because of their size and density, a rate-zonal centrifugation step with sucrose cushion is included. Different volumes of the combined supernatant 1 (CS1) are layered on top of different volumes of a $0.7 \mathrm{M}$ sucrose cushion and centrifuged varying in force and time. After centrifugation fractions are taken and subjected to SDS-PAGE followed by immunoblotting testing with antibodies against synaptophysin (synaptic vesicle marker) and against Rpt4 (proteasome marker). Separation profiles of SVs and proteasomes are shown in (Fig. $7 \mathrm{~A}$ and B).
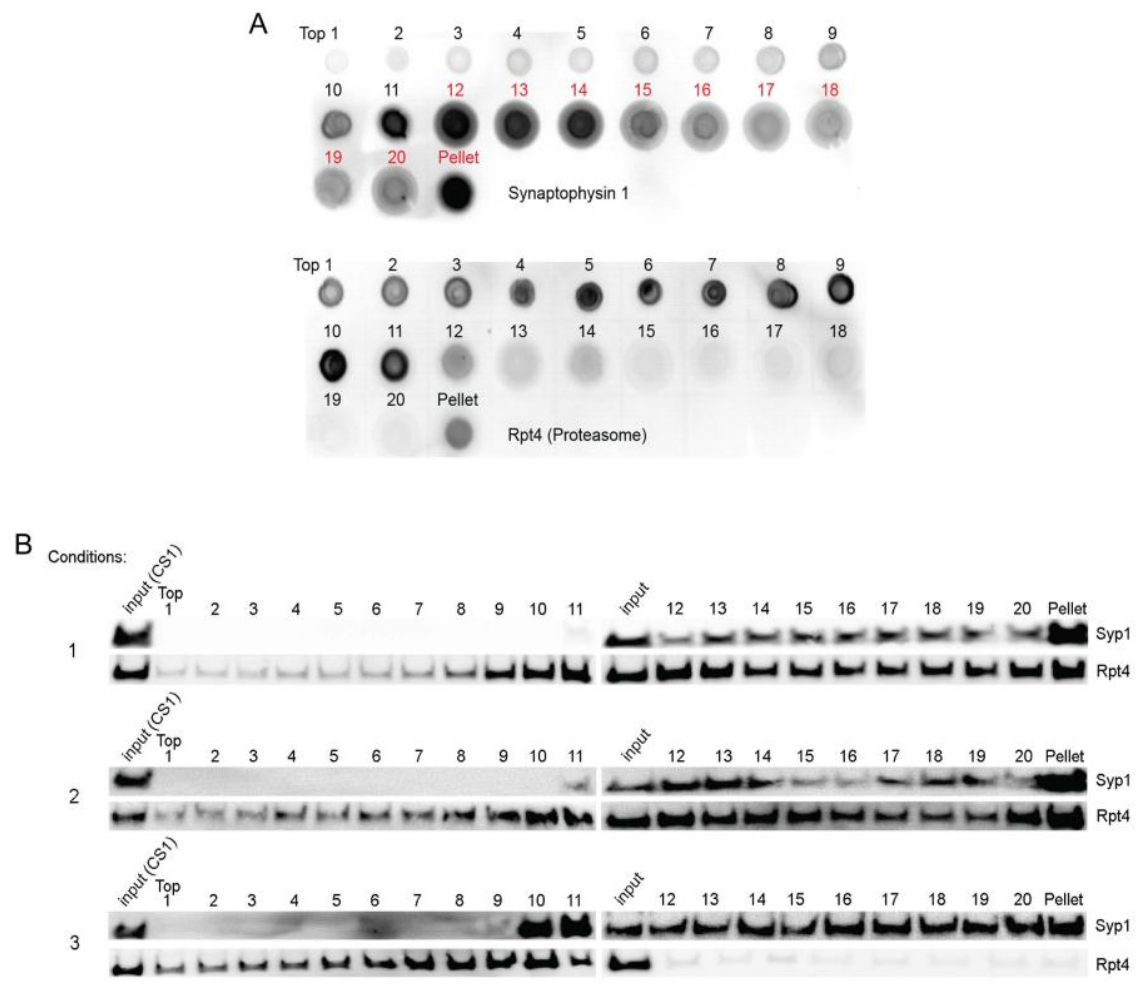

Figure 7. Optimisation of the sucrose cushion step. Representative (A) dotblots and (B) immunoblots of fractions taken from the sucrose cushion, following centrifugation under different conditions. Fractions were tested for the presence of synaptophysin (synaptic vesicle marker) or Rpt4 (proteasome marker). Different relative volumes of the input fraction (CS1) to $0.7 \mathrm{M}$ sucrose cushion were used. Centrifugation forces and times for a 70.1 Ti rotor were also systematically varied (although only data for $5 \mathrm{ml} \mathrm{CS1} \mathrm{on} \mathrm{a} 5 \mathrm{ml}$ cushion centrifuged at 400,000 $\mathrm{g}_{\max }$ (condition 1), 270,000 $\mathrm{g}_{\max }$ (condition 2) and 133,000 $\mathrm{g}_{\max }$ (condition 3) are shown). 
Best separation is found layering $5 \mathrm{ml}$ of CS1 on top of $5 \mathrm{ml} 0.7 \mathrm{M}$ sucrose cushion and centrifuged at $133,000 \mathrm{~g}_{\max }$ for $1 \mathrm{~h}$. Note the differential separation of Rpt4 from synaptophysin under condition 3 (Fig. 7B). Testing purity during SV isolation, a dotblot assay is performed direct after centrifugation (Jahn et al., 1984), spotting $5 \mu$ l of each fraction from sucrose cushion using condition 3 on a nitrocellulose membrane and tested for $\mathrm{SV}$ and proteasome markers for quick estimation to pool the desired fractions. 


\subsection{Biochemical and morphological characterisation of synaptic vesicles}

\subsubsection{Distribution of SV proteins and marker proteins for other compartments}

For studies of synaptic vesicle structure and function it is essential to show that the final vesicle fraction is free both from contamination by other membranes and particles produced as a 'by-product' of the fractionation procedure and associated cytoplasmic components. Traditionally, the methods used for assessing purity were largely limited to electron microscopic analysis of size and shape, and enzymatic assays, to test for contaminating proteins originating from mitochondria etc. (Hell et al., 1988). While electron microscopy still remains a powerful tool, the identification of SV specific proteins, such as synaptophsyin, synaptobrevin and synaptotagmin, means that biochemical homogeneity is now more easily assessed with immunological techniques such as immunoblotting, which allows SVs to be differentiated from other cellular transport vesicles, or from vesiculated membrane fragments of similar size. Therefore subfractions from purification procedure were immunoblotted and analysed for SV integral membrane proteins, SV associated proteins and contaminants. Synaptic vesicle integral membrane proteins like synaptophysin, synaptobrevin, synaptotagmin and vesicular neurotransmitter transporter VGLUT are enriched in the final SV fraction (Fig. 8 B). Synaptic vesicle associated proteins like NSF which plays a role in endocytosis of SVs, dynamin and clathrin are either absent or present in low amounts in the final SV fraction. In contrast, markers for myelin (MBP) and glia (GFAP), plasma membranes $\left(\mathrm{Na}^{+} / \mathrm{K}^{+}\right.$-ATPase and NMDA-R1) and mitochondria (SDHA) are not enriched or completely depleted in the final $\mathrm{SV}$ fraction. With rate-zonal centrifugation protein complexes such as proteasomes (section 3.1.2) and spliceosomes are removed. To completely free the final SV fraction from transport vesicles that shares similar physical properties like size and density, such as those involved in the traffic between the endoplasmic reticulum and Golgi apparatus (mSec22 and $\mathrm{mUse} 1)$ is not possible (Fig. $8 \mathrm{~B}$ ). 


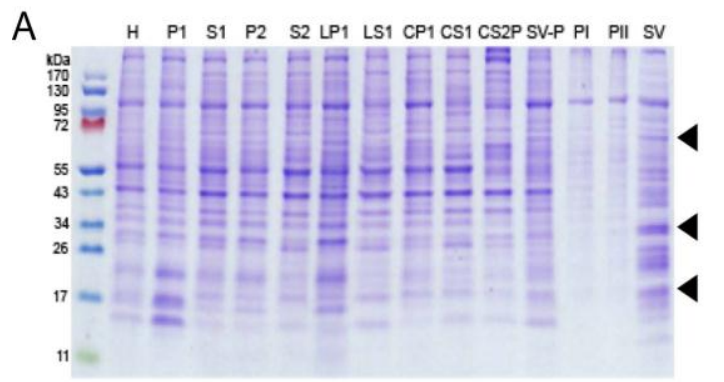

B SV Integral Membrane Proteins

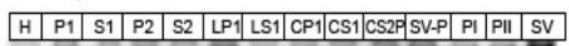

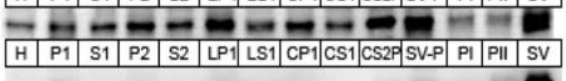

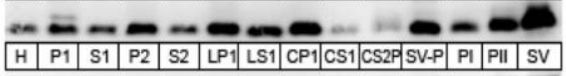

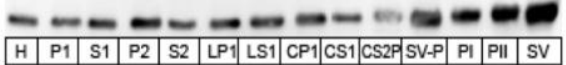

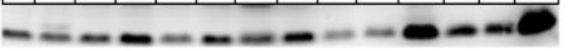

SV Associated Proteins

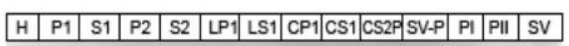

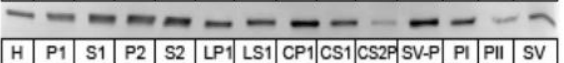

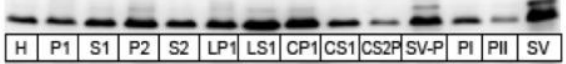
H. -

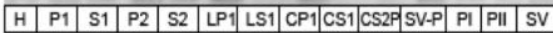

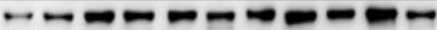

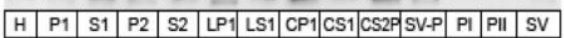

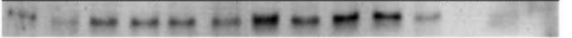

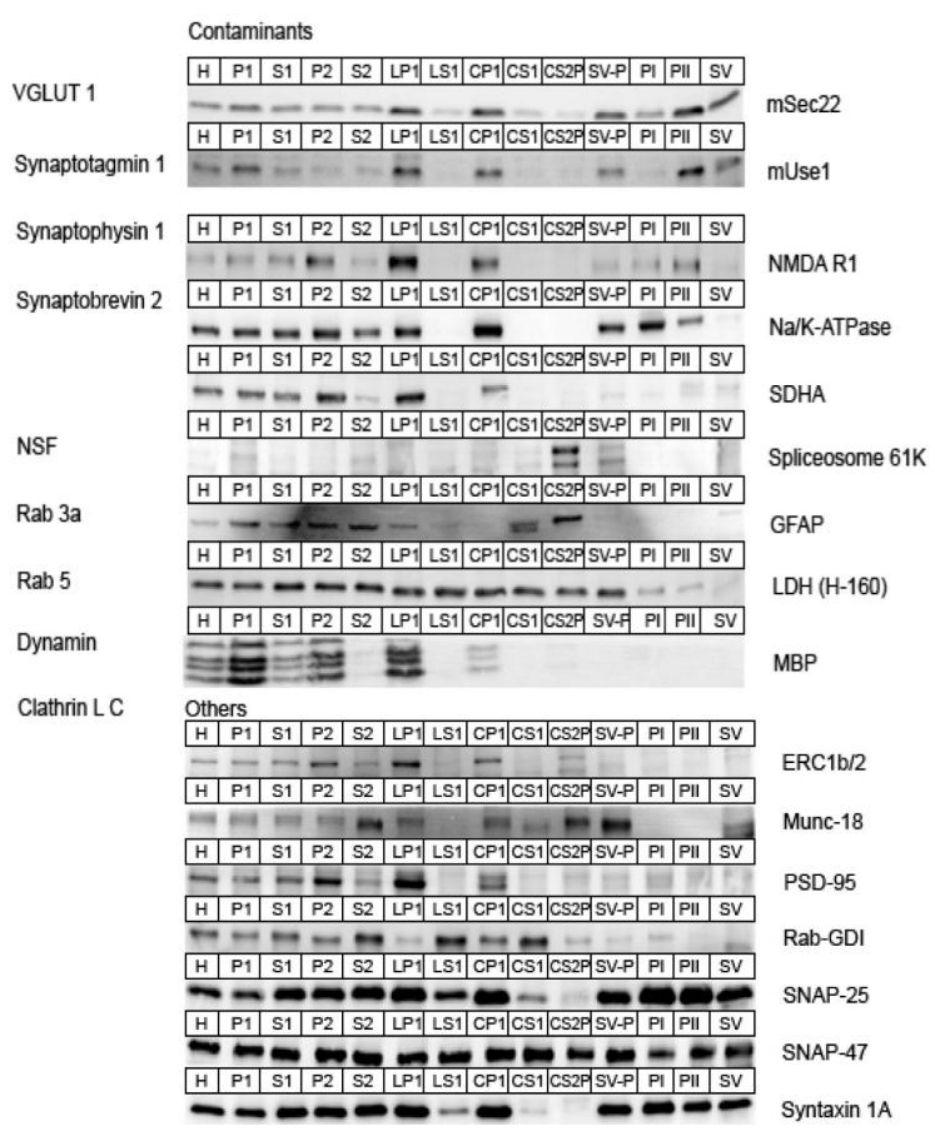

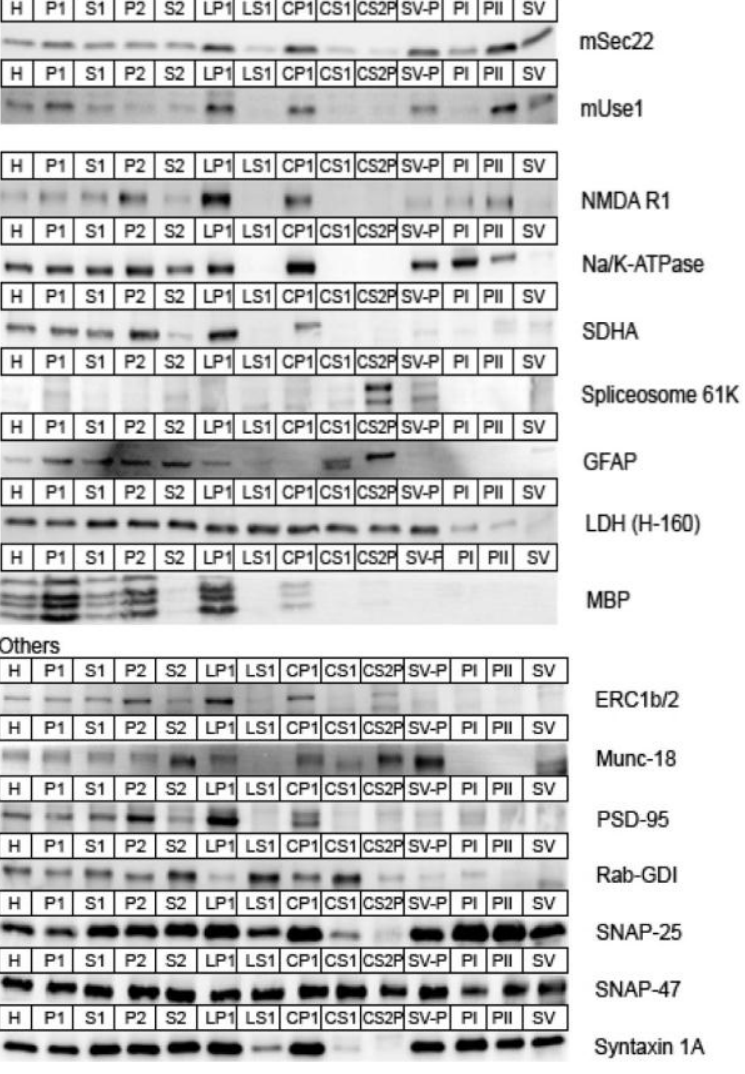

Figure 8. Separation by SDS-PAGE of subfractions taken during the isolation of synaptic vesicles.

Subfractions taken during the isolation of synaptic vesicles were separated by SDS-PAGE and immunoblotted to determine the distribution profiles of various marker proteins. (A) Coomassie Blue staining. $5 \mu \mathrm{g}$ total protein from each fraction was subjected to SDS-PAGE followed by Coomassie staining. Synaptic vesicles show a characteristic protein profile. In a clean preparation, major protein bands at $18 \mathrm{kDa}, 38 \mathrm{kDa}$ and 65 $\mathrm{kDa}$ are clearly visible, which correspond to the major membrane proteins synaptobrevin, synaptophysin and synaptotagmin (arrowheads). (B) Immunoblots of the various subfractions. $5 \mu \mathrm{g}$ total protein from each 


\section{Results}

fraction was subjected to SDS-PAGE followed by immunoblotting for various marker proteins. Known integral membrane proteins on SVs enrich from homogenate to the final vesicle fraction. By contrast, proteins that are markers for other contaminants are expected to be reduced during the final purification steps. The dynamin antibody used does not discriminate between dynamin isoforms 1, 2 and 3, which are all expressed in brain. Some markers ERC1b/2 (active zone proein), PSD-95 (post-synaptic scaffolding protein) and RabGDI (regulator of Rab protein activity) are absent from the purified vesicle fraction. The remaining protein profiles are for known residents of the plasma membrane (syntaxin 1A and SNAP-25, or for known interacting partners such as Munc-18). While the degree of plasma membrane contamination within the synaptic vesicle fraction is known to be low (as judged by $\mathrm{Na}+\mathrm{K}+$-ATPase immunoactivity), it is conceivable that some plasma membrane proteins may use synaptic vesicle as part of their recycling pathway. This is especially true for syntaxin 1 and SNAP-25, that are both members of the synaptic core-complex essential for vesicle fusion, and which may be recycled to some degree with synaptic vesicles (Walch-Solimena et al., 1995). 


\subsubsection{Characterisation of synaptic vesicle fractions by electron microscopy}

In previous studies purity of isolated SVs was mainly monitored with electron microscopy. In our case, the final vesicle fraction consists mainly of uniformly sized vesicles, with a diameter ranging from $40-50 \mathrm{~nm}$. To optimise purity and enrichment of SVs, individual fractions eluting from the Sephacryl column were analysed by electron microscopy. Effective separation of SVs and membrane structures which were both present in the loading fraction (Fig. 9E), could be effectively separated resulting in fractions containing pure vesicles which where then pooled and centrifuged resulting in the pure final SV pellet. Electron micrographs of pooled fractions from the first peak (Fig. 6B) show large membranous fragments in the size of $100-200 \mathrm{~nm}$ (Fig. 9A). Synaptic vesicles along with larger membranous fragments are seen in fractions eluting between first and second peak (Fig. 9B), whereas fractions of the second peak mainly consists of large populations of SVs with a size of $40-50 \mathrm{~nm}$ (Fig. 9C). To identify individual SVs and to further determine the purity of the samples immunogold labelling of purified SVs was performed using antibody against SV specific proteins (Fig. 9D). It is observed that more than $90 \%$ of these vesicles are immunoreactive for the integral membrane protein synaptophysin (Fig. 9D and inset). Thus, the degree of contamination in SV preparation by other membranes is lower than $10 \%$, as judged by immunolabelling (Fig. 9C and D). The total protein recovery and relative enrichment of purified SVs was assessed by quantitative immunoblotting, which is $\sim 25$-fold in classical protocol (Jahn et al., 1985). In vesicle fractions purified by the procedure described in section 3.1.1, enrichment of synaptophysin is 20 -fold (Tab. 4) which compares well with that of the above mentioned classical protocol. However, the yield of SV purified by this method is $\sim 300 \mu \mathrm{g}$ total protein / $\mathrm{g}$ brain wet weight, which is approximately six times higher than that of the classical procedure using rat brain (Jahn et al., 1985), and more than two times higher than an alternative preparation claiming enhanced yield with comparable purity (Hell et al., 1988). 


\section{Results}
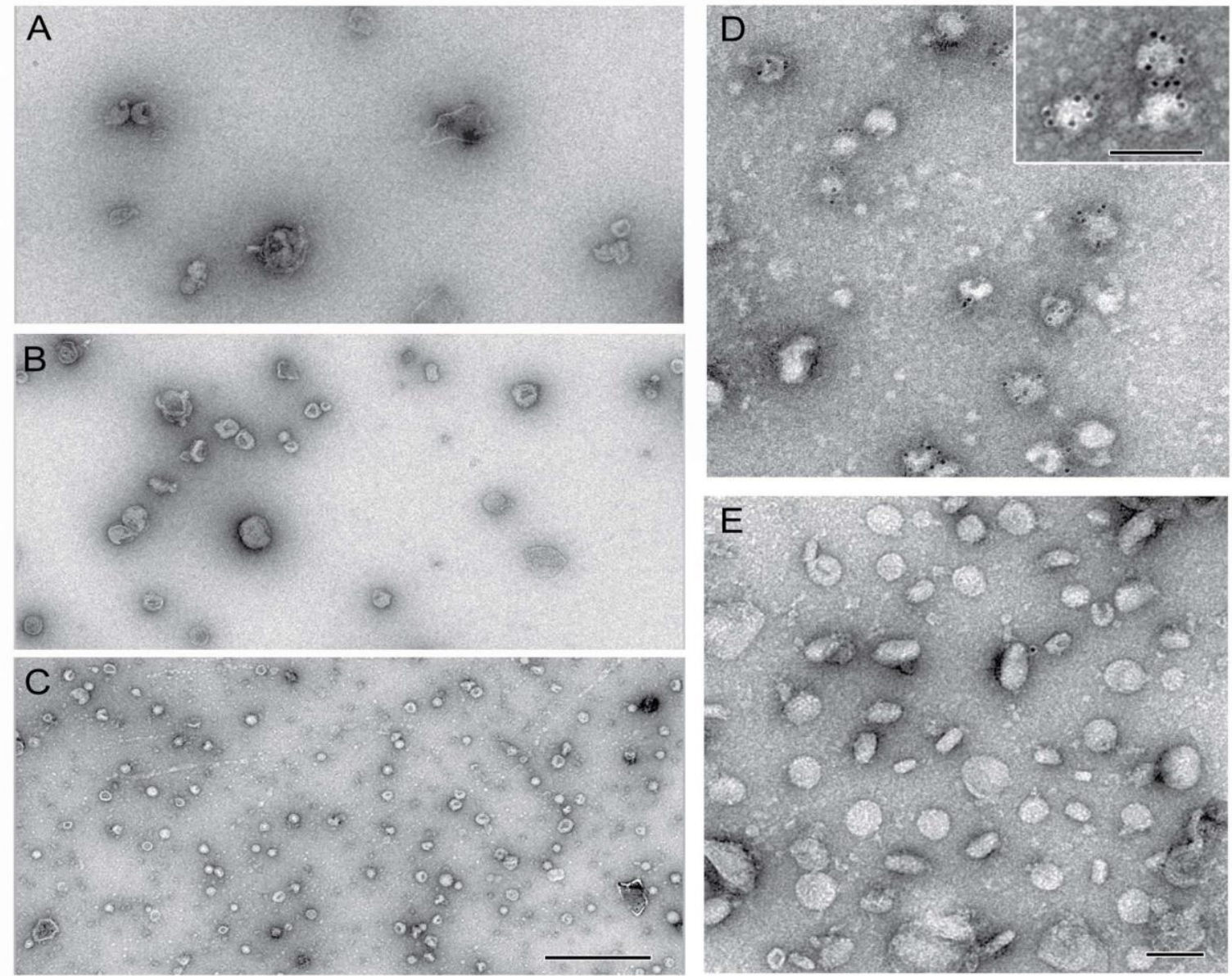

Figure 9. Effects of size-exclusion chromatography on synaptic vesicle purity assessed by electron microscopy. Negative stain electron micrographs of elution fractions from the size-exclusion column. The large, heterogeneous membrane structures present in the loading fraction ((E); SV-P containing membranes with diameters of $100 \mathrm{~nm}$ or more), are concentrated in the first peak (PI) after chromatography (A). Homogeneous small synaptic vesicles with diameters ranging from 40 to $50 \mathrm{~nm}$ are concentrated in the second peak (SV) (C). Fractions between these two peaks contain low amounts of membranes (B). More than $90 \%$ of these small vesicles are immunopositive for the specific vesicle marker synaptophysin (D). The inset shows immunogold labelled vesicles at a higher magnification. Scale bars; A-C $500 \mathrm{~nm}$; D, E and inset 100 $\mathrm{nm}$. 


\section{Results}

Table 4. Quantification of synaptic vesicle enrichment during the isolation procedure.

\begin{tabular}{|l|c|c|c|c|c|c|}
\hline Fraction & $\begin{array}{c}\text { Protein } \\
\text { Concentration } \\
(\mathrm{mg} / \mathrm{ml})\end{array}$ & $\begin{array}{c}\text { Volume } \\
(\mathrm{ml})\end{array}$ & $\begin{array}{c}\text { Total Protein } \\
(\mathrm{mg})\end{array}$ & $\begin{array}{c}\text { Total Protein } \\
\% \text { of } \mathrm{H}\end{array}$ & $\begin{array}{c}\text { Synaptophysin } \\
\% \text { of H }\end{array}$ & $\begin{array}{c}\text { Enrichment } \\
\text { Factor }\end{array}$ \\
\hline H & $4.8 \pm 0.5$ & $18.9 \pm 0.8$ & $90.1 \pm 12.3$ & $100.0 \pm 0.0$ & $100.0 \pm 0.0$ & $1.0 \pm 0.0$ \\
\hline P1 & $8.7 \pm 1.4$ & $2.6 \pm 0.4$ & $22.4 \pm 5.3$ & $25.0 \pm 4.4$ & $19.0 \pm 4.1$ & $0.8 \pm 0.1$ \\
\hline S1 & $3.7 \pm 0.6$ & $17.0 \pm 1.0$ & $63.3 \pm 10.5$ & $70.0 \pm 2.2$ & $63.0 \pm 6.7$ & $0.9 \pm 0.1$ \\
\hline P2 & $7.8 \pm 1.3$ & $2.9 \pm 0.2$ & $22.4 \pm 2.4$ & $25.0 \pm 2.9$ & $33.0 \pm 6.6$ & $1.3 \pm 0.2$ \\
\hline S2 & $2.1 \pm 0.5$ & $15.3 \pm 1.5$ & $32.0 \pm 7.3$ & $35.0 \pm 3.0$ & $28.0 \pm 1.0$ & $0.8 \pm 0.1$ \\
\hline LP1 & $7.5 \pm 1.1$ & $1.7 \pm 0.6$ & $12.5 \pm 7.0$ & $14.0 \pm 5.3$ & $15.0 \pm 7.8$ & $1.1 \pm 0.2$ \\
\hline LS1 & $0.2 \pm 0.1$ & $15.5 \pm 3.9$ & $3.4 \pm 1.2$ & $4.0 \pm 1.7$ & $4.5 \pm 1.7$ & $1.1 \pm 0.3$ \\
\hline CP1 & $10.8 \pm 1.9$ & $1.1 \pm 0.1$ & $12.2 \pm 2.8$ & $14.0 \pm 4.4$ & $13.0 \pm 0.2$ & $0.9 \pm 0.3$ \\
\hline CS1 & $0.8 \pm 0.1$ & $30.2 \pm 2.9$ & $23.1 \pm 2.7$ & $26.0 \pm 6.5$ & $17.0 \pm 2.1$ & $0.7 \pm 0.2$ \\
\hline CS2P & $3.4 \pm 0.5$ & $0.1 \pm 0.1$ & $0.5 \pm 0.3$ & $0.5 \pm 0.4$ & $0.5 \pm 0.4$ & $1.0 \pm 0.0$ \\
\hline SV-P & $2.7 \pm 0.3$ & $0.7 \pm 0.1$ & $2.0 \pm 0.2$ & $2.2 \pm 0.2$ & $9.0 \pm 1.9$ & $4.1 \pm 0.2$ \\
\hline PI & $0.8 \pm 0.5$ & $0.1 \pm 0.1$ & $0.1 \pm 0.0$ & $0.1 \pm 0.1$ & $0.1 \pm 0.0$ & $0.7 \pm 0.1$ \\
\hline PII & $0.7 \pm 0.4$ & $0.1 \pm 0.0$ & $0.1 \pm 0.0$ & $0.1 \pm 0.0$ & $0.2 \pm 0.1$ & $1.7 \pm 0.5$ \\
\hline SV & $1.2 \pm 0.1$ & $0.2 \pm 0.0$ & $0.2 \pm 0.0$ & $0.3 \pm 0.1$ & $5.4 \pm 1.0$ & $20.0 \pm 1.0$ \\
\hline
\end{tabular}

The table shows the total protein recovery and relative enrichment of synaptophysin in the various subfractions taken during the isolation procedure, as assessed by quantitative immunoblotting. For synaptophysin, the enrichment in the final vesicle fraction is approx. 20-fold compared to the starting homogenate. A similar level of enrichment is seen for other integral membrane proteins, such as synaptotagmin and synaptobrevin. Figures represent the mean \pm standard deviation from three independent experiments. Each experiment was performed using two mouse brains as the initial starting material. Figures are rounded to the fist decimal place. 


\subsection{Quantitative analysis of physical parameters}

\subsubsection{Size determination by cryo EM}

In previous publications the sizes of SVs from other species than mouse have been reported (Takamori et al., 2006). As described in section 2.2.5 size distribution of SVs results in a unimodal distribution curve with an average diameter of $40.0 \mathrm{~nm}$ (Fig. 10A). To exclude any measurements errors, diameter were measured along two axes and averaged. These measurements are within range reported by (Harris and Sultan, 1995) using fixed and stained brain sections from rat. A mass/diameter correlation can be established with the given density in section 3.3.2 (Fig. 10B).
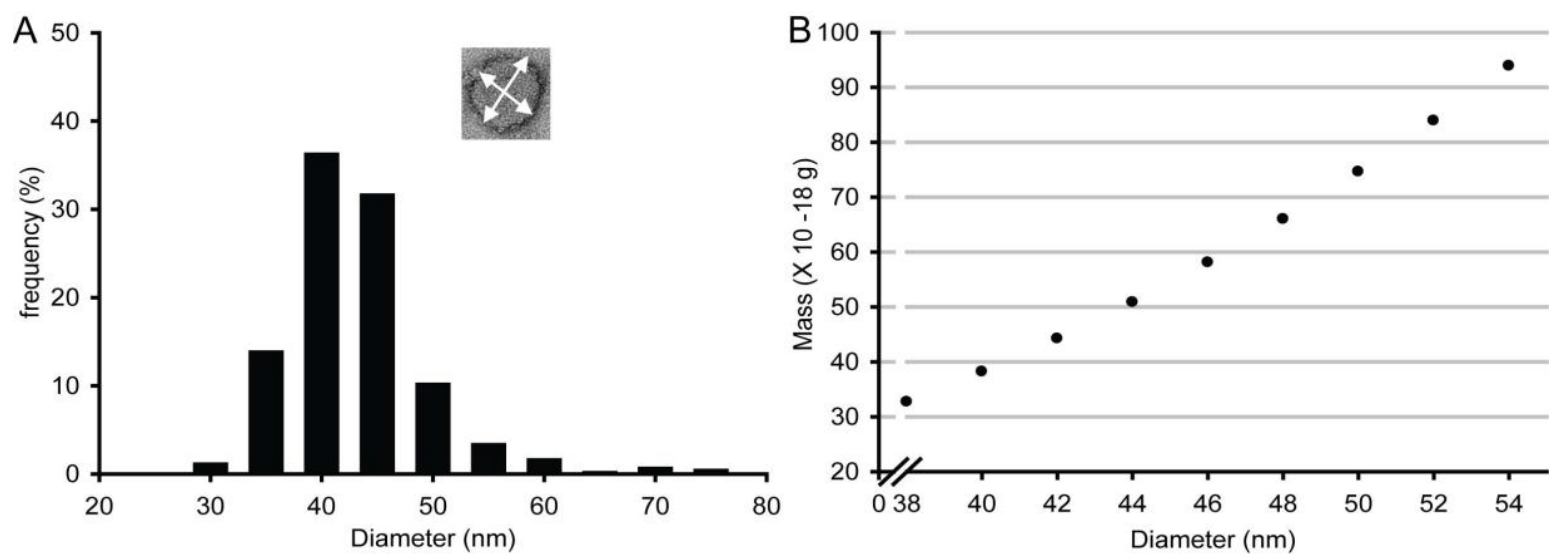

Figure 10. Size distribution of synaptic vesicles, determined by cryo electron microscopy. (A) Diameters were measured from the outer rims of the bilayer. The longest and shortest diameter of each vesicle were measured and averaged (see inset). The distribution gives an average diameter of $40 \mathrm{~nm}(\mathrm{n}=600)$. (B) Mass/diameter relationship calculated using the vesicle density $(\rho)$ of $1.14 \mathrm{~g} / \mathrm{ml}$. Assuming that synaptic vesicles have spherical shape, the mass $(\mathrm{m})$ can be calculated according to $\mathrm{m}=(4 \pi \mathrm{r} 3 / 3) \rho$. 


\subsubsection{Determination of buoyant density}

Determination of buoyant density of purified synaptic vesicles was carried out described in section 2.2.9. Equilibrium density gradient centrifugation in iodixanol shows the migration of SVs in a certain density range. As already mentioned in section 3.3.1 SVs have an average diameter of $40.0 \mathrm{~nm}$ (Fig. 10A) and a spherical shape assessed by negatively stained electron micrographs (Fig. 9C), they migrate according to their size and shape along the density gradient. Protein content analysis with Bradford reagent shows a peak at fraction number 14 (Fig. 11). To verify that fraction 14 contains SVs, a dot blot assay was performed testing with antibody against synaptophysin as a vesicle marker (Fig. 11 inset). The dotblot also reveals maximum migration of SVs to fraction 14 that gives a $\mathrm{SV}$ density of $1.14 \mathrm{~g} / \mathrm{ml}$ calculated from the refractive index.

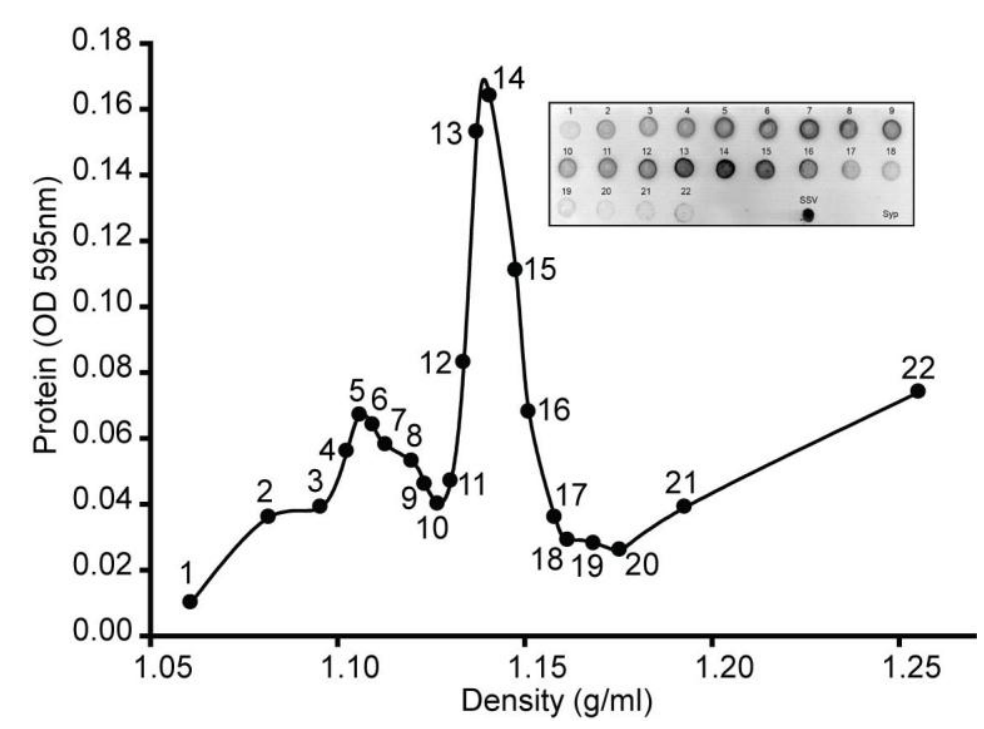

Figure 11. Determination of buoyant density of synaptic vesicle using iodixanol density gradients.

Purified synaptic vesicles were loaded on top of the iodixanol density gradient (5-35\%) corresponding to a density range of $1.05-1.22 \mathrm{~g} / \mathrm{ml}$. After centrifugation, fractions were analyzed for protein content and plotted against density, which was calculated from the refractive index. The distribution shows a peak at a density of $1.14 \mathrm{~g} / \mathrm{ml}$. Inset shows dotblot of fractions taken from the gradient. 


\subsubsection{Vesicle counting by FCS and derivation of vesicular mass}

The number of SVs was measured by fluorescence correlation spectroscopy (FCS), which allows counting of particles in solution (Magde et al., 1972; Muller et al., 2003). To determine the amount of protein per vesicle, two parameters are required. Fist the exact amount of protein and second the concentration of vesicle particles of the sample (Fig. $12 \mathrm{~A}$ ). Whereas the amount of protein can be determined using conventional methods (see section 2.2.2), the accurate determination of the vesicle concentration is a more challenging task. To overcome this task, SVs were labelled in solution with the fluorescent dye FM 143, which becomes fluorescent upon membrane insertion and the particle number was measured by fluorescence correlation spectroscopy (FCS). To avoid vesicle clustering, samples were used directly from the size exclusion column without any concentration or centrifugation. The background fluorescence of FM dye in Tris buffer is measured before the actual measurements (Fig. 12B). Synaptic vesicles are dropped on a coverslip to $5 \mu \mathrm{M}$ FM 1-43 solution. Upon addition of SVs onto coverslip, intensity is recorded for at least 30 $\mathrm{s}$ resulting in increase of the fluorescence signal (Fig. 12B). The ACF (autocorrelation function) for SVs is shown in (Fig. 12C). The protein concentration of samples used in the FCS measurements was determined in parallel. The following average values are then calculated for single vesicles: protein $=21.14 \pm 2.5 * 10^{-18} \mathrm{~g} /$ vesicle or $12.73 \pm 0.74 \mathrm{MDa}$ (Fig 12D). 

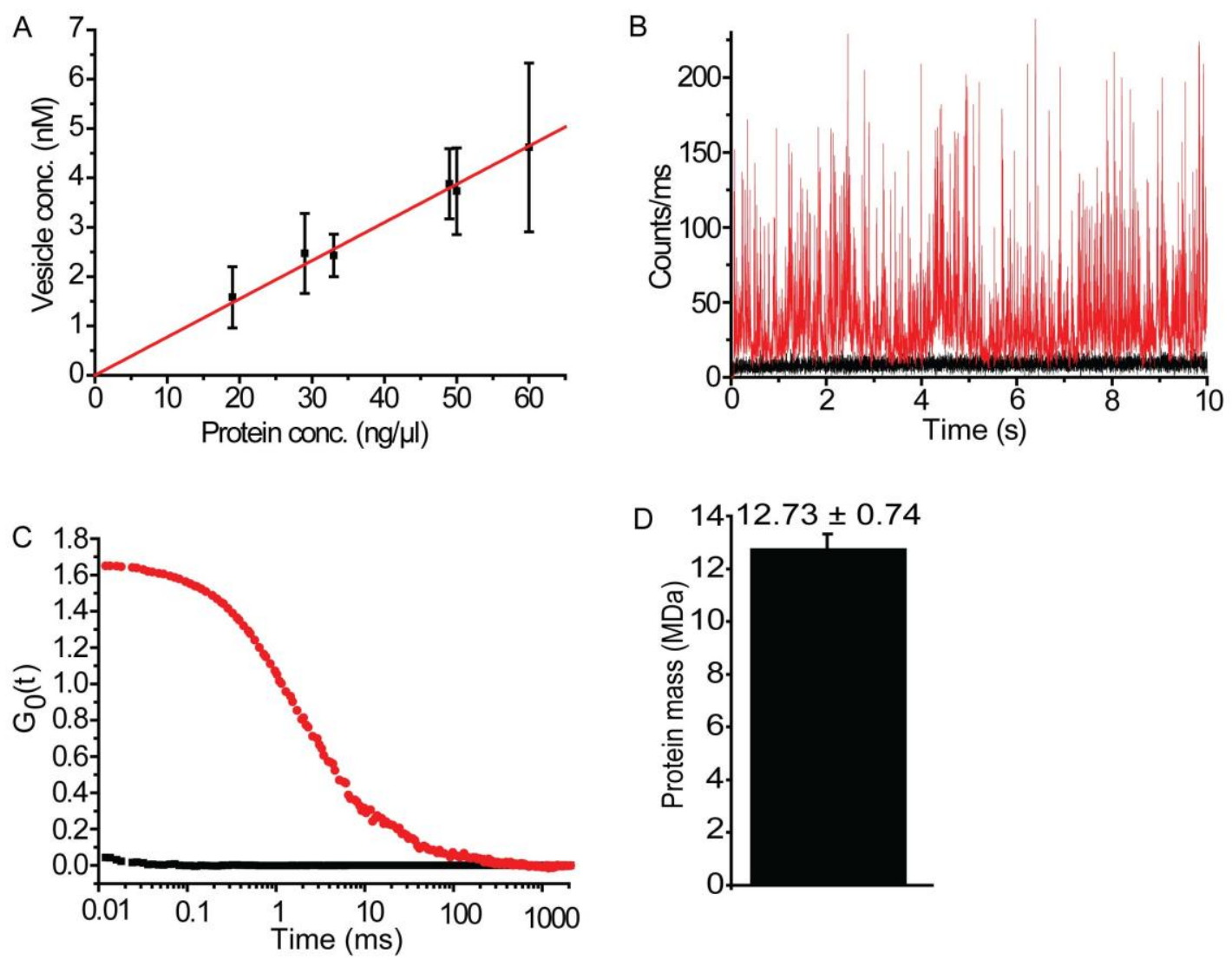

Figure 12. Determination of synaptic vesicle concentration by Fluorescence Correlation Spectroscopy.

(A) Synaptic vesicle concentration determined by FCS plotted against measured protein concentration, allowing the amount of protein per vesicle to be derived for the samples. (B) $10 \mathrm{~s}$ intensity traces for measurement of column buffer (100 mM Tris-HCl, $100 \mathrm{mM} \mathrm{KCl,} \mathrm{pH} \mathrm{7.6)} \mathrm{before} \mathrm{addition} \mathrm{of} \mathrm{SVs} \mathrm{(black)} \mathrm{and}$ after (red). (C) Typical autocorrelation functions were taken from $5 \mathrm{~s}$ detection periods (red lines). The black trace is the ACF of a $5 \mathrm{~s}$ measurement of background fluorescence before addition of the vesicles. (D) Protein mass of a vesicle calculated from FCS measurements. 


\subsubsection{Lipid composition of synaptic vesicles}

Synaptic vesicles consist of a lipid bilayer, made of different types of lipids. The lipid composition of SVs was measured using electrospray ionisation (ESI) that is coupled with collision-induced dissociation (CID) and mass spectrometry. Analysing the lipid composition of SVs using this method provided highly sensitive, qualitative and quantitative data (Brügger et al., 1997). The results in Fig. 13 reveal a high content of cholesterol (34\%), which seems to be high at first place but this finding is not surprising, since high cholesterol content was already observed previously (Takamori et al., 2006). Another interesting point is the very low amount of phosphatidylinositol (5\%) and a large portion of phophatidylethanolamine (16\%). The results for all phospholipids and even for cholesterol match with previous measurements using different methods (Nagy et al., 1976; Benfenati et al., 1989; Takamori et al., 2006).

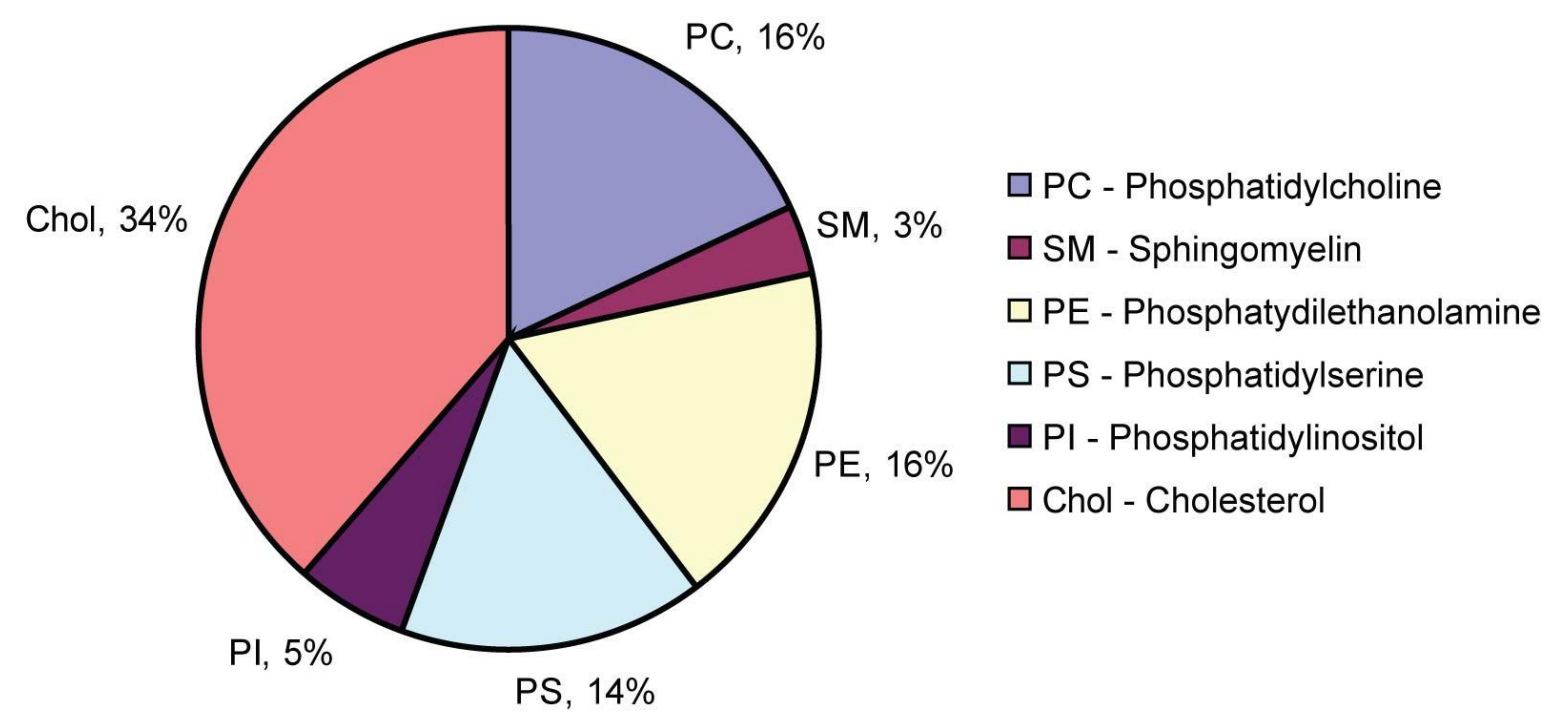

Figure 13. Quantitative measurements of synaptic vesicle lipids. The diagram shows the mol $\%$ of the phospholipid species distribution. Note the high presence of cholesterol and PC. 


\subsection{Functional characterisation of synaptic vesicles}

\subsubsection{Acidification of synaptic vesicles}

The intra-vesicular $\mathrm{pH}$ in $\mathrm{SVs}$ is acidic in comparison to the cytosolic $\mathrm{pH}$ in the presynaptic terminal. The $\mathrm{pH}$ gradient $(\Delta \mathrm{pH})$ is maintained by vacuolar $\mathrm{H}+$-ATPasem which is an ATPdriven proton pump. Previous studies have shown that glutamate uptake can lead to acidification of SVs (Maycox et al., 1988). Intra-vesicular acidification was monitored using the fluorescent dye Acridine orange (AO) as an indicator. Following equilibration, addition of ATP to purified SVs causes a decrease in fluorescence of AO due to proton influx (Fig 14). Addition of glutamate results in uptake. Glutamate uptake occurs with a cotransport of protons, resulting in a glutamate dependent acidification of the vesicle interior. Addition of potassium chloride results in lower acidification of the vesicle interior. The proton gradient is dissipated by the addition of ammonium sulphate.

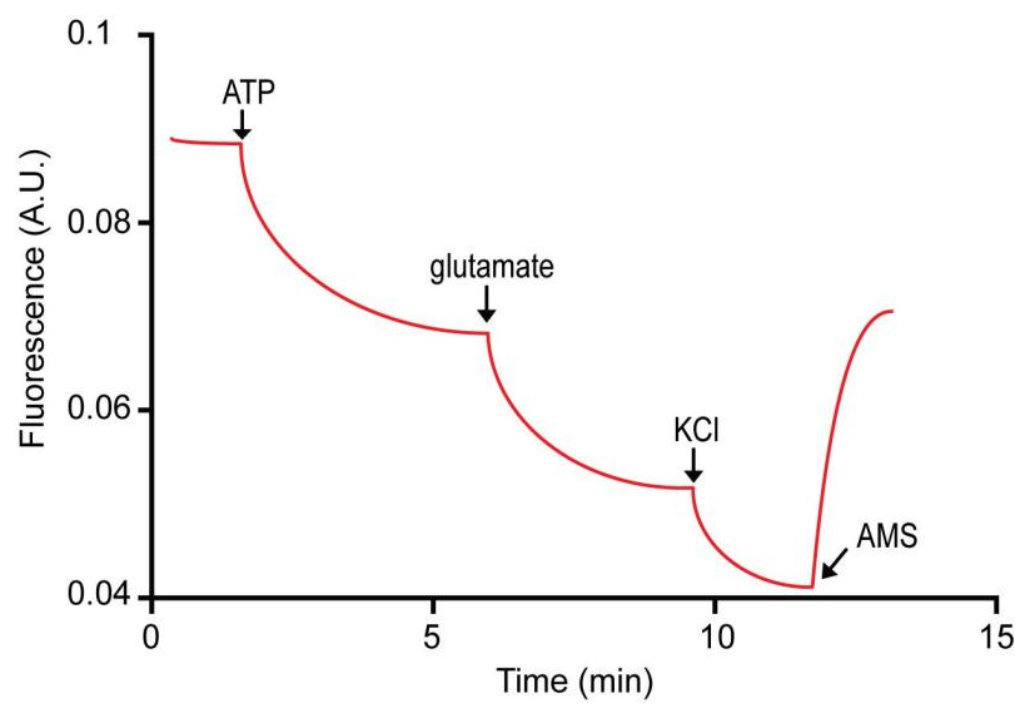

Figure 14. Glutamate induced acidification of synaptic vesicles. Potassium glutamate is added $4 \mathrm{~min}$ after addition of ATP to generate a proton gradient. L-glutamate induced intravesicular acidification resulting in maximal quenching of acridine orange. Addition of $\mathrm{KCl}$ produced a lower quenching of AO. Proton gradient is dissipated by the addition of ammonium sulfate. 


\subsubsection{Neurotransmitter uptake into synaptic vesicles}

Purified synaptic vesicles retain the ability to perform their primary in vivo function, the ability to uptake neurotransmitters. Neurotransmitters are transported actively into SVs by specific vesicular transporters. This transport is dependent on the proton electrochemical potential $(\Delta \Psi)$ across the vesicle membrane, generated by a vacuolar ATPase. Previously, ATP-dependent uptake of $\left[{ }^{3} \mathrm{H}\right] \mathrm{L}$-glutamate was reported in SV fraction from rat and bovine brain (Disbrow et al., 1982; Naito \& Ueda, 1983; Naito \& Ueda, 1985; Jahn and Maycox, 1988). The vesicular glutamate transporter that is responsible for glutamate transport into SVs was first identified by (Takamori et al., 2000). Synaptic vesicles purified by the procedure described in section 3.3.1 shows a high activity of glutamate uptake in an ATPdependent manner. The failure to transport glutamate into SVs would probably represent in dissociation of the V-ATPase during purification procedure, or membrane damage that prevents the maintenance of a stable membrane potential which is not the case (Fig. 15). To test that there is no non-specific uptake, the uncoupler FCCP (carbonyl cyanide $p$ (trifluoromethoxy) phenylhydrazone) was added to the reaction. FCCP is an ionophore that acts as an ion carrier. The uptake is inhibited to a high degree by FCCP.

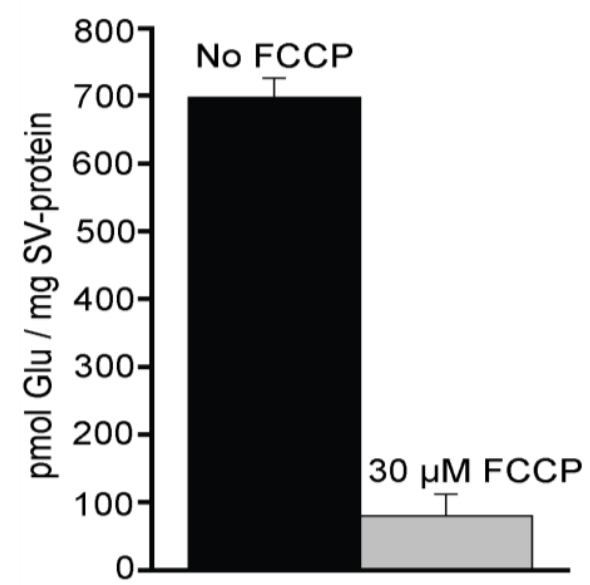

Figure 15. Glutamate uptake into synaptic vesicle. $\left[{ }^{3} \mathrm{H}\right] \mathrm{L}$-glutamate uptake by synaptic vesicles isolated from mouse brain. Synaptic vesicles containing the vesicular glutamate transporter accumulate glutamate under appropriate assay conditions. Glutamate uptake requires ATP-dependent vesicular acidification (produced by the vesicular proton pump). Addition of the uncoupler FCCP prevents glutamate uptake, by dissipation of the proton gradient. 


\subsubsection{SNARE mediated fusion}

In vivo, fusion of synaptic vesicles is mediated by SNARE proteins on the plasma membrane. Previous studies have shown that the minimal machinery required for membrane fusion is the formation of a ternary SNARE complex by three SNARE proteins, synaptobrevin, syntaxin 1 and SNAP-25 (Weber et al., 1998). Many studies were performed using recombinant proteins reconstituted into artificial membranes. Liposomes were labelled with the fluorophores NBD and rhodamine and reconstituted with syntaxin1 and SNAP-25 ( $\triangle \mathrm{N}$-complex) using gel filtration at protein to lipid ratio of 1:200. An in vitro lipid mixing assay was used as an indirect measurement of fusion between labelled liposomes and unlabeled SVs. The increase in spatial distance between the donor fluorophore (NBD) and acceptor fluorophor (rodamine) upon fusion results in decrease of the acceptor signal intensity and increase of the donor fluorescence intensity. Fusion should be SNARE dependent, to display the importance of specific interaction between synaptobrevin on SV membrane with syntaxin 1 and SNAP-25 liposomes, SVs are preincubated with clostridial neurotoxin tetanus toxin (TeNT), resulting in the cleavage of synaptobrevin into two fragments (Fig. 16). Pre-incubation of SVs with TeNT shows a reduction in fusion with some basal fusion visible in the fluorescence dequenching curve. Fusion is also effectively inhibited when liposomes and SVs are pre-incubated with the cytosolic fragments of either synaptobrevin (1-96) or syntaxin/SNAP-25 as expected for competitive SNARE inhibition. 


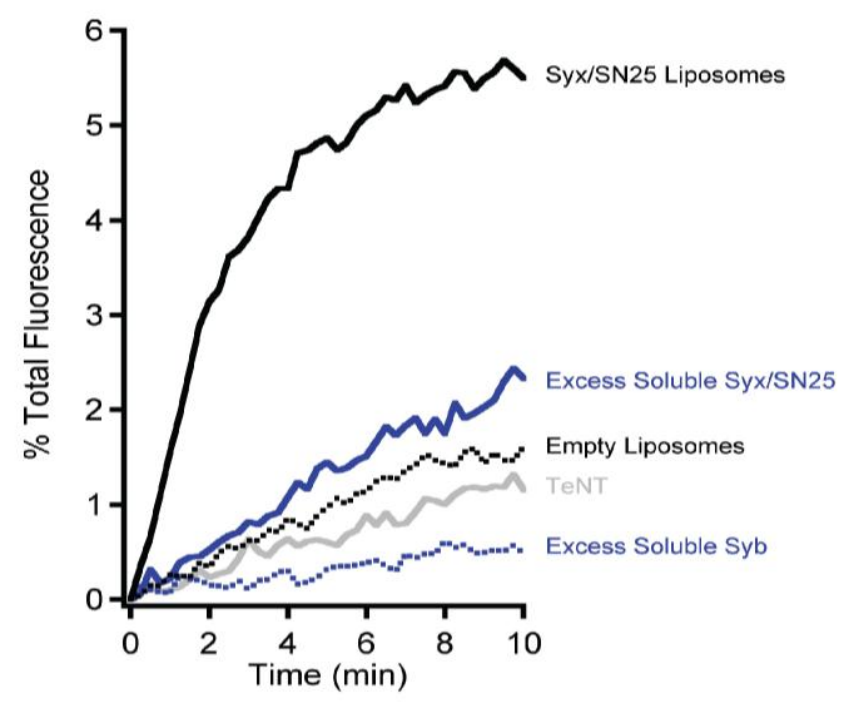

Figure 16. SNARE mediated fusion of synaptic vesicle with liposomes. The FRET based lipid-mixing assay reports SNARE mediated fusion of purified synaptic vesicles with liposomes. FRET decreases resulting in a measurable increase in NBD fluorescence when vesicles fuse with liposomes containing the SNARE proteins syntaxin 1 and SNAP-25 (Syx/SN25 liposomes). This occurs as the larger (unlabelled) surface area of the fusion product allows greater spatial separation of the two dyes, resulting from lipid diffusion. Fusion is normalised to the total NBD fluorescence measured after liposomes are completely solubilised by Trition X100 , resulting in maximal spatial separation of NBD and Rhodamine. Fusion is SNARE dependent. No fusion is seen between synaptic vesicles and empty liposomes, or when the vesicular SNARE protein synaptobrevin is cleaved with the light chain of tetanus toxin (TeNT). Fusion is also being effectively inhibited when liposome and synaptic vesicles are preincubated with the cytosolic fragments of either synaptobrevin or syntaxin/SNAP-25 respectively, as expected for competitive SNARE inhibition. 


\subsection{Comparison of synaptic vesicles from mouse and rat}

\subsubsection{Distribution of SV and other marker proteins of rat synaptic vesicles}

A biochemical and morphological comparison between mouse and rat synaptic vesicles was carried out. Rat SVs have a distinct protein pattern on a coomassie gel, with prominent bands at the molecular weight of $65 \mathrm{kDa}$ for synaptotagmin, $38 \mathrm{kDa}$ for synaptophysin and $18 \mathrm{kDa}$ for synaptobrevin (Fig. 17A), which compares well to the protein pattern of mouse SVs (Fig. 8A). The above mentioned SV proteins show a similar enrichment in the final SV fraction determined by immunoblotting (Fig. 17B) to that of mouse SVs (Fig. 8B). Similar results are obtained for the SV associated proteins like NSF, Rab3a etc. (Fig. 8B and Fig. 17B). Contaminants are also effectively removed during the isolation procedure. Purification of SV from rat brain using the above described method, leads to the assumption that SVs from both species have similar protein pattern. 


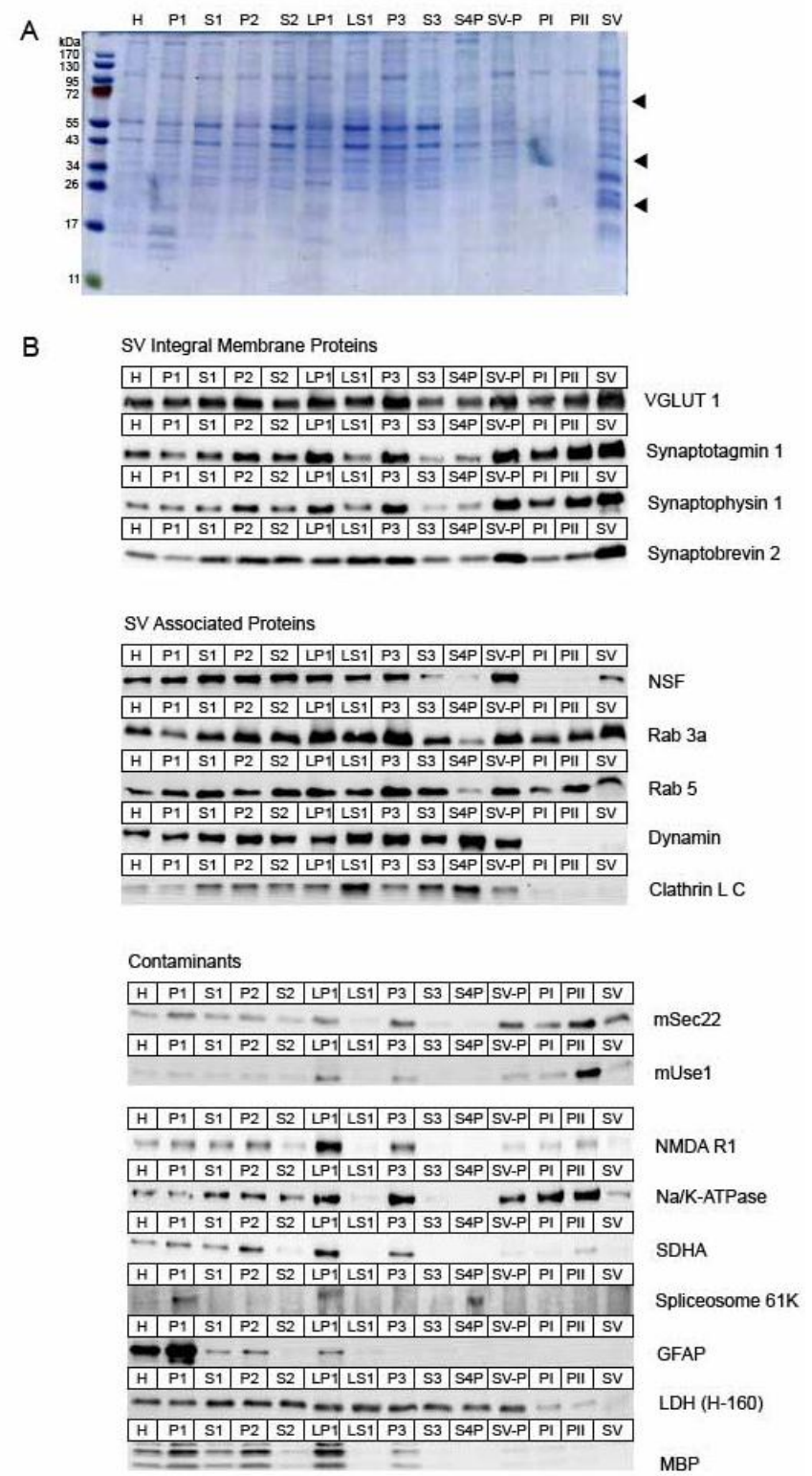

Figure 17. Protein profile of subfractions from rat synaptic vesicle preparation. (A) Similar protein pattern of subfractions is seen in mouse fractions. Prominent bands are pointed out with arrowheads indicating probably bands for Synaptotagmin, synaptophysin and synaptobrevin. (B) Synaptic vesicle proteins are enriched in final SV fraction. Synaptic vesicle associated proteins like NSF, Rab3a and Rab5 are present in small amounts in final SV fraction. Due to the high ionic strength of the elution buffer dynamin dissociates from SVs. Contaminants are effectively removed by size exclusion chromatography (for details see figure legend 9). 


\subsubsection{Level of synaptic vesicle proteins in whole brain}

Mice and rats are very similar in appearance and anatomy except of body size. Differences in brain size and neuron number are for interest in terms of the biological significance, especially in animal development and behaviour. The fact that mice have a four to five times smaller body than rats, impacts as well on the brain size. With an average body weight of $30 \mathrm{~g}$ of an adult mouse, the weight of the brain contributes $1.33 \%$ to the body weight. Whereas the brain mass of a rat compared to its body is $1.25 \%$. Having 5 times more brain mass (rat brain $2 \mathrm{~g}$; mouse brain $0.4 \mathrm{~g}$ ), does it mean mice have less synapses with equal number of SVs or equal synapses with less SVs compared to rats? However, it has been reported, neuron number can vary within closely related families of species, or even within individuals of the same species (Wingert, 1969; Holloway, 1980; Mann et al., 1986). Therefore, total brain homogenates were immunoblotted to indicate any differences in SV protein levels, to reason of neuron or synapse number. The total protein content was determined which is $197.2 \mathrm{mg}$ for rat brain and $43.04 \mathrm{mg}$ for mouse brain. Different amounts of homogenate were immunoblotted using antibodies against synaptotagmin, synaptophysin and synaptobrevin. Results in Fig. 18A shows identical levels of SV protein synaptophysin, identical results were obtained for synaptotagmin and synaptobrevin (see Appendix Figure 1), providing some hints for similarities in SV numbers. To estimate SV number in species, brain homogenates and recombinant synaptobrevin was used for quantitative immunoblotting. From standard curve of recombinant protein, the amount of synaptobrevin in total brain homogenate was calculated (Fig. 18B) resulting in $0.44 \% \pm 0.043$ (mouse) and $0.47 \% \pm 0.041$ (rat). With given weight of synaptobrevin and copy numbers on SVs, total vesicle number was calculated. An adult mouse brain contains on average $1.38 * 10^{14} \mathrm{SVs}$ and $4.24 * 10^{14} \mathrm{SVs}$ are probably present in rat brain. 

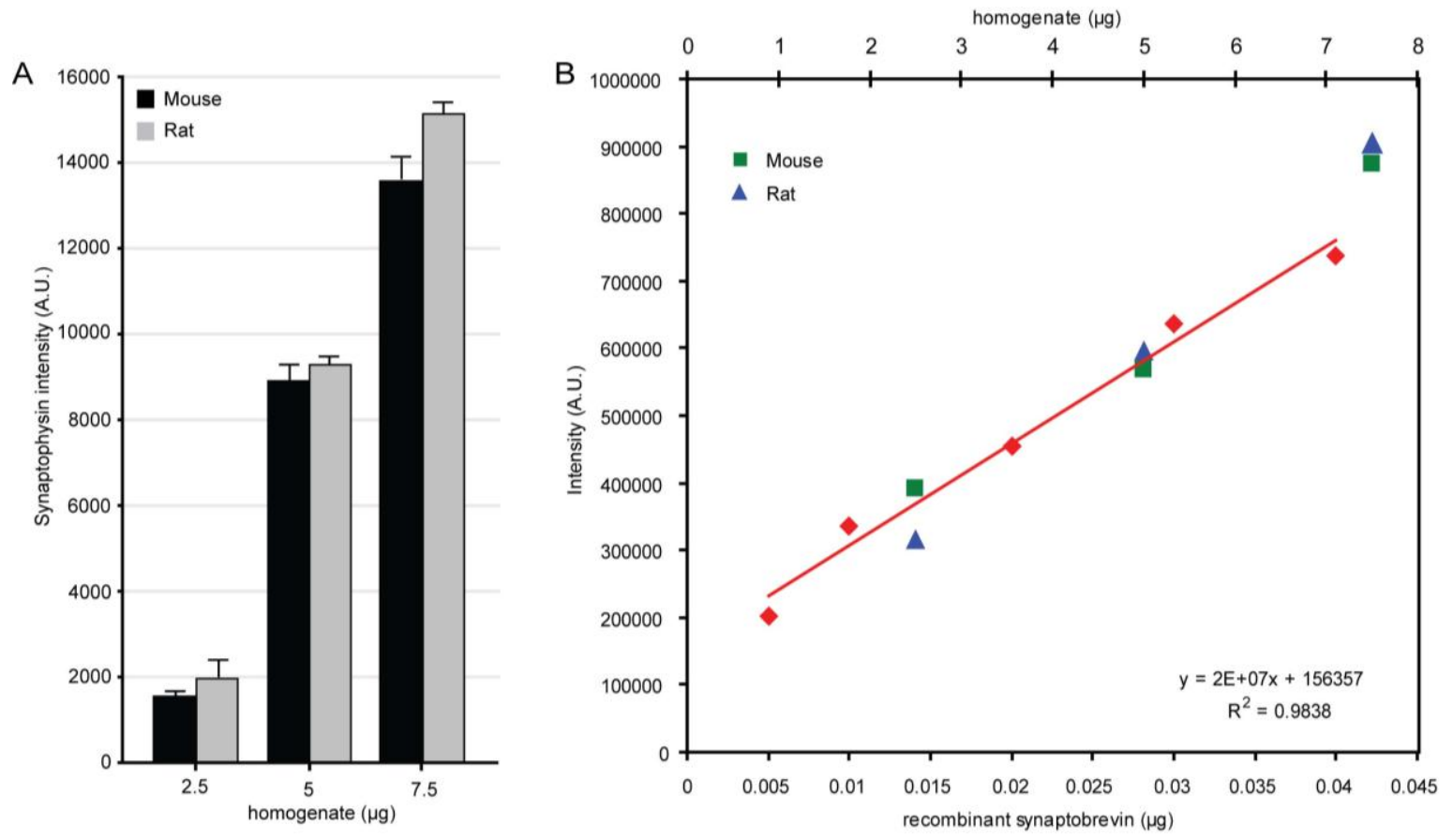

Figure 18. Synaptophysin and synaptobrevin level in brain homogenates. (A) Equal amounts of homogenate from mouse and rat are immunoblotted with antibody against synaptophysin, indicating similar amount of SV protein in brain. (B) Determination of the amount of synaptobrevin in total brain homogenate using quantitative immunobloting of homogenates in comparison to standard curve of recombinant synaptobrevin. 


\subsubsection{Quantitation of major SV proteins on mouse and rat vesicles}

Successful purification of mouse and rat synaptic vesicles on a small-scale basis leaded to a fundamental question, whether proteins are distributed and available in an equal frequency on vesicles. To reply to this question, purified SVs from both species were immunoblotted using primary antibodies against some of the major vesicle proteins and quantified using fluorescent labelled secondary antibodies. Fluorescent labelled secondary antibodies provided more accurate number for quantification than HRP (horseradish peroxidase) conjugated secondary antibodies detected with ECL. Primary antibodies were used where the epitopes used for immunisation were identical in sequence between mouse and rat (see Appendix Table 1 of sequences - against accession number searched in Pubmed). Quantitative analysis of proteins on rat SVs was previously carried out, providing the stoichiometry (Takamori et al., 2006). Taking these copy numbers as a basis, ratio of mouse SV proteins were calculated. The result shows, that synaptophsyin, synaptotagmin and synaptobrevin which are among the most abundant SV proteins, are present in similar copy numbers on both SV species (Fig. 19A). Two vesicular glutamate transporters (VGLUT1 and VGLUT2) and the vesicular GABA transporter were included in the analysis, are also present in equal amounts on both SVs. The amount of Rab3a on mouse SVs is significant lower than of rat SVs (Fig 19C). Due to the fact that mouse SVs are smaller (Fig. 10A) compared to rat SVs (Fig. 20A), it may provides less free membrane surface area for Rab3a binding, resulting in decrease amount of Rab3a on mouse SVs. However, it seems to be that the stoichiometry of both SV species is very similar with small discrepancies. Sequence alignment revealed a high degree of identity for SV proteins tested in this experiment. 

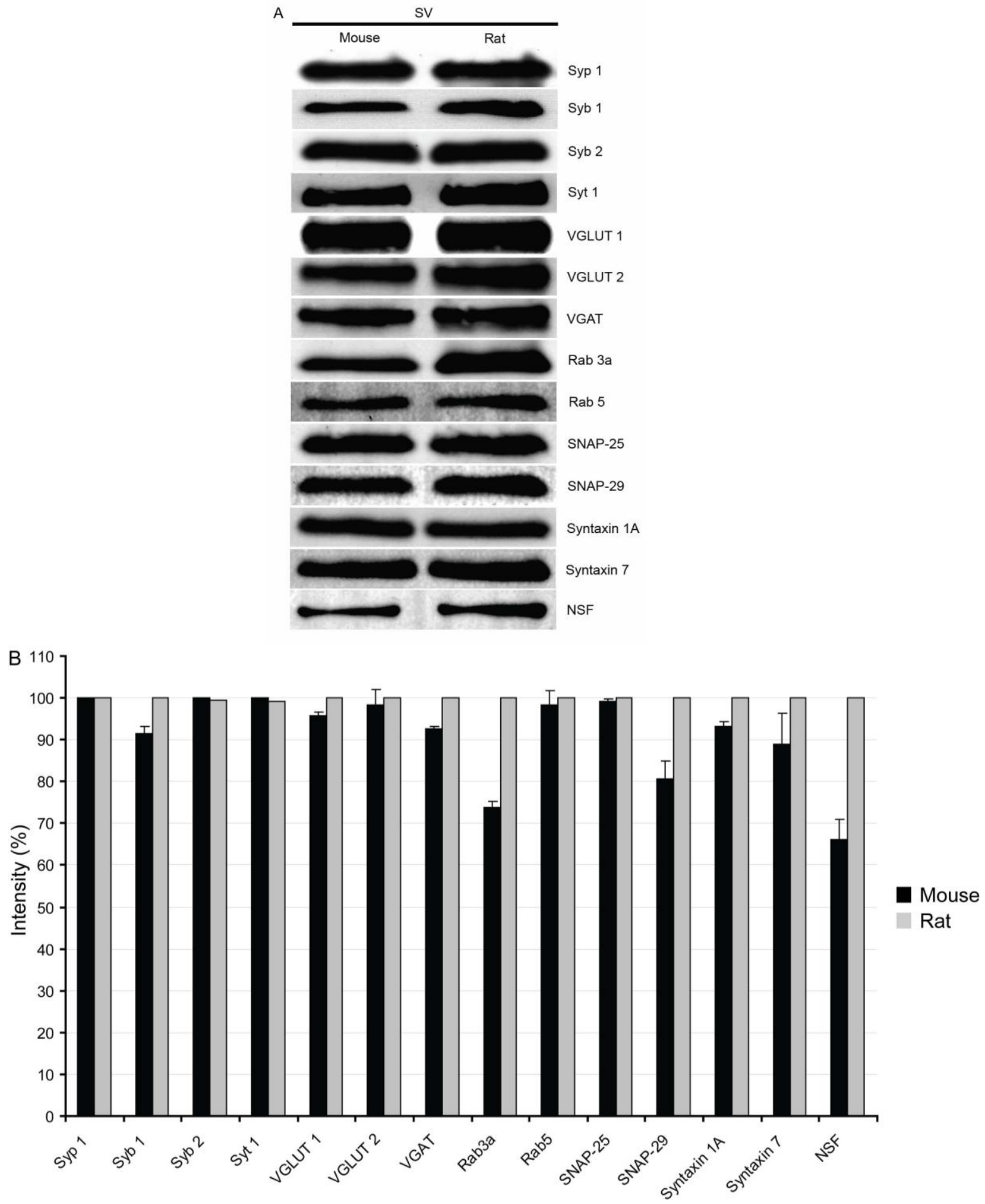

Figure 19. Quantitative comparison of major synaptic vesicle proteins from mouse and rat. (A) $5 \mu \mathrm{g}$ of mouse and rat SVs were immunoblotted and band intensities were measured with a fluorescence scanner. Band intensities are normalised against synaptophysin, to ensure loading of equal amount of proteins. (B) Ratio of calculated band intensities is plotted for mouse and rat SVs, whereas intensities of rat SVs are set to $100 \%$. Results averaged from three individual experiments. 


\subsubsection{Quantitative analysis of physical parameters and lipids of rat synaptic vesicles}

The comparison of physical parameters of mouse and rat synaptic vesicles probably provides an insight into possible variations between these SV species. Details of rat SVs, purified using the classical method of Nagy (Nagy et al., 1976) are already available (Takamori et al., 2006). To role out any purification bias, SVs of both species were purified using the same method and compared to the parameters of rat CPG SVs (Takamori et al., 2006). As already observed in section (3.3.1) mouse SVs have an average diameter of 40.0 $\mathrm{nm}$, it is marginal smaller than rat SVs (Fig. 20A), determined by cyro electron microscopy. Size distribution of rat SVs results in a unimodal distribution curve with an average diameter of $41.7 \mathrm{~nm}$. Buoyant density gradient centrifugation was applied, resulting in a density of $1.11 \mathrm{~g} / \mathrm{ml}$ (Fig. 20C), which is little lower than the density of mouse SVs. From the size and density, the mass/diameter relationship was calculated; which is slightly higher than for mouse SVs (Fig. 20B). The lipid composition was determined and matched with that of mouse SVs. The results provided no significant alterations; the cholesterol portion is $32 \%$, whereas the percentage of phosphatidylinositol is $4 \%$ and $17 \%$ of phophatidylethanolamine. At last, particle counting was performed using FCS (see section 3.3.3 for details), and protein concentration was determined in parallel. FCS counting gives an average value for single vesicle: protein $=17.91 \pm 1.21 * 10^{-18} \mathrm{~g} / \mathrm{vesicle}$ (Fig. 20D) which is less than of mouse SVs. All data shows not striking, but relative small differences between both SV species. 

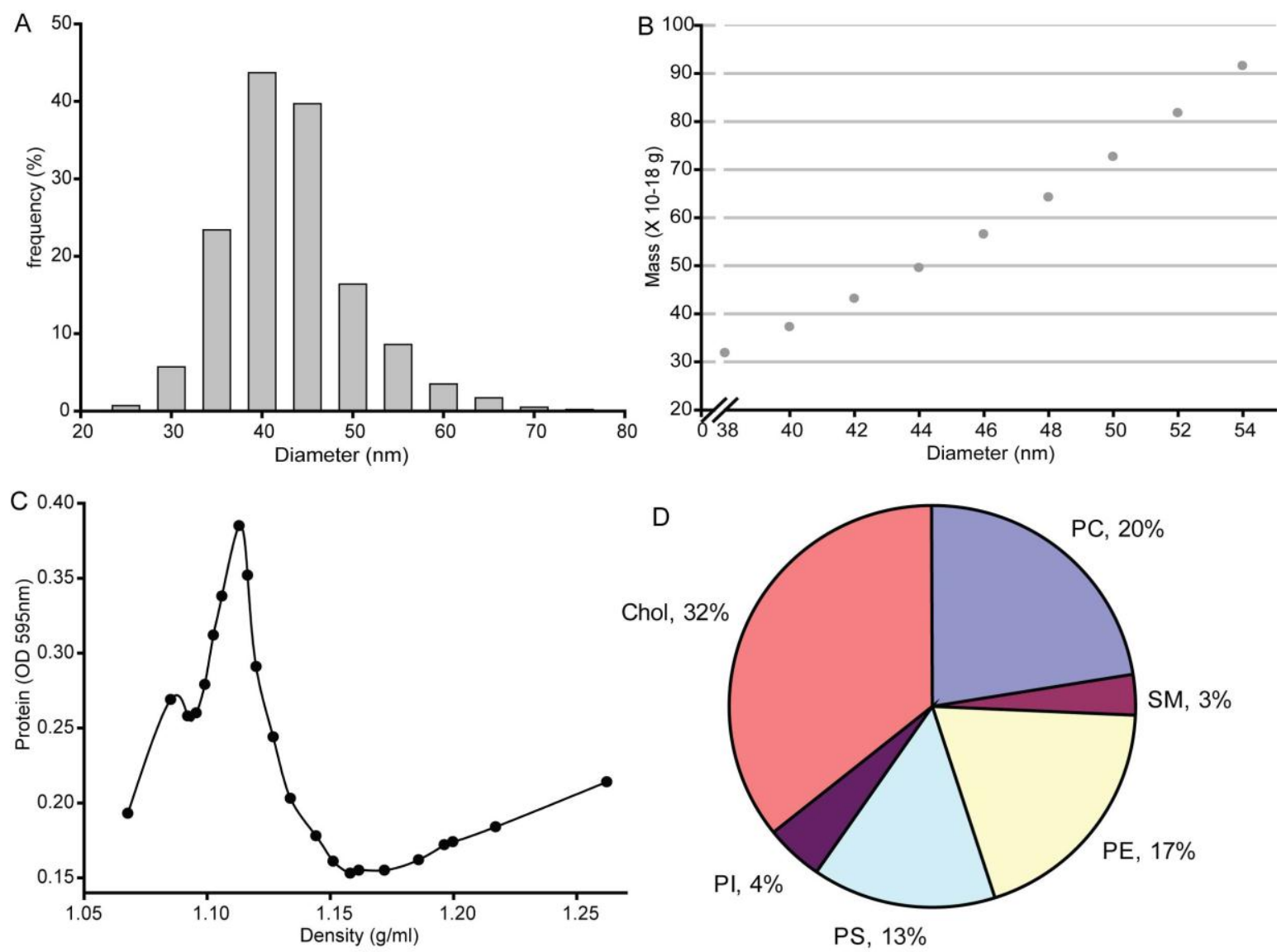

PS, $13 \%$

$\square$ PC - Phosphatidylcholine

口SM - Sphingomyelin

$\square P E$ - Phosphatydilethanolamine

口PS - Phosphatidylserine

aP - Phosphatidylinositol

$\square$ Chol - Cholesterol

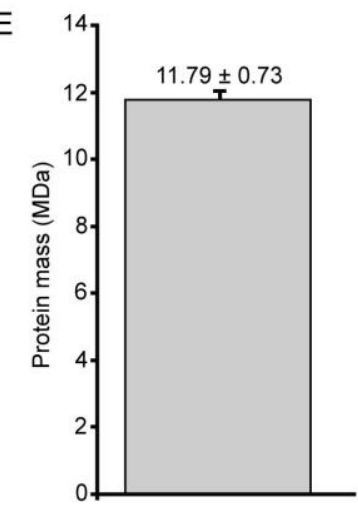

Figure 20. Physical and biochemical characterisation of rat synaptic vesicles. (A) Size distribution of SVs, determined by cyroelectron microscopy $(n=900)$ with an average diameter of $41.7 \mathrm{~nm}$ (for details see Figure legend 10). (B) Mass/diameter relationship calculated using a particle density of $\rho 1.11 \mathrm{~g} / \mathrm{ml}$. (C) Buoyant density of SVs defined using iodixanol density gradients, density plotted against protein content (for details see Figure legend 11). (D) A pie diagram of lipid constituents of rat SVs, with high amount of cholesterol and low amount of phosphatidylinositol. (E) Protein mass of a vesicle, calculated from FCS measurements. 
Table 5. Physical parameters of moue and rat synaptic vesicles.

\begin{tabular}{|l|c|c|}
\hline Physical Parameters & Mouse & Rat \\
\hline Density (g/ml) & 1.14 & 1.11 \\
\hline Outer Diameter (nm) & 40.0 & 41.7 \\
\hline Inner aqueous volume (1) & $17.15 * 10^{-21}$ & $20.04 * 10^{-21}$ \\
\hline Protein Mass $(\mathrm{g})$ & $21.14 * 10^{-18}$ & $17.91 * 10^{-18}$ \\
\hline Protein Mass (MDa) & 12.73 & 11.97 \\
\hline
\end{tabular}

Summary of data obtained from quantitative physical parameter experiments. Note the small differences in diameter and density, which effectively impacts on the protein mass and inner volume. With a smaller size of mouse SVs, protein density is presumably higher, by reason of dense packing with proteins. 


\subsection{Functional analysis of synaptic vesicles}

\subsubsection{Glutamate uptake into synaptic vesicles}

As already mentioned in section 3.4.2 purified mouse SVs retain their main function to uptake glutamate. Having similar copy numbers of glutamate transporter (VGLUT1) on both SV species, it leads to the question; can these SVs filled with different number of neurotransmitter molecules, because of differences in the inner volume. It was previously reported that an average rat SV can fit 1790 molecules of glutamate (Takamori et al., 2006). Results in Fig. 21 shows slightly more glutamate uptake in rat than in mouse SVs. Glutamate uptake is specific and ATP-dependent, no uptake is seen with addition of FCCP.

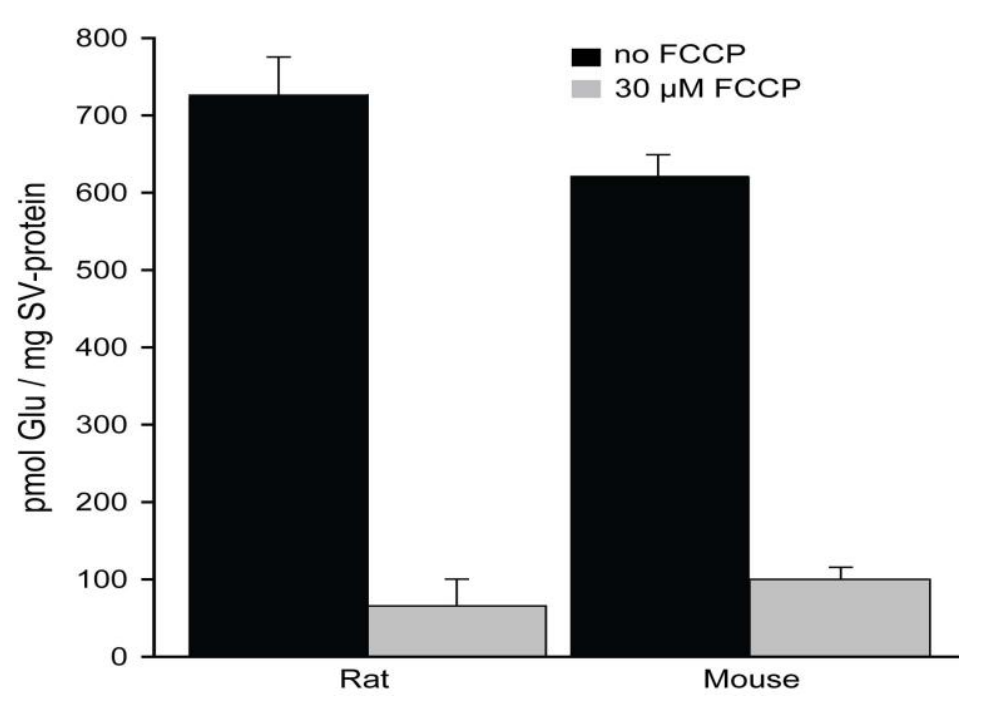

Figure 21. Glutamate uptake by two synaptic vesicle populations. Rat SVs shows higher degree of glutamate uptake per mg protein than mouse SVs. Uptake is inhibited by FCCP. 


\subsubsection{Synaptic vesicle fusion}

Synaptic vesicle fusion with the presynaptic plasma membrane is SNARE dependent. Similar copy numbers of SNARE proteins on both SV species (Fig. 19A) leads to the assumption, that fusion rate should be equivalent. Freshly purified SVs were fused with liposomes reconstituted with syntaxin 1 and SNAP-25 at different SNARE densities. Acceptor complex liposomes were reconstituted with a protein-to-lipid ratio of 1;1,000 and 1:16,000, in vitro fusion was performed using a FRET based system (see section 3.4.3 for details). Upon fusion the decrease of the acceptor signal intensity results in increase of the donor fluorescence intensity. Donor fluorescence increases to the same level in both cases using either 1:1,000 (green trace) or 1:16,000 (blue trace) acceptor complexes (Fig. 22A (mouse) and B (rat)). No differences are seen even in the initial face of fusion. Acceptor SNARE complex liposomes were pre-incubated with a soluble fragment of synaptobrevin 2, which forms a ternary SNARE complex, addition of SVs to the reaction results in no fusion. No free acceptor SNARE complex is available any more for synaptobrevin 2 binding from SVs. Fusion is inhibited to a certain degree with a soluble fragment of synaptobrevin 2 (1-96) for 1:1,000 and 1:16,000 acceptor complexes. The level of inhibition is effectively similar in both cases and for both SV species. This experiment was performed by Dr. Geert van den Bogaart Dept. of Neurobiology MPIbpc Göttingen. 


\section{Results}
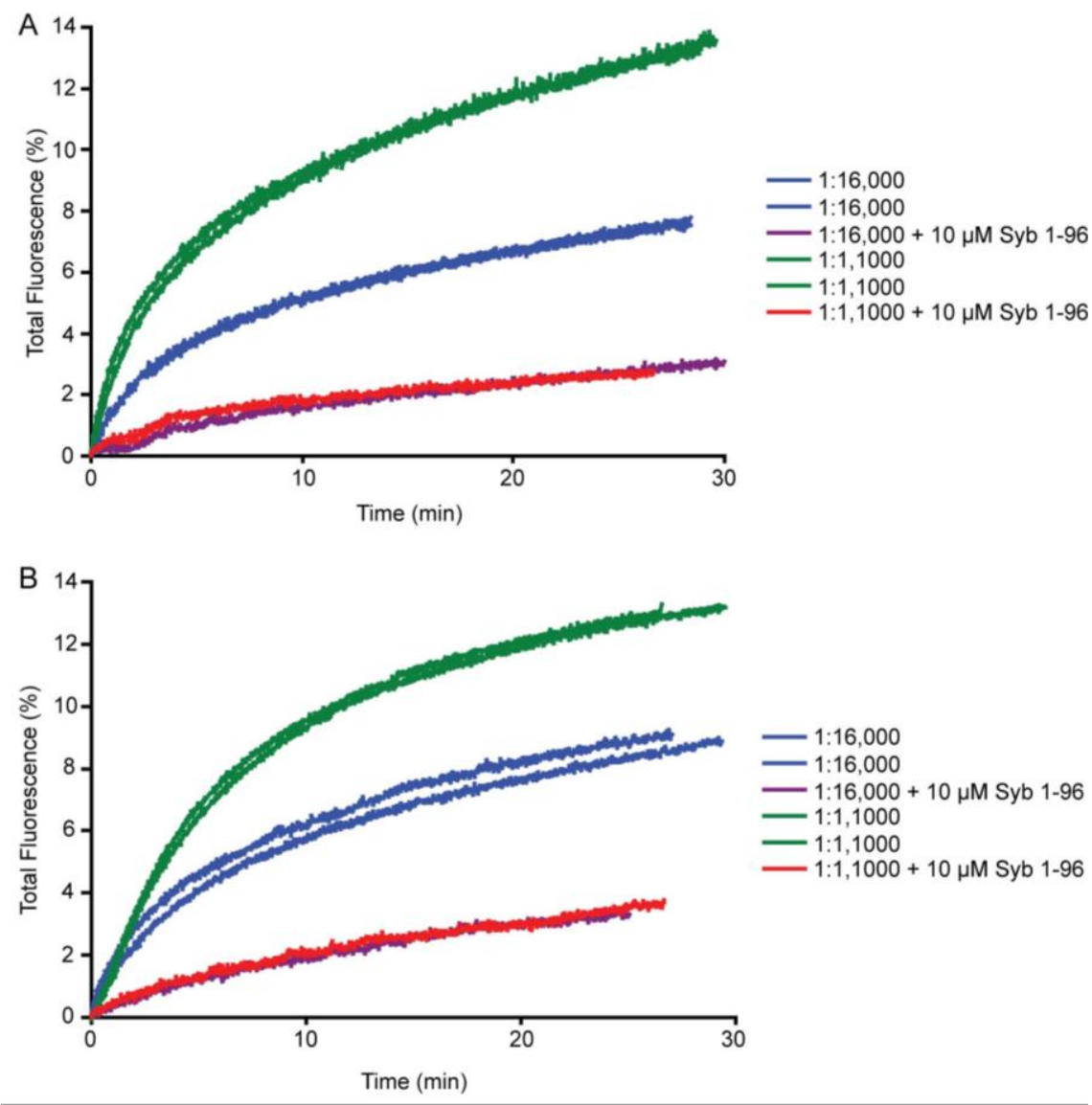

Figure 22. Mouse and rat synaptic vesicle fusion with liposmes. Acceptor SNARE complex liposomes fused to SV with protein-to-lipid ratio of 1:1,000 (green lines) and 1:16,000 (blue lines). Fusion is inhibited through pre-incubation of acceptor SNARE complex liposomes with soluble fragment of synaptobrevin 2 (196). Overall fusion rates are similar between mouse (A) and rat (B). Note the large initial jump, probably caused by light scattering at addition of SVs. 


\subsection{Analysis of subcellular fractions from Rab-GDI1 KO mice}

Purification of SVs on a small-scale basis using one mouse brain opens the chance to analyse synaptic transmission in a precised manner with the help of genetically modified mice models in this case Rab-GDI1 deficient mice (D’Adamo et al., 2002). Synaptic vesicles purified from Gdil-deficient mice were first of all analysed using electron microscopy (Fig. 23) that reveals no discrepancies in morphology to wildtype vesicles (Fig. 9C).

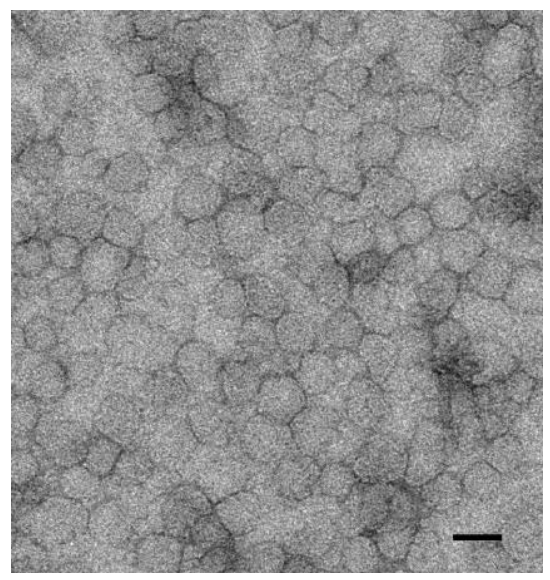

Figure 23. Electron micrograph of synaptic vesicles from Gdil-deficient mice. Purity of SVs was maintained during isolation. Synaptic vesicles showed no incongruities in shape and size. Scale bar 50nm.

Due to the fact that $\alpha$ Gdi is a cytosolic protein, it is not classified as a SV protein and not even found in purified vesicle fractions (Fig. 8B; Fig. 25) but is highly present in cytosolic fractions like LS2 (lysed supernatant 2) of wildtype mice (Fig. 25). While aGdi is supposed to be an important candidate in vesicle fusion and intracellular trafficking, it has no influence in basal function of SVs, the ability to be filled with neurotransmitter by vesicular glutamate transporter. Glutamate uptake by these knock-out vesicles remains unaffected (Fig. 24A) as well as glutamate induced acidification (Fig. 24B). 

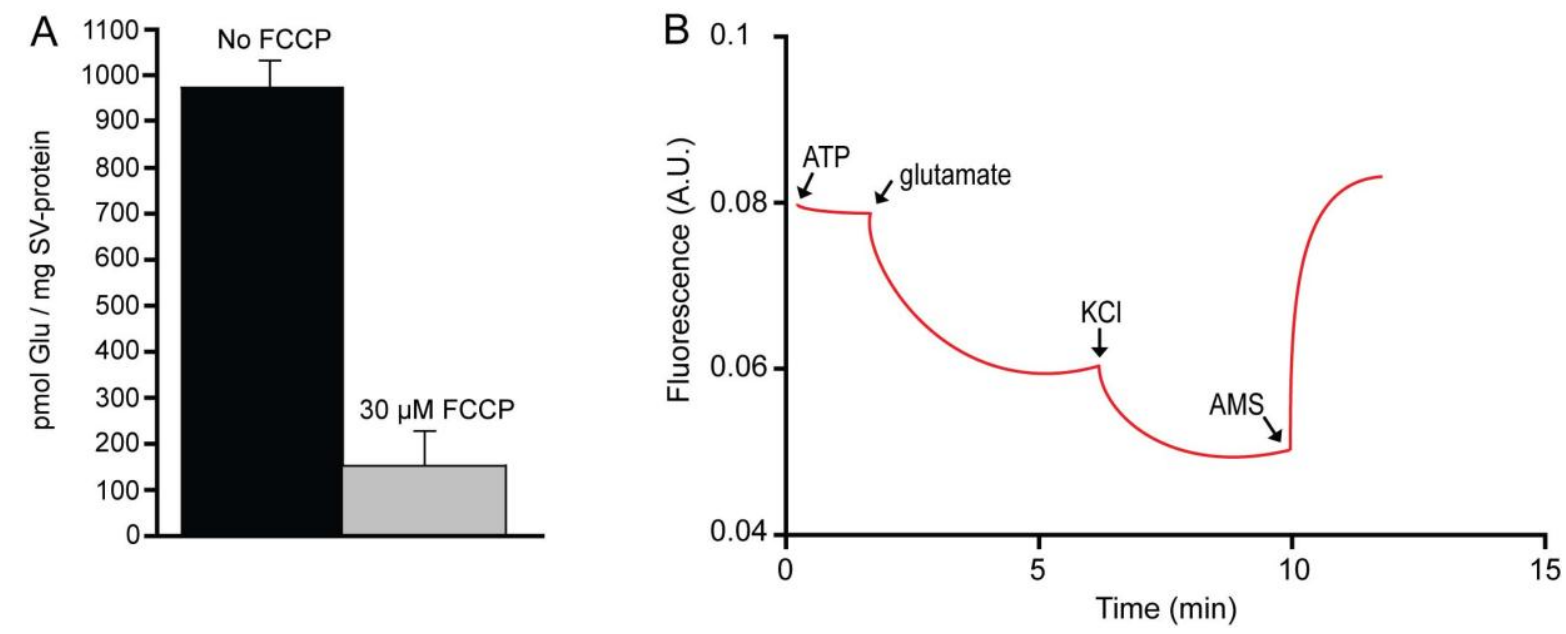

Figure 24. Synaptic vesicles from knock-out mice retain their functionality. (A) Glutamate uptake is not affected by the deletion of the GDI 1 gene. (B) Synaptic vesicle retained their ability to acidify in a glutamate dependent manner.

Gdil-deficient mice show minor phenotype in electrophysiological experiments, exocytosis is maintained at a relative normal level compared to wiltdtype animals (D’Adama et al., 2002; Bianchi et al., 2009). Analysing the distribution of various Rab and SV proteins involved in exocytosis and recycling was carried out to observe any alterations by the deletion. Membrane fraction LP2, synaptosolic fraction LS2 and enriched SV fraction of wildtype and knock-out mice were immunoblotted, which reveals an unexpected phenotype. None of the major SV proteins are altered in their presence on SVs (Fig. 24D), whereas the situation for the Rab proteins is quite different. Rabs analysed in this study, can be classified in three categories; A) secretory Rabs including Rab3a,-b,-c,-d and Rab27a,-b; B) endosomal Rabs including Rab4, Rab5, Rab10, Rab14, Rab 35 and Rab 39; C) Golgi Rabs including Rab1b, Rab2, Rab6,-6b and Rab33b. While secretory Rabs involved in the exocytotic pathway are not effected by the deletion of GDI1 gene (Fig. 25A), endosomal Rabs involved in the endocytotic pathway like Rab 14 and Rab39 are completely depleted in the cytosolic fraction LS2 (Fig. 25B) but are still found in purified SV fraction. Rab 14 functions in the recycling pathway between endosomal and Golgi membranes through clathrin-coated micro-domains (Junutula et al., 2004; Proikas-Cezanne et al., 2006). Another interestingly finding is the presence or absence of Golgi Rabs like Rab2, Rab6a 
and Rab6b from the cytosolic and vesicle fractions. Complete depletion of Rab2 in SV fraction of $\mathrm{KO}$ mice is observed, while Rab6a and 6b are abolished in LS2 fractions only (Fig. 25C). Further analyses based on these observations are currently carried out, which might provide new insights into the role of various Rab proteins involved in exo-endocytic pathways and effects of Rab-GDI. Rab-GDI1 knock-out mice were kindly provided by $D r$. Patrizia D'Adamo Institute of Genetics, Biochemistry and Evolution, Pavia, Italy.

A

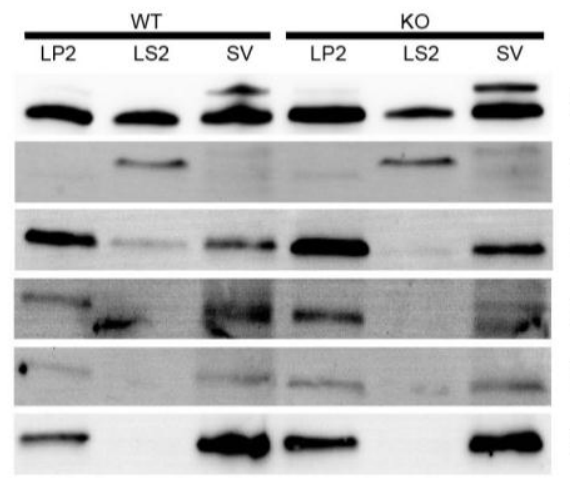

B

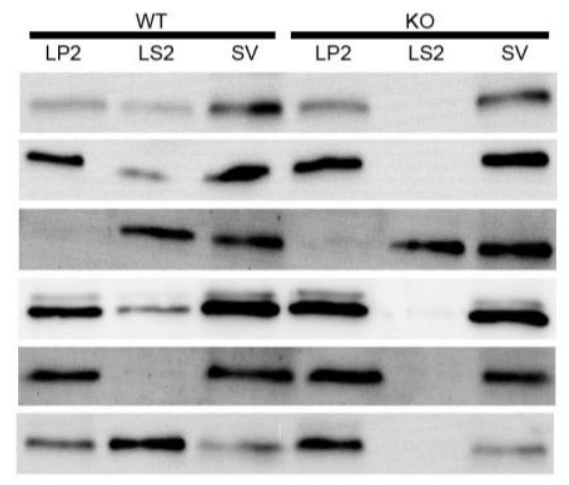

C

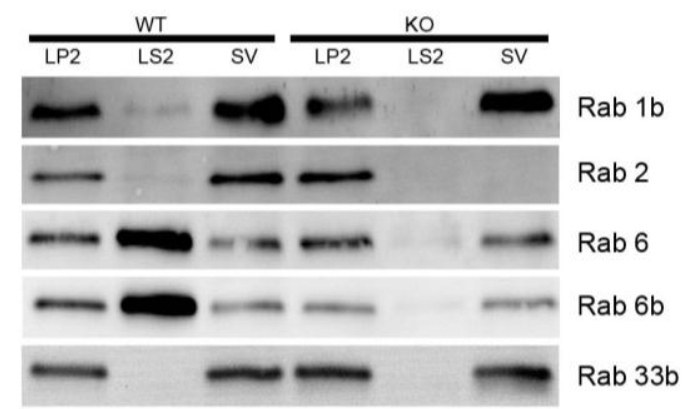

D

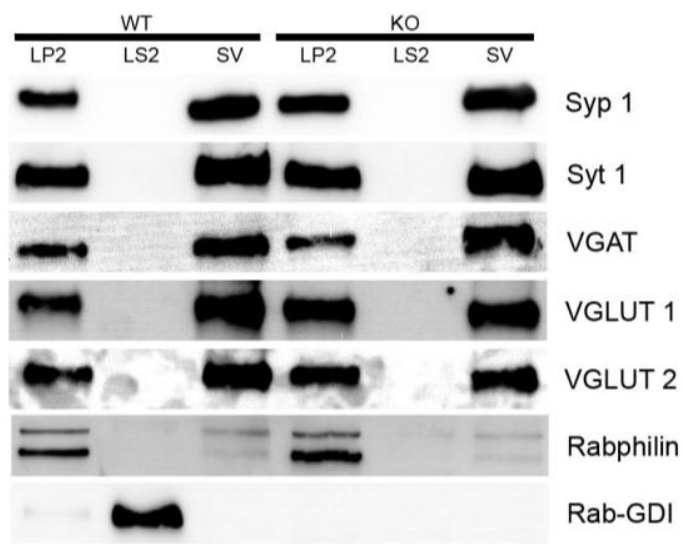

Figure 25. Subcellular distribution of Rab-GTPases and synaptic vesicle proteins. Analysis of Rab and SV proteins in crude SV fractions (LP2), synaptic cytosol (LS2) and purified SVs of wildtype and Gdi1 KO mice. $5 \mu \mathrm{g}$ of each fraction was subjected to SDS-PAGE and immunoblotted using antibodies against Rab and SV proteins. (A) Secretory Rabs are not effected, distribution in all three fractions of WT and KO are relative identical. (B) Endosomal Rabs shows a larger effect of GDII deletion, especially Rab14 and Rab39, are depleted in LS2 fraction of KO mice while LP2 and SV fractions are not altered. (C) Golgi Rabs also shows the influence of GDII absence, in form of Rab6 and Rab6b which are not present in LS2 fraction of KO mice. (D) No alteration are seen for SV proteins including NT transporters, Rab-GDI antibody recognise the $\alpha$ isoform only. 


\section{Discussion}

\subsection{Purification of synaptic vesicles}

In this thesis, a novel small-scale purification method of synaptic vesicles (SV) from mouse and rat brain was developed. The new protocol yields in a final vesicle fraction of high purity as judged by both immunoblot analysis and electron microscopy. It also provided higher yield than of any previously described protocol. Quantitative characterisation of SV with regard to size, density, mass, protein and lipid composition yielded values very similar to those obtained previously using a classical protocol (Takamori et al., 2006). This protocol can be applied to purify SVs from very small amount of starting material, thus allowing biochemical characterisation of SVs isolated from a single brain, or even brain parts.

Existing protocols for the isolation of SVs can be divided into two categories. The first category (which is more widely used) involves the intermediate isolation of released nerve terminals (synaptotsomes) that are generated during initial homogenisation of brain tissue, as originally introduced by Whittaker and colleagues (Whittaker et al., 1964). The main advantage is that synaptosomes can be easily collected by differential centrifugation at moderate g-forces, with mitochondrial and myelin being major contaminants, allowing for the removal of all small particles, vesicles and membrane fragments that were generated during the initial homogenisation step. Synaptic vesicles are then released by hypotonic rupture of synaptosomes and are further purified by differential and density gradient centrifugation. Following osmotic lysis, larger particles (including plasma membranes, mitochondria and myelin) are removed by differential centrifugation, leaving a supernatant highly enriched in synaptic vesicles. An enriched SV fraction can then be collected by high-speed centrifugation, with further purification steps involving a combination of differential centrifugation and density gradient centrifugation. Due to the small and homogeneous size of SVs, size-exclusion chromatography on beads with large pores (CPG) (Nagy et al., 1976) or Sephacryl S-1000 (Stadler et al., 1978) is then frequently employed as a final purification step, to further remove contaminating membranes and any remaining 
cytosolic proteins. While such protocols can yield SV fractions of exceptional purity, the recovery of SVs in the final fraction is exceedingly low, ranging between 1-3\% (Jahn et al., 1985). Indeed, major losses are already occurring during the initial fractionation, with the recovery of SV-proteins in the synaptosome fraction being around $20 \%$. This is mainly due to the fact that during initial homogenisation many nerve terminals are damaged and release their SV content (at least partially) into the supernatant, resulting in a major loss of vesicles.

The second, less commonly used procedures involve direct isolation of SVs from brain homogenate. An example is the protocol developed by (Hell et al., 1988); accordingly, homogenization conditions are harsher using shock-frozen brains as starting material followed by further purification steps using step-gradient centrifugation and size-exclusion chromatography. Using this procedure results in high purity which is comparable to those $\mathrm{SV}$-fractions obtained using protocols involving synaptosome isolation.

Based on these data I have designed a novel purification procedure that not only involves isolation of synaptosomes and the subsequent release of SVs but also collects SVs released during initial homogenization. Removal of all particles larger than SVs by differential centrifugation yields a fraction that is sufficiently enriched to allow for attaining $90 \%$ purity with only two additional purification steps (density gradient and size-exclusion chromatography). Marker protein analysis revealed that (with the exception of small trafficking vesicles and endosomes) all other membranous compartments were effectively removed, including mitochondria, myelin, plasma membranes and post-synaptic densities. The only significant contamination was due to cytoplasmic supramolecular protein complexes such as proteasomes, spliceosomes and ribosomes. These particles are of smaller size but higher density than SVs. Adjusting velocity density gradient centrifugation allowed for a reasonable separation of the protein particles from SVs in the end. With a 20 fold enrichment of SV-proteins over homogenate and more than 90\% purity as judged by electron microscopy the result is comparable to the best protocols published previously. The significantly increased yield (6x more than the classical protocol by (Huttner et al., 1983), 2x more than the improved protocol by (Hell et al., 1988)) will not only reduce 
animal consumption but also allow for the biochemical characterization of SVs from small samples such as transgenic mice of brain regions. 


\subsection{SNARE mediated fusion, structural integrity and functionality of synaptic vesicles}

SNARE mediated fusion of synaptic vesicles with the pre-synaptic membrane during neuronal exosytosis is one of the key events during the life cycle of vesicles. Purified SVs on a small-scale basis retain their primary physiological function of fusing with membranes using an in vitro system. Fusion rates of in vitro data are not comparable to in vivo data due to lesser complexity and regulatory mechanism in the artificial target membrane. Effects of membrane restriction of SNARE proteins and their interaction with SVs are highly debated. In vitro fusion assays were performed with purified SVs and proteoliposomes reconstituted with syntaxin 1 and SNAP-25 which suggest that SNAREs are the main components driving vesicle fusion (Weber et al., 1988). Fluorescence dequenching by lipid mixing is a reliable tool to study membrane fusion to specify factors regulating this process (Weber et al., 1988). Reconstituted proteoliposomes with syntaxin 1 and SNAP-25 mimics the pre-synaptic plasma membrane where SVs can fuse to. The most abundant SNARE protein on SVs is synaptobrevin, present in $\sim 70$ copies (Takamori et al., 2006). In this study it has been shown that synaptobrevin is able to form a core complex resulting in fusion. Specific toxins like TeNT (tetanus toxin) which reduces the overall fusion rate due to cleavage of synaptobrevin into two fragments was used to further illustrate the role of synaptobrevin (Hayashi et al., 1994). Nevertheless, some basal fusion was visible which reflects the incomplete proteolysis by TeNT. Moreover, fusion was observed to some extent using protein free liposomes, residual detergent could be present after liposomes synthesis which might cause an elevated background signal due to liposome lysis. Fusion was inhibited when liposomes and SVs were preincubated with the cytosolic fragments of either synaptobrevin or syntaxin/SNAP-25 respectively, as expected for competitive SNARE inhibition.

It was observed that purified SVs retained their ability to acidify their lumen, which is mediated by the V-ATPase. The ability to uptake glutamate proved that SV membranes maintain their structural integrity and was not damaged during purification. Glutamate transport into SVs leaded to intra-vesicular acidification caused by proton influx through 
the vacuolar $\mathrm{H}^{+}$-ATPase. The negative charge of glutamate molecules transported into the vesicles is balanced by the positive charge of a proton and charge neutrality is maintained (Maycox et al., 1988). 


\subsection{Distinctions and similarities between mouse and rat}

Mice and rats belong to different species of rodents but shares a common ancestor descend millions of years ago (Jacobs and Pilbeam, 1980, Kumar and Hedges, 1998). Even though, mice and rats descended from common ancestor minor differences in genetic, development, morphology and anatomy exist (Levan, 1991). The most striking difference is seen in the morphology, whereas rats are much lager, heavier and longer than mice. Due to their larger body size, they have a larger brain but the brain weight only comprises approximately $1.3 \%$ to total body weight which is relatively equal to mouse (Roth and Dicke, 2005). Does size of the brain matter in number of synaptic vesicles? In general, larger individuals or larger species do have larger brains with more neurons, but neurons are larger and packed more loosely (Holloway 1968; Lange, 1975). The level of synaptic vesicle proteins was identical and number of SV was very close in brain homogenates of mouse and rat. More neurons do not automatically mean more SVs. Quantitative analysis revealed small structural differences of SVs from both species, especially in physical parameters of size and density. Whereas SVs from mouse had smaller size and higher density, rat SV showed a marginally lager size with lower density, the size of SVs reflected on calculated inner aqueous volume. Major vesicle proteins were present in equal amounts on both SV populations, with similar lipid composition, which at cholesterol content was high. The high amount of cholesterol measured is probably influencing SV exocytosis, since many SNAREs are concentrated in cholesterol clusters (Lang et al., 2001). It was recently reported that exocytosis is significantly reduced in cholesterol-depleted neurons (Linetti et al., 2010). It is also believed that cholesterol have an effect on membrane curvature and SNARE protein structure (Tong et al., 2009). No significant changes were seen in neurotransmitter uptake and fusion rates. 


\subsection{Effects of Rab-GDI1 deletion on Rab-GTPases}

Mental retardation (MR) is a very common human disorder that probably results from genetic factors. A group of MR includes the non-specific mental retardation (NSMR) that is characterised by mental handicap as the only clinical symptom. NSMR is caused by alterations in molecular pathways, which are important for cognitive functions. Recently identified genes for MR include GDI1, which encodes $\alpha$ Gdi (D'Adamo et al., 1998). $\alpha \mathrm{Gdi}$ is one of the proteins that controls the activity of the small GTPases of the Rab family in vesicle fusion and intracellular trafficking (Novick et al., 1997). Gdil-deficient mice show a defect in short-term memory (D'Adamo et al., 2002).

In this study, I characterised Rab proteins in subcellular brain fractions from Gdil-deficient mice with no visible morphological alterations. Rab proteins belong to the ras-like superfamily of small monomeric GTPases. Rab GTPases are regulatory factors involved in vesicular trafficking in endocytic and secretory pathways where they mainly comprise in vesicle budding, docking and fusion.

To determine the distribution of various Rab-GTPases in membrane and cytosolic fractions from Rab-GDI1 deficient mice, a large set of antibodies against Rab-GTPases was used. The screening provided interesting information on which Rabs were affected by the absence $\alpha$ Gdi. As explained in section 3.7, I classified the Rabs in three functional groups, involved in secretory, endosomal and Golgi trafficking. Overall, the amount of all secretory Rabs was increased in the LP2 fraction of KO compared to WT (see Appendix Figure2). The level of membrane-bound secretory Rab3a was slightly higher in KO, whereas the amount of soluble Rab3a was marginally decreased in KO. For the endosomal Rabs, the most significant difference was the complete depletion of the cytosolic fraction in KO except of Rab10, resulting in increased levels of the membrane fractions. The level of Rab10 was not affected by $\alpha$ Gdi deletion. Rab4 and Rab5 GTPases regulate the transport to and from early endosomes and participate actively in SV biogenesis and recycling (Bucci et al., 1992; Mohrmann et al., 2002). Therefore, the alterations of Rab4 and Rab5 in cytosolic fractions of the KO could be a result of less efficient endosomal recycling. Similar membrane accumulations of the Rabs involved in transport from the Golgi to the 
endoplasmic reticulum or the plasma membrane were observed. Especially Rab6 and Rab6b were present in relatively high amounts in the cytosolic fractions in WT, whereas no Rab protein was present in LS2 of KO. Thus, I found a substantial depletion in LS2 fractions of most Rabs in KO mice, while the level of these Rabs in the membrane fractions was increased in KO compared to WT. A possible explanation for this membrane accumulation is that Rab-GDI regulates the cycling of Rabs from the membrane to the cytosol. Rab-GDI usually mediates the delivery of Rab-GTPases cargo to the membrane and cycles the Rab-GTPases back to the cytosol (Ullrich et al., 1993; Soldati et al., 1994), and the absence of Rab-GDI potentially prevents this cycling and the Rab-GTPases remain attached to the membrane. This effect was observed for many but not all Rabs studied in this screen. 


\section{Summary and Conclusions}

Synapses are specialist points of contact between individual neurones, where communication takes place. At the majority of synapses, communication occurs through the release of a specific chemical, a so-called 'neurotransmitter'. Synaptic vesicles are secretory organelles that store neurotransmitter in the presynaptic nerve terminal. When an action potential arrives in the nerve terminal, the plasma membrane is depolarized, leading to the opening of voltage-gated $\mathrm{Ca}^{2+}$ channels in the plasma membrane. The accompanying rise in intracellular $\mathrm{Ca}^{2+}$ leads to the fusion (exocytosis) of the synaptic vesicles with the plasma membrane, resulting in the release of neurotransmitter, which diffuses across the synaptic cleft and binds to receptors on the postsynaptic membrane, eliciting a response. Following exocytosis, synaptic vesicle membrane is recovered by endocytosis and used to reform vesicles, which are then refilled with neurotransmitter and used for subsequent rounds of exocytosis. This entire process occurs locally in the presynaptic terminal and this autonomy allows synapses to function independently of the cell body - a prerequisite for fast exocytosis and recycling.

As the synaptic vesicle itself is the only constant during this cycle, it is a key player in the fusion process, containing, or able to transiently recruit from the cytoplasm, effector molecules that regulate this activity. Thus, the ability to isolate synaptic vesicles in a pure, homogenous form is an extremely important requirement in studying the biochemistry of the synapse. Studies on isolated synaptic vesicles have taught us a great deal about the composition and membrane organisation of this organelle. In a primary approach to understanding synaptic vesicle function, individual proteins on isolated vesicles were identified and their functions elucidated. To date, many proteins have been localized specifically to the synaptic vesicle membrane. With exception of some variations due to isoforms, most of these proteins are residents of all synaptic vesicles, irrespective of their neurotransmitter content or of the location of the neuron; in fact, several proteins first identified in synaptic vesicles turned out to be founding members of conserved protein families involved in all trafficking pathways. In this way, proteins such as synaptobrevin 2 (which is the SNARE protein thought to be playing a role in both fusion and vesicle 
recycling) and synaptotagmin (the vesicular $\mathrm{Ca}^{2+}$ sensor) were identified and their functions elucidated.

In this study a protocol for the small-scale isolation of pure synaptic vesicles from one mouse brain was established. It is based on the standard fractionation techniques of differential centrifugation, rate-zonal centrifugation and size-exclusion chromatography. The protocol is a hybrid of existing techniques and has been optimized to minimize vesicle loss during the isolation procedure, through the combing of vesicles released by lysis of synaptosomes and those released during the initial homogenisation step. The purity was ensured through a combination of sucrose density centrifugation and size-exclusion chromatography and checked by immunoblotting and electron microscopy. The protocol can be completed in less than a day, and allows recovery of microgram levels of highly pure vesicles from a single adult mouse brain. The purified vesicles were characterised according to their biochemistry and physical properties. Functional assays including neurotransmitter uptake and fusion with liposomes proved the integrity of purified vesicles. In the second part of this thesis, mouse and rat SVs were purified using the new protocol and quantitative comparison of the biochemistry and physical parameters was analysed revealing some discrepancies, especially in size and density, whereas no differences in protein and lipid composition was observed. To finally show the applicability of the new established protocol, SVs from Rab-GDI1 knock-out mice were purified and analysed using a large number of antibodies against various Rab-GTPases. The initial screening provided interesting information about the effect of Rab-GDI1 deletion on Rab-GTPases. 


\section{Appendix}
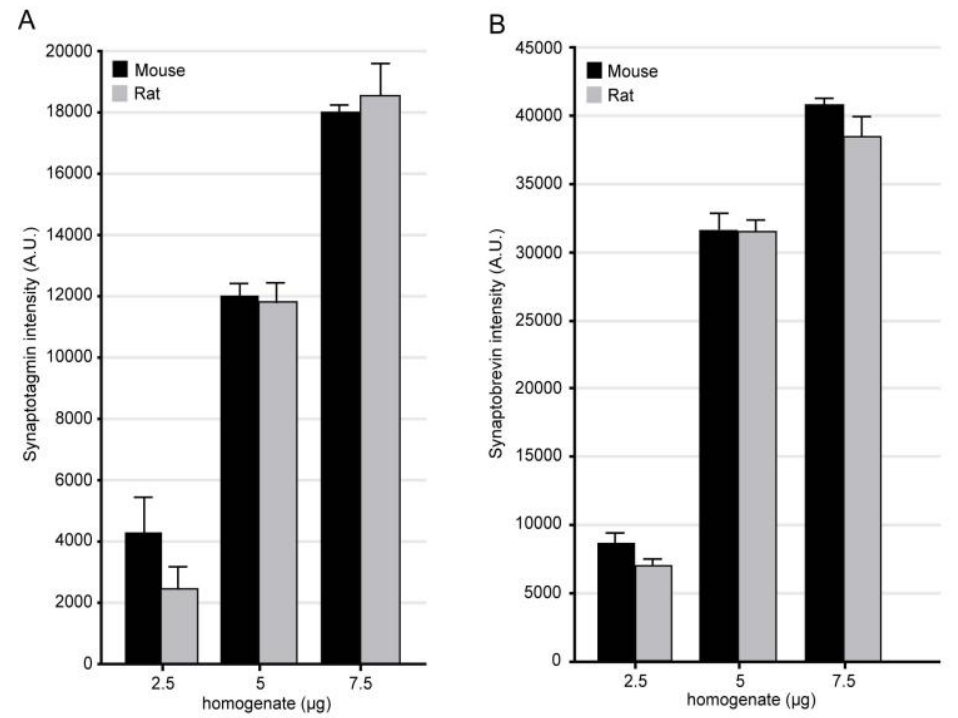

Appendix Figure 1. Level of synaptic vesicle proteins in brain homogenate. Synaptic vesicle proteins synaptotagmin (A) and synaptobrevin (B) are present in equal amounts in homogenate from mouse and rat (for details see section 3.5.2). 

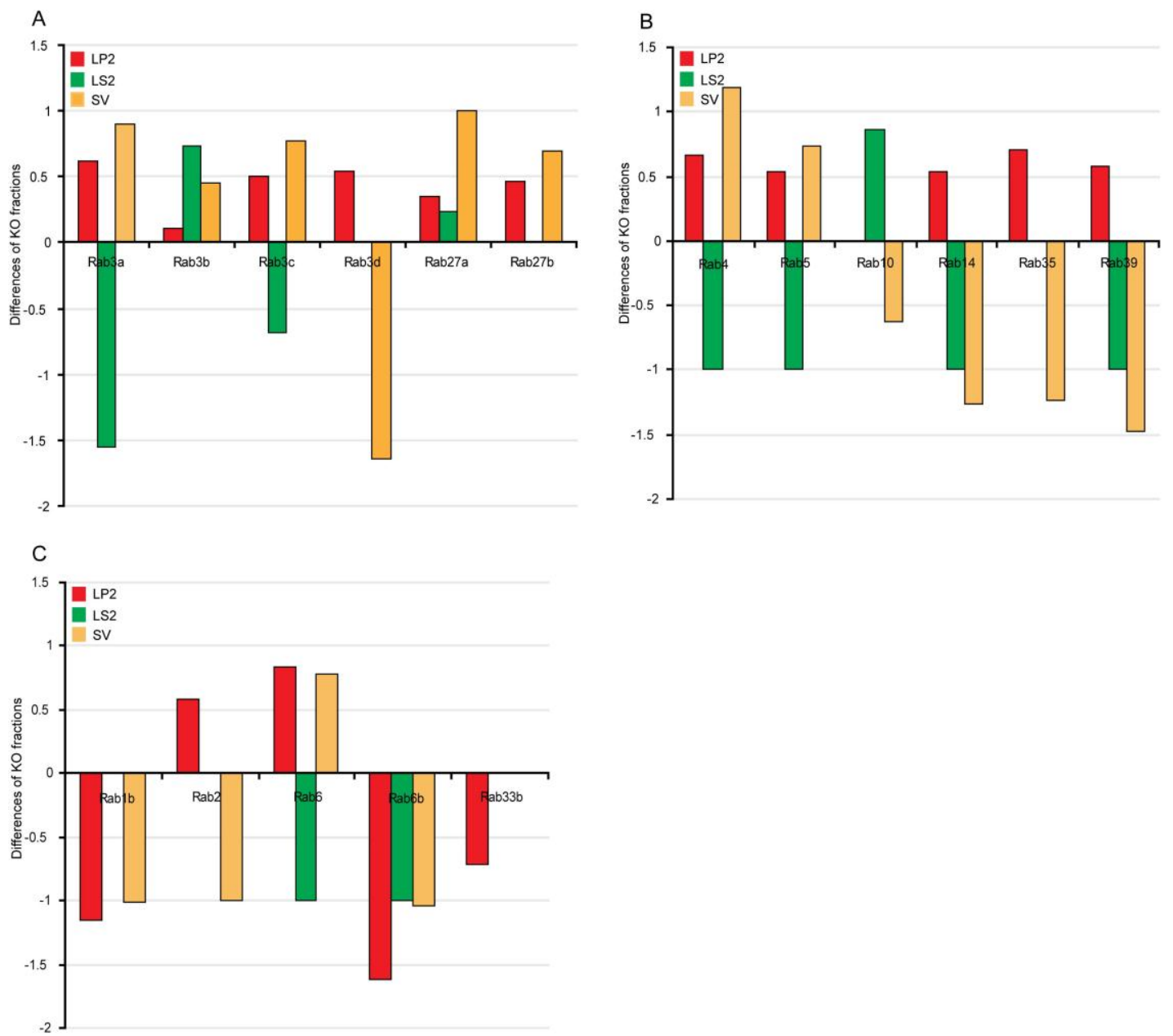

Appendix Figure 2. Quantitative analysis of Rab-GTPases in LP2, LS2 and SV fractions. Individual bands from immunoblots of WT and KO fractions were quantified (Fig. 25) and the differences between the WT and the KO fractions were calculated. The differences of Rab-GTPases are plotted. The amounts of Rab proteins in the $\mathrm{KO}$ are increased for almost all membrane fractions (LP2) compared to WT, whereas a decrease is seen in cytosolic fractions (LS2). Rabs are divided into three categories A, B and C (for details see section 3.7) 
Appendix

Appendix Table 1. Epitope sequences for antibody binding

\begin{tabular}{|c|c|c|}
\hline Protein & $\begin{array}{l}\text { Accession } \\
\text { number }\end{array}$ & Sequence of epitope \\
\hline Synaptophysin 1 & $\begin{array}{l}\text { gi|6981622 } \\
\text { gi|} 166235165\end{array}$ & $\begin{array}{l}\text { Rattus norvegicus aa } 301 \text { GAPTSFSNQM } 313 \\
\begin{array}{ll}\text { Mus musculus aa } 301 \text { GAPTSFSNQM } 313\end{array}\end{array}$ \\
\hline Synaptobrevin 1 & $\begin{array}{l}\text { gi|76443677 } \\
\text { gi|2842651 }\end{array}$ & $\begin{array}{l}\text { aa } 1 \text { MSAPA...QAGAS } 76 \\
\text { aa } 1 \text { MSAPA...QAGAS } 76\end{array}$ \\
\hline Synaptobrevin 2 & $\begin{array}{l}\text { gi } 6981614 \\
\text { gi|} 6678551\end{array}$ & $\begin{array}{l}\text { aa } 2 \text { SATAATVPPAAPAGEG } 17 \\
\text { aa } 2 \text { SATAATVPPAAPAGEG } 17\end{array}$ \\
\hline Synaptotagmin 1 & $\begin{array}{l}\text { gi|74229928 } \\
\text { gi|} 27502823\end{array}$ & $\begin{array}{l}\text { aa } 120 \text { DDDAETGLTDGE } 131 \\
\text { aa } 120 \text { DDDAETGLTDGE } 131\end{array}$ \\
\hline VGLUT 1 & $\begin{array}{l}\text { gi|} 16758726 \\
\text { gi|218156282 }\end{array}$ & $\begin{array}{l}\text { aa } 324 \text { SQPAYFEEVFGFEISK } 339 \\
\text { aa } 324 \text { SQPAYFEEVFGFEISK } 339\end{array}$ \\
\hline VGLUT 2 & $\begin{array}{l}\text { gi|16758166 } \\
\text { gi||188219544 }\end{array}$ & $\begin{array}{l}\text { aa } 332 \text { SQPAYFEEVFGFEISK } 339 \\
\text { aa } 332 \text { SQPAYFEEVFGFEISK } 339\end{array}$ \\
\hline VGAT & $\begin{array}{l}\text { gi|2587061 } \\
\text { gi|} \mid 125490380\end{array}$ & $\begin{array}{l}\text { aa } 510 \text { HSLEGLIEAYRTNAED } 525 \\
\text { aa } 510 \text { HSLEGLIEAYRTNAED } 525\end{array}$ \\
\hline Rab 3a & $\begin{array}{l}\text { gi|} 56270582 \\
\text { gi|} \mid 112292943\end{array}$ & $\begin{array}{l}\text { aa } 191 \text { LDTADPAVTGAKQGPQLTDQQAPPHQDCAC } 220 \\
\text { aa } 191 \text { LDTADPAVTGAKQGPQLTDQQAPPHQDCAC } 220\end{array}$ \\
\hline Rab 5 & $\begin{array}{l}\text { gi|3309068 } \\
\text { gi|13385374 }\end{array}$ & $\begin{array}{l}\text { aa } 182 \text { PKNEPQNPGANSARG } 196 \\
\text { aa } 182 \text { PKNEPQNPGANSARG } 196\end{array}$ \\
\hline SNAP-25 & $\begin{array}{l}\text { gi|} 56388575 \\
\text { gi|} \mid 17390575\end{array}$ & $\begin{array}{l}\text { aa } 1 \text { MAEDADMRNELEEMQRRADQ } 20 \\
\text { aa } 1 \text { MAEDADMRNELEEMQRRADQ } 20\end{array}$ \\
\hline SNAP-29 & $\begin{array}{l}\text { gi|62751974 } \\
\text { gi|139948568 }\end{array}$ & $\begin{array}{l}\text { aa } 1 \text { MSGYPKSYNPFDDDVE } 16 \\
\text { aa } 1 \text { MSGYPKSYNPFDDDVE } 16\end{array}$ \\
\hline Syntaxin 1a & $\begin{array}{l}\text { gi|6665797 } \\
\text { gi|72679879 }\end{array}$ & $\begin{array}{l}\text { aa } 172 \text { GNPAIFASGIIMDSSISK } 189 \\
\text { aa } 172 \text { GNPAIFASGIIMDSSISK } 189\end{array}$ \\
\hline Syntaxin 7 & $\begin{array}{l}\text { gi|3152727 } \\
\text { gi|3123924 }\end{array}$ & $\begin{array}{l}\text { aa } 1 \text { MSYTP...RKSRK } 236 \\
\text { aa } 1 \text { MSYTP...RKSRK } 236 \\
\end{array}$ \\
\hline NSF & $\begin{array}{l}\text { gi|6007811 } \\
\text { gi|123242089 }\end{array}$ & $\begin{array}{l}\text { aa } 733 \text { MREEGASPLDFD } 744 \\
\text { aa } 733 \text { MREEGASPLDFD } 744\end{array}$ \\
\hline
\end{tabular}

Primary antibodies were used where the epitopes used for immunisation were identical in sequence between mouse and rat. 
Appendix Table 2. Summary of proteins identified by mass spectrometry in purified mouse synaptic vesicles.

\begin{tabular}{|c|c|c|c|c|}
\hline $\begin{array}{l}\text { Accession } \\
\text { No. }\end{array}$ & Protein Name & $\begin{array}{l}\text { Protein } \\
\text { Score }\end{array}$ & $\begin{array}{l}\text { Peptide } \\
\text { Score }\end{array}$ & Peptide Sequence \\
\hline \multicolumn{5}{|c|}{$\begin{array}{l}\text { Trafficking } \\
\text { proteins (SNAREs) }\end{array}$} \\
\hline gi|15011853 & syntaxin $1 \mathrm{~A}$ & 816 & 83.07 & FMDEFFEQVEEIR \\
\hline gi|124298088 & syntaxin 1B2 & 2681 & 113.12 & FVEVMTEYNATQSK \\
\hline gi|10946800 & syntaxin 6 & 300 & 70.96 & AVNTAQGLFQR \\
\hline gi|3123924 & syntaxin 7 & 50 & 50.11 & ITQCSAEIQR \\
\hline gi|14715019 & syntaxin 12 & 339 & 96 & QLEADILDVNQIFK \\
\hline gi|6755588 & SNAP-25 & 1546 & 100.38 & ENEMDENLEQVSGIIGNLR \\
\hline gi|21362303 & SNAP-47 & 298 & 100.8 & NLPLFSEGEAQELTQILSK \\
\hline gi|49619203 & tomosyn m & 96 & 65.48 & ILAVGTQTGALR \\
\hline gi|6678549 & synaptobrevin 1 & 1112 & 119.49 & LQQTQAQVEEVVDIMR \\
\hline gi|2253399 & synaptobrevin 2 & 2974 & 108.48 & ADALQAGASQFETSAAK \\
\hline gi|33468929 & VAMP 7 & 71 & 51.95 & AILFAVVAR \\
\hline gi|6755448 & Secc22-like1 & 26 & 26.39 & KLYIDSRAR \\
\hline \multicolumn{5}{|c|}{$\begin{array}{l}\text { Endocytosis- } \\
\text { related proteins }\end{array}$} \\
\hline gi|6671561 & $\begin{array}{l}\text { AP-1b1 (adaptor-related protein } \\
\text { complex) }\end{array}$ & 175 & 85.57 & VAAQVDGGAQVQQVLNIECLRDFLTPPLLSVR \\
\hline gi|13591908 & $\begin{array}{l}\text { AP-2a2 (adaptor-related protein } \\
\text { complex) }\end{array}$ & 75 & 52.96 & TSVSLAVSR \\
\hline gi|18034787 & $\begin{array}{l}\text { AP-2b1 (adaptor-related protein } \\
\text { complex) }\end{array}$ & 39 & 38.85 & EYATEVDVDFVR \\
\hline gi|123230374 & dynamin 1 & 906 & 50.8 & CVDMVISELISTVR \\
\hline gi|27369922 & dynamin 3 & 479 & 60.29 & NLVDSYMSIINK \\
\hline gi|256773220 & synaptojanin 1 & 48 & 36.33 & NQPSPQAGLAGPGPSGYGAARPTIPAR \\
\hline
\end{tabular}




\begin{tabular}{|c|c|c|c|c|}
\hline $\begin{array}{l}\text { Accession } \\
\text { No. }\end{array}$ & Protein Name & $\begin{array}{l}\text { Protein } \\
\text { Score }\end{array}$ & $\begin{array}{l}\text { Peptide } \\
\text { Score }\end{array}$ & Peptide Sequence \\
\hline \multicolumn{5}{|c|}{$\begin{array}{l}\text { Small GTPases } \\
\text { and related proteins }\end{array}$} \\
\hline gi|112292935 & Rab1a & 1097 & 119.4 & FADDTYTESYISTIGVDFK \\
\hline gil112292937 & Rab1b & 990 & 107.13 & NATNVEQAFMTMAAEIK \\
\hline gi|112292939 & Rab2a & 687 & 113.8 & IQEGVFDINNEANGIK \\
\hline gi|112292941 & Rab2b & 571 & 31.29 & DVKREEGEAFAR \\
\hline gi|112292943 & Rab3a & 4047 & 126.75 & LQIWDTAGQER \\
\hline gi|12963723 & Rab3b & 1494 & 100.31 & YADDTFTPAFVSTVGIDFK \\
\hline gi|13470090 & Rab3c & 1441 & 86.46 & LGEQLGFEFFETSAK \\
\hline gi|9082186 & Rab3d & 63 & 58 & LQIWDTAGQER \\
\hline gi|112292953 & Rab4b & 486 & 88.3 & GAAGALLVYDITSR \\
\hline gi|112292955 & Rab5a & 108 & 29.14 & DEPQNPGANSAR \\
\hline gi|112292957 & Rab5b & 593 & 97.09 & GAQAAIVVYDITNQETFAR \\
\hline gi|20072723 & Rab5c & 824 & 115.48 & GAQAAIVVYDITNTDTFAR \\
\hline gi|13195674 & Rab6a & 309 & 66.62 & ELNVMFIETSAK \\
\hline gi|30424655 & Rab6b & 351 & 76.01 & DSTVAVVVYDITNLNSFQQTSK \\
\hline gi|1050551 & Rab7 & 60 & 60.22 & EAINVEQAFQTIAR \\
\hline gi|112292971 & Rab8b & 552 & 95.48 & SSTNVEEAFFTLAR \\
\hline gi|112292975 & Rab9b & 96 & 95.8 & FVTLQIWDTAGQER \\
\hline gi|7710086 & Rab10 & 63 & 32.94 & AFLTLAEDILRK \\
\hline gi|6679583 & Rab11b & 226 & 62.95 & AQIWDTAGQER \\
\hline gi|106507168 & Rab12 & 220 & 45.66 & FNSITSAYYR \\
\hline gi|112292985 & Rab13 & 104 & 26.46 & SGGRRSGNHSKPSSTDLKPSDK \\
\hline gi|112292987 & Rab14 & 70 & 22.7 & LTSEPQPQR \\
\hline gi|112292989 & Rab15 & 405 & 76.55 & ASNELALAELEEDEGKPEGPANSSK \\
\hline gi|13177612 & Rab16 & 131 & 26.88 & LVDIICDK \\
\hline gi|515041 & Rab18 & 160 & 75.47 & TCDGVQCAFEELVEK \\
\hline gi|2598565 & Rab19 & 33 & 32.61 & IILIGDSNVGK \\
\hline gi|148747177 & Rab22a & 145 & 79.2 & NAININELFIEISR \\
\hline
\end{tabular}




\begin{tabular}{|c|c|c|c|c|}
\hline $\begin{array}{l}\text { Accession } \\
\text { No. }\end{array}$ & Protein Name & $\begin{array}{l}\text { Protein } \\
\text { Score }\end{array}$ & $\begin{array}{l}\text { Peptide } \\
\text { Score }\end{array}$ & Peptide Sequence \\
\hline gi|194306533 & Rab26 & 231 & 23.58 & DGEKLAK \\
\hline gi|127138858 & Rab27b & 219 & 93.64 & VVYDTQGADGASGK \\
\hline gi|15277920 & Rab30 & 265 & 39.55 & EIEQYASNK \\
\hline gi|26341846 & Rab31 & 30 & 29.78 & MMAIRELKVCLLGDTGVGK \\
\hline gi|8394133 & Rab33b & 435 & 49.38 & IIVIGDSNVGK \\
\hline gi|112293031 & Rab35 & 404 & 64.96 & QQQQQQNDVVK \\
\hline gi|7677422 & Rab37 & 256 & 45.28 & DAQALLLLYDITNQSSFDNIR \\
\hline gi|112293041 & Rab39b & 546 & 91.75 & FAQVSDPTVGVDFFSR \\
\hline gi|31980729 & $\begin{array}{l}\text { GAP1-like (RAS protein activator } \\
\text { like) }\end{array}$ & 81 & 54.24 & NVNDLNQWLSALR \\
\hline gi|16945962 & rabphilin 3A & 180 & 70.41 & TGPAGGFQAAPHTAAPYSQAAPAR \\
\hline \multicolumn{5}{|c|}{$\begin{array}{l}\text { Other trafficking } \\
\text { proteins }\end{array}$} \\
\hline gi|2626980 & $\mathrm{DOC} 2$ & 71 & 23.28 & LMSALTQLKER \\
\hline gi|30725780 & MAL2 proteolipid protein & 40 & 40.06 & ITLPAGPDILR \\
\hline gi|3810884 & Munc18-1 (syntaxin biding protein) & 150 & 91.65 & SSASFSTTAVSAR \\
\hline gi|13385392 & NSF & 162 & 84.33 & SQLSCVVVDDIER \\
\hline gi|223461064 & synaptogyrin 1 & 50 & 49.63 & AGGAFDPYTLVR \\
\hline gi|4731936 & synaptogyrin 3 & 57 & 56.97 & TAPGPGTAQAGDAAR \\
\hline gi|12854143 & SCAMP 1 & 51 & 50.69 & TVQTAAANAASTAATSAAQNAFK \\
\hline gi|2232237 & SCAMP 3 & 105 & 81.12 & TAAANAAAGAAENAFR \\
\hline gi|9937988 & SCAMP 5 & 51 & 50.53 & AQEEWTTGAWK \\
\hline gi|148668411 & synapsin 1 & 341 & 137.58 & VKVDNQHDFQDIASVVALTK \\
\hline gi|42406392 & synapsin 2 isoform 1 & 565 & 112.87 & QTAASAGLVDAPAPSAASR \\
\hline gi|6449081 & synapsin 3 & 34 & 34.48 & SPGSPQLSR \\
\hline gi|166235165 & synaptophysin 1 & 1089 & 112.93 & MLLLADMDVVNQLVAGGQFR \\
\hline gi|27502823 & synaptotagmin 1 & 4452 & 100.72 & VFVGYNSTGAELR \\
\hline
\end{tabular}




\begin{tabular}{|c|c|c|c|c|}
\hline $\begin{array}{l}\text { Accession } \\
\text { No. }\end{array}$ & Protein Name & $\begin{array}{l}\text { Protein } \\
\text { Score }\end{array}$ & $\begin{array}{l}\text { Peptide } \\
\text { Score }\end{array}$ & Peptide Sequence \\
\hline gi|7739733 & synaptotagmin 2 & 2603 & 87.94 & IFVGSNATGTELR \\
\hline gi|8394392 & synaptotagmin 5 & 1016 & 103.49 & VAVGAAVGGAGLR \\
\hline gi|19527400 & synaptotagmin 7 & 510 & 78.88 & VTVAESSSDGR \\
\hline gi|19527400 & synaptotagmin 12 & 39 & 39.36 & RDDPNPVFNEAMIFSVPAIVLQDLSLR \\
\hline gi|20149722 & synaptotagmin 17 & 47 & 37.29 & LNVDIIR \\
\hline gi|7305631 & VPS45 (vacuolar protein sorting) & 436 & 98.66 & SFLEEVLASGLHSR \\
\hline \multicolumn{5}{|c|}{$\begin{array}{l}\text { Transporter / } \\
\text { Channel }\end{array}$} \\
\hline gi|77627990 & V-ATPase V0-a1 & 74 & 52.75 & LGFVAGVINR \\
\hline gi|62647031 & V-ATPase V0-a4 & 53 & 52.68 & CLIAEVWCPVTDLDSIQFALR \\
\hline gi|1184661 & V-ATPase V1-B1 & 120 & 67.79 & IPIFSAAGLPHNEIAAQICR \\
\hline gi|17105370 & V-ATPase V1-B2 & 240 & 72.08 & AVVQVFEGTSGIDAK \\
\hline gi|3955098 & V-ATPase V1-C1 & 170 & 78.49 & VQENLLASGVDLVTYITR \\
\hline gi|40786463 & V-ATPase V1-D1 & 76 & 64.99 & LLFEGAGSNPGDK \\
\hline gi|38454230 & V-ATPase V1-E1 & 51 & 51 & GALFGANANR \\
\hline gi|12834081 & V-ATPase V1-F & 161 & 79.81 & LIAVIGDEDTVTGFLLGGIGELNK \\
\hline gi|12963559 & V-ATPase V1-G2 & 47 & 47.08 & QVQGMQSSQQR \\
\hline gi|6978557 & Ca2+-ATPase, plasma membrane 2 & 53 & 47.95 & MVTGDNINTAR \\
\hline gi|6978543 & $\mathrm{Na}+/ \mathrm{K}+-\mathrm{ATPase}, \mathrm{a} 1$ & 254 & 70.39 & DAFQNAYLELGGLGER \\
\hline gi|6978545 & $\mathrm{Na}+/ \mathrm{K}+-\mathrm{ATPase}, \mathrm{a} 2$ & 278 & 108.25 & QAADMILLDDNFASIVTGVEEGR \\
\hline gi|54130 & $\mathrm{Na}+/ \mathrm{K}+-\mathrm{ATPase}, \mathrm{B1}$ & 70 & 44.51 & VAPPGLTQIPQIQK \\
\hline gi|61557417 & ZnT-3 (zinc transporter) & 56 & 55.91 & VSQSGLSPER \\
\hline gi|78126161 & GLT-1 (glutamate transporter) & 76 & 76.07 & NDEVSSLDAFLDLIR \\
\hline gi|218156282 & $\begin{array}{l}\text { VGLUT-1 (vesicular glutamate } \\
\text { transporter) }\end{array}$ & 42 & 41.56 & FFTSMPVYAIIVANFCR \\
\hline gi|2826776 & $\begin{array}{l}\text { VGAT (vesicular inhibitory amino } \\
\text { acid transporter) }\end{array}$ & 82 & 82.26 & GSEALGGGGGGAAGTR \\
\hline
\end{tabular}




\begin{tabular}{|l|l|l|l|l|l|}
\hline & $\begin{array}{l}\text { Accession } \\
\text { No. }\end{array}$ & Protein Name & $\begin{array}{l}\text { Protein } \\
\text { Score }\end{array}$ & $\begin{array}{l}\text { Peptide } \\
\text { Score }\end{array}$ & Peptide Sequence \\
\hline & gi|55715891 & $\begin{array}{l}\text { VAT-1 homolog (vesicle amine } \\
\text { transport homolog) }\end{array}$ & 41 & 41.27 & LQSRPAVPPAPGPGQVTLR \\
\hline & gi|559766 & $\begin{array}{l}\text { VAChT (vesicular acetylcholine } \\
\text { transporter) }\end{array}$ & 94 & 67.19 & AILQLLVNPLSGPFIDR \\
\hline & gi|11528518 & SV2a (synaptic vesicle glycoprotein) & 123 & 77.91 & GGLSDGEGPPGGR \\
\hline & gi|27261824 & SV2b (synaptic vesicle glycoprotein) & 50 & 49.94 & ATAFGILNGLCK \\
\hline & gi|187950819 & SV2c (synaptic vesicle glycoprotein) & 675 & 75.41 & ATGFGFLNALCK \\
\hline
\end{tabular}

The protein composition of purified SV was analysed by mass spectrometry as described previously (Takamori et al., 2006). Only synaptic vesicle related proteins are included in this list. 


\section{Measurements of synaptic vesicle concentration using FCS}

For FCS measurements samples were treated according to the description in section 2.2.11. After addition of SVs, a 60s fluorescence trace was measured in $5 \mathrm{~s}$ intervals and autocorrelated using equation 1 :

$$
G(\tau)=\frac{\langle\delta F(t) \cdot \delta F(t+\tau)\rangle}{\langle F(t)\rangle^{2}} \quad \text { Equation 1 }
$$

The autocorrelation amplitude $\mathrm{G}(0)$ is the normalised variance of the fluctuating fluorescence signal $\delta \mathrm{F}(\mathrm{t})$.

For freely diffusing SVs the autocorrelation function was fitted according to equation 2:

$$
G(\tau)=\frac{1}{V_{e f f}\langle C\rangle} \cdot \frac{1}{\left(1+\frac{\tau}{\tau_{D}}\right)} \cdot \frac{1}{\sqrt{1+\left(\frac{r_{0}}{z_{z}}\right)^{2} \cdot \frac{\tau}{\tau_{D}}}} \text { Equation 2 }
$$

By setting the dimension of $r_{0}$ and $z_{0}$, the concentration of SVs was determined from the amplitude $\mathrm{G}(0)$ of the autocorrelation curve:

$$
G(0)=\frac{1}{\langle N\rangle}=\frac{1}{V_{e f f} \cdot\langle C\rangle}
$$




\section{Abbreviations and Symbols}

aa

$\mathrm{AO}$

APS

ATP

a.u.

BSA

DTT

DOC

EDTA

$\mathrm{EtOH}$

FCCP

FRET

GA

GABA

GDI

GFAP

$\mathrm{h}$

HEPES

HRP

$\mathrm{KCl}$

$\mathrm{kDa}$

$\mathrm{KO}$

$\mathrm{LDH}$

$\mathrm{mA}$

$\mathrm{MeOH}$

$\min$

$\mathrm{NaOH}$

$\mathrm{nm}$
Amino acid

Acridine Orange

Ammonium persulfate

Adenosine triphosphate

Arbitrary units

Bovine serum albumin

Dithiothreitol

Deoxycholic acid

Ethylenediaminetetraacetic acid

Ethanol

Carbonyl cyanide-p-trifluoromethoxyphenylhydrazone

Förster resonance energy transfer

Glutaraldehyde

Gamma-amino butyric acid

Guanosine nucleotide dissociation inhibitors

Glial Fibrillary Acidic Protein

Hours

N(-2-Hydroxyethyl)piperazine-N"-2-ethanesulfonic acid

Horseradish peroxidase

Potassium chloride

Kilo Dalton

Knock-out

Lactate dehydrogenase

Milliampere

Methanol

Minutes

Sodium hydroxide

Nanometer 


\begin{tabular}{|c|c|}
\hline NMDA R1 & N-methyl D-aspartate receptor 1 \\
\hline NSF & N-ethylmaleimide-sensitive factor \\
\hline PAGE & Polyacrylamide gel electrophoresis \\
\hline PBS & Phosphate buffered saline \\
\hline PCR & Polymerase chain reaction \\
\hline PFA & Paraformaldehyde \\
\hline $\mathrm{pH}$ & Negative logarithm of $\mathrm{H}+$ concentration \\
\hline $\mathrm{rpm}$ & Revolutions per minute \\
\hline RT & Room temperature \\
\hline S & Seconds \\
\hline SDHA & Succinate dehydrogenase \\
\hline SDS & Sodium dodecyl sulfate \\
\hline SNAP & Soluble-NSF-attachment protein \\
\hline SNAP-25 & Synaptosome associated protein of $25 \mathrm{kDa}$ \\
\hline SNARE & soluble N-ethylmaleimide-sensitive-factor attachment receptor \\
\hline SV & Synaptic vesicle \\
\hline Syb & Synaptobrevin \\
\hline Syp & Synaptophysin \\
\hline Syt & Synaptotagmin \\
\hline $\mathrm{t}$ & Time \\
\hline TCA & Trichloroacetic acid \\
\hline TEMED & N,N,N',N'-Tetramethylethylene diamine \\
\hline TeNT & Tetanus toxin \\
\hline Tris & Tris-(hydroxymethyl)aminomethane \\
\hline UV & Ultraviolet \\
\hline V & Voltage \\
\hline VGAT & Vesicular GABA transporter \\
\hline VGLUT & Vesicular glutamate transporter \\
\hline
\end{tabular}




$\begin{array}{ll}\text { V/v } & \text { Volume/volume } \\ \text { WT } & \text { Wild type } \\ \text { W/v } & \text { Weight/volume }\end{array}$




\section{Bibliography}

1. Adachi, I., Puopolo, K., Marquez-Sterling, N., Arai, H., Forgac, M. Dissociation, crosslinking, and glycosylation of the coated vesicle proton pump. J Biol Chem. 15, 967-73 (1990).

2. Adrian, M., Debochet, J. L. J., McDowall, A. W. Cryo-electron microscopy of viruses. Nature 308, 32-36 (1984).

3. Baumert, M., Maycox, P.R., Navone, F., De Camilli, P., Jahn, R. Synaptobrevin: an integral membrane protein of 18,000 daltons present in small synaptic vesicles of rat brain. EMBO J 8, 379-384 (1989).

4. Benfenati, F., Greengard, P., Brunner, J., Bähler, M. Electrostatic and hydrophobic interactions of synapsin I and synapsin I fragments with phospholipid bilayers. J. Cell Biol. 108, 1851-1862 (1989).

5. Bligh, E. G. and Dyer, W. J. A rapid method of total lipid extraction and purification. Can. J. Biochem. Physiol. 37, 911-917 (1959).

6. Bock, J. B., Matern, H. T., Peden, A. A., Scheller, R. H. A genomic perspective on membrane compartment organization. Nature 409, 839-841 (2001).

7. Bowman, E. J., Tenney, K., Bowman, B. J. Isolation of genes encoding the Neurospora vacuolar ATPase. Analysis of vma-1 encoding the $67-\mathrm{kDa}$ subunit reveals homology to other ATPases. J Biol Chem. 5, 13994-4001 (1988).

8. Brose, N., Petrenko, A. G., Südhof, T. C., Jahn, R. Synaptotagmin: a calcium sensor on the synaptic vesicle surface. Science 256, 1021-1025 (1992).

9. Brügger, B., Erben, G., Sandhoff, R., Wieland, F. T., Lehmann, W. D. Quantitative analysis of biological membrane lipids at the low picomole level by nano electrospray ionization tandem mass spectrometry. Proc. Nat. Acad. Sci. 94, 2339-2344 (1997).

10. Brügger, B., Gorgas, K., Malsam, J., Helms, J. B., Lehmann, W. D., Nickel, W., Wieland, F. T. Evidence for segregation of sphingomyelin and cholesterol during formation of COPI-coated vesicles. J. Cell Biol. 151, 507-518 (2000).

11. Brunger, A. T. Structure of proteins involved in synaptic vesicle fusion in neurons. Annu Rev Biophys Biomol Struct. 30, 157-71 (2001).

12. Bucci, C., Parton, R. G., Mather, I. H., Stunnenberg, H., Simons, K., Hoflack, B., Zerial, M. The small GTPase rab5 functions as a regulatory factor in the early endocytic pathway. Cell 70, 715-728 (1992). 
13. Ceccarelli, B., Hurlbut, W. P., Mauro, A. Turnover of transmitter and synaptic vesicles at the frog neuromuscular junction. J Cell Biol. 57, 499-524 (1973).

14. Chen, Y. A., Scheller, R. H. SNARE-mediated membrane fusion. Nat Rev Mol Cell Biol. 2, 98-106 (2001).

15. Clark, J., Lin, L., Kriz, R., Ramesha, C., Sultzman, L., Lin, A. Y., Milona, N., Knopf, J. L. A novel arachidonic acid-selective cytosolic PLA2 contains a $\mathrm{Ca}(2+)$-dependent translocation domain with homology to PKC and GAP. Cell 65, 1043-51. (1991).

16. Cypionka, A., A. Stein, M. Hernandez, H. Hippchen, R. Jahn and P. J. Walla. Discrimination between docking and fusion of liposomes reconstituted with neuronal SNARE-proteins using FCS. Proc Natl Acad Sci 106, 18575-18580 (2009).

17. D'Adamo, P., Menegon, A., Lo Nigro, C., Grasso, M., Gulisano, M., Tamanini, F., Bienvenu, T., Gedeon, A., Oostra, B., Wu, S., Tandon, A., Valtorta, F., Balch, W., Chelly, J., Toniolo, D. Mutations in GDI1 are responsible for X-linked non-specific mental retardation. Nat Genet. 2, 134-9 (1998).

18. D'Adamo P, Welzl H, Papadimitriou S, Raffaele di Barletta M, Tiveron C, Tatangelo L, Pozzi L, Chapman PF, Knevett SG, Ramsay MF, Valtorta F, Leoni C, Menegon A, Wolfer DP, Lipp HP, Toniolo D. Deletion of the mental retardation gene Gdi1 impairs associative memory and alters social behavior in mice. Hum Mol Genet. 11, 2567-80 (2002).

19. Del Castillo, J., Katz, B. Quantal components of the end-plate potential. J. Physiol. 124, 560-73 (1954).

20. Del Castillo, J., Katz, B. Local activity at a depolarized nerve-muscle junction. $J$. Physiol. 128, 396-411 (1955).

21. De Robertis, E., Bennett, H. Anat. Rec. 118,336 (1954).

22. De Robertis, E., Pellegrino De Iraldi, Rogriguez, G., Gomez, C. The isolation of nerve endings and synaptic vesicles. J. of Biophys. and Biochem. Cytology 9, 229-235 (1961).

23. De Robertis, E., Rodriguez De Lores Arnaiz, G., Salganicoff, L., Pellegrino De Iraldi, A., Zieher, L. Isolation of synaptic vesicles and structural organization of the acetycholine system within brain nerve endings. J. Neurochem. 10, 225-235 (1963).

24. Disbrow, J., Gershten, M., Ruth, J. Uptake of L-[3H] glutamic acid by crude and purified synaptic vesicles from rat brain. Biochem Biophys Res Commun. 108, 1221-7 (1982). 
25. Duman, J.G. and Forte, J.G. What is the role of SNARE proteins in membrane fusion? Am J Physiol Cell Physiol. 285, 237-49 (2003).

26. Fasshauer, D., Sutton, R.B., Brünger, A.T. and Jahn, R. Conserved structural features of the synaptic fusion complex: SNARE proteins reclassified as Q- and R-SNAREs. Proc. Natl. Acad. Sci. USA 95, 15781-15786 (1998).

27. Fasshauer, D, Margittai, M. A transient N-terminal interaction of SNAP-25 and syntaxin nucleates SNARE assembly. J Biol Chem. 279, 7613-21 (2004).

28. Fiebig, K.M., Rice, L.M., Pollock, E., and Brunger, A.T. Folding intermediates of SNARE complex assembly. Nat Struct Biol 6, 117-123 (1999).

29. Fischer von Mollard, G., Mignery, G., Baumert, M, Perin, M., Hanson, T., Burger, P., Jahn, R., Südhof, T. rab3 is a small GTP-binding protein exclusively localized to synaptic vesicles. Proc. Natl. Acad. Sci. 87, 1988-92 (1990).

30. Fischer von Mollard, G, Südhof, T., Jahn, R. A small GTP-binding protein dissociates from synaptic vesicles during exocytosis. Nature 349, 79-81 (1991).

31. Fykse, E., Fonnum, F. Uptake of gamma-aminobutyric acid by a synaptic vesicle fraction isolated from rat brain. J Neurochem. 4, 1237-42 (1988).

32. Granseth, B., Odermatt, B., Royle, S., Lagnado, L. Clathrin-mediated endocytosis is the dominant mechanism of vesicle retrieval at hippocampal synapses. Neuron. 51, 773-86 (2006).

33. Gray, E. G., Whittaker, V. P. The isolation of synaptic vesicles from the central nervous system. J. Physiol. 153, 35-37 (1960).

34. Gray, E. G. and Whittaker, V. P. The isolation of nerve endings from brain: an electronmicroscopic study of cell fragments derived by homogenization and centrifugation. $J$. Anat. 96, 79-88 (1962).

35. Hanson, P. I., Heuser, J. E., Jahn, R. Neurotransmitter release-four years of SNARE complexes. Curr. Opin. Neurobiol. 7, 310-315 (1997).

36. Harris, K. M. and Sultan, P. Variation in the number, location and size of synaptic vesicles provides an anatomical basis for the nonuniform probability of release at hippocampal CA1 synapses. Neuropharmacology 34, 1387-1395 (1995).

37. Hayashi, T., McMahon, H., Yamasaki, S., Binz, T., Hata, Y., Südhof, T.C. and Niemann, H. Synaptic vesicle membrane fusion complex: Action of clostridial neurotoxins on assembly. EMBO J. 13, 5051-5061 (1994). 
38. Hell, J. W., Maycox, P. R., Stadler, H., Jahn, R. Uptake of GABA by rat brain synaptic vesicles isolated by a new procedure. EMBO J. 7, 3023-3029 (1988).

39. Heuser, J., Reese, T., Dennis, M., Jan, Y., Jan, L., Evans, L. Synaptic vesicle exocytosis captured by quick freezing and correlated with quantal transmitter release. J Cell Biol 81, 275300 (1979).

40. Hirsch, S., Strauss, A., Masood, K., Lee, S., Sukhatme, V., Gluck, S. Isolation and sequence of a cDNA clone encoding the 31-kDa subunit of bovine kidney vacuolar H+ATPase. Proc Natl Acad Sci 9, 3004-8 (1988).

41. Holloway, R.L. The evolution of the primate brain: Some aspects of quantitative relations. Brain Res. 7, 121-72 (1968).

42. Holloway, R.L. Within species brain body weight variability: A reexamination of the Danish data and other primate species. Am. J. Phys. Anthropol. 53, 109-21 (1980).

43. Holt, M., Riedel, D., Stein, A., Schuette, C., Jahn, R. Synaptic vesicles are constitutively active fusion machines that function independently of $\mathrm{Ca}^{2+}$. Curr. Biol. 18, 715-722 (2008).

44. Huttner, W. B., Schiebler, W., Greengard, P., De Camilli, P. Synapsin I (protein I), a nerve terminal-specific phosphoprotein. III. Its association with synaptic vesicles studied in a highly purified synaptic vesicle preparation. J. Cell Biol. 96, 1374-1388 (1983).

45. Jacobs, L. and Pilbeam, D. Of mice and men: Fossil-based divergence dates and molecular "clocks"", Journal of Human Evolution 9, $90062-7$ (1980).

46. Jahn, R., Schiebler, W., Greengard, P. A quantitative dot-immunobinding assay for proteins using nitrocellulose membrane filters. Proc. Natl. Acad. Sci. USA 81, 16841687 (1984).

47. Jahn, R., Schiebler, W., Ouimet, C., Greengard, P. A 38,000-dalton membrane protein (p38) present in synaptic vesicles. Proc. Natl. Acad. Sci. USA 82, 4137-4141 (1985).

48. Jahn, R. \& Maycox, P.R. Protein components and neurotransmitter uptake in brain synaptic vesicles. In: Molecular Mechanisms in Secretion. Alfred Benzon Symposium 25 (Thorn, N.A., Treiman, M. \& Petersen,O.H. eds.) Munksgaard, Copenhagen, 411-424 (1988).

49. Jahn, R, Lang, T and Südhof, T.C., (2003). Membrane fusion. Cell. 112, 519-533 
50. Jahn, R. and Scheller, H. 2006 SNAREs - engines for membrane fusion. Nature Reviews. Molecular Cell Biology. 7, 631-643 (2006).

51. Johnson, R.G. Accumulation of biological amines into chromaffin granules: a model for hormone and neurotransmitter transport. Physiol Rev. 68, 232-307 (1988).

52. Junutula, J., De Maziére, A., Peden, A., Ervin, K., Advani, R., van Dijk, S.M, Klumperman, J., Scheller, R.H. Rab14 is involved in membrane trafficking between the Golgi complex and endosomes. Mol Biol Cell. 5, 2218-29 (2004).

53. Kanaseki, T., Kadota, K. The "vesicle in a basket". A morphological study of the coated vesicle isolated from the nerve endings of the guinea pig brain, with special reference to the mechanism of membrane movements. J Cell Biol. 42, 202-220. (1969).

54. Kavalali, E.T. SNARE interactions in membrane trafficking: a perspective from mammalian central synapses. Bioessays. 10, 926-36 (2002).

55. Koivusalo, M., Haimi, P., Heikinheimo, L., Kostiainen, R., Somerharju, P. Quantitative determination of phospholipid compositions by ESI-MS: effects of acyl chain length, unsaturation, and lipid concentration on instrument response. J Lipid Res. 42, 663-72 (2001).

56. Kouranti, I., Sachse, M., Arouche, N., Goud, B., Echard, A. Rab35 regulates an endocytic recycling pathway essential for the terminal steps of cytokinesis. Curr Biol. 16, 1719-25 (2006).

57. Kumar, S. and Hedges, S. B. A molecular timescale for vertebrate evolution. Nature 392, 917-20 (1998).

58. Lang, T., D. Bruns, D. Wenzel, D. Riedel, P. Holroyd, C. Thiele and R. Jahn: SNAREs are concentrated in cholesterol-dependent clusters that define docking and fusion sites for exocytosis. EMBO Journal 20, 2202-2213 (2001).

59. Lange, W. Cell number and cell density in the cerebellar cortex of man and some other mammals. Cell Tissue Res.;157, 115-24 (1975).

60. Lapetina, E.G,, Soto, E.F, De Robertis, E. Gangliosides and acetylcholinesterase in isolated membranes of the rat-brain cortex. Biochim Biophys Acta. 135, 33-43 (1967).

61. Levan, G., Szpirer, J., Szpirer, C., Kling, A. K., Hanson, C., Islam, M. Q. The gene map of the Noway rat (Ruttus noruegicus) and comparative mapping with mouse and man. Genomrcs 10, 699- 718 (1991). 
62. Linetti, A., Fratangeli, A., Taverna, E., Valnegri, P., Francolini, M., Cappello, V., Matteoli, M., Passafaro, M., Rosa, P. Cholesterol reduction impairs exocytosis of synaptic vesicles. J Cell Sci. 123, 595-605 (2010).

63. Link, E., Edelmann, L., Chou, J., Binz, T., Yamasaki, S., Eisel, U., Baumert, M., Südhof, T. , Niemann, H., Jahn, R. Tetanus toxin action: inhibition of neurotransmitter release linked to synaptobrevin proteolysis. Biochem Biophys Res Commun. 189, 1017 23. (1992).

64. Magde, D., Elson, E., Webb, W. W. Thermodynamic fluctuations in a reacting system measurement by fluorescence correlation sprectroscopy. Phys. Rev. Lett. 29, 705-708 (1972).

65. Makarova, O., Makarov, E., Liu, S., Vornlocher, H., Lührmann, R. Protein 61K, encoded by a gene (PRPF31) linked to autosomal dominant retinitis pigmentosa, is required for $\mathrm{U} 4 / \mathrm{U} 6 * \mathrm{U} 5$ tri-snRNP formation and pre-mRNA splicing. EMBO J. 21, 1148-1157 (2002).

66. Mann, M. D., Towe, A. L. Glickman, S. E. Relationship between brain size and body size among Myomorph rodents. Soc. Neurosci Abs. 12-111 (1986).

67. Marchbanks, R. M. Exchangeability of radioactive acetylcholine with the bound acetylcholine of synaptosomes and synaptic vesicles. Biochem J. 106, $87-95$ (1968).

68. Marshall, I. G., Parson, S. M. The vesicular acetylcholine transport system. TINS 10, 174-77 (1987).

69. Matthew, W. D., Tsavaler, L., Reichardt, L. F. Identification of a synaptic vesiclespecific membrane protein with a wide distribution in neuronal and neurosecretory tissue. J. Cell Biol. 91, 257-269 (1981).

70. Maycox, P. R., Deckwerth, T., Hell, J. W., Jahn, R. Glutamate uptake by brain synaptic vesicles. Energy dependence of transport and functional reconstitution in proteoliposomes. J. Biol. Chem. 263, 15423-15428 (1988).

71. Maycox, P. R., Hell, J. W., Jahn, R. Amino acid neurotransmission: Spotlight on synaptic vesicles. Trends Neurosci 13, 83- 87 (1990).

72. McMahon, H., Ushkaryov, Y., Edelmann, L., Link, E., Binz, T., Niemann, H., Jahn, R., Südhof, T. Cellubrevin is a ubiquitous tetanus-toxin substrate homologous to a putative synaptic vesicle fusion protein. Nature 364, 346-9 (1993). 
73. Mohrmann, K., Leijendekker, R., Gerez, L. and van Der Sluijs, P. Rab4 regulates transport to the apical plasma membrane in Madin-Darby canine kidney cells. J. Biol. Chem. 277, 10474-10481 (2002).

74. Morgan, I. G., Vincendon, G., Gombos, G. Adult rat brain synaptic vesicles I. Isolation and characterization. Biochimica et Biophysica Acta 320, Pages 671-680 (1973).

75. Morris, S. J. Removal of residual amounts of acetylcholinesterase and membrane contamination from synaptic vesicles isolated from the electric organ of Torpedo. $J$. Neurochem. 21, 713-715 (1973).

76. Müller, J.D, Chen, Y., Gratton, E. Fluorescence correlation spectroscopy. Methods Enzymol. 361, 69-92 (2003).

77. Nagy, A., Baker, R. R., Morris, S. J., Whittaker, V. P. The preparation and characterization of synaptic vesicles of high purity. Brain Res. 109, 285-309 (1976).

78. Naito, S. and Ueda T. Adenosine triphosphate-dependent uptake of glutamate into protein I-associated synaptic vesicles. J Biol Chem. 258, 696-9 (1983).

79. Naito S. and Ueda T. Characterization of glutamate uptake into synaptic vesicles $J$. Neurochem. 44, 99-109 (1985).

80. Nicholls, J. G., A. R. Martin, et al. From neuron to brain : a cellular and molecular approach to the function of the nervous system. Sunderland, Mass., Sinauer Associates (1992).

81. Novick, P. and Zerial, M. The diversity of Rab proteins in vesicle transport. Curr. Opin. Cell. Biol. 9, 496-504 (1997).

82. Opdam, F., Echard, A., Croes, H., van den Hurk, J., van de Vorstenbosch, R., Ginsel, L., Goud, B., Fransen, J. The small GTPase Rab6B, a novel Rab6 subfamily member, is cell-type specifically expressed and localised to the Golgi apparatus. J Cell Sci. 113, 2725-35 (2000).

83. Palay, S. L., and Palade, G. E. Anat. Rec. 188, 336 (1954).

84. Palmgren, M. G. Acridine orange as a probe for measuring $\mathrm{pH}$ gradients across membranes: mechanism and limitations. Anal Biochem. 192, 316-21 (1991).

85. Perin, M., Fried, V., Mignery, G., Jahn, R., Südhof, T. C. Phospholipid binding by a synaptic vesicle protein homologous to the regulatory region of protein kinase C. Nature 345, 260-3 (1990). 
86. Peterson, G. L. A simplification of the protein assay method of Lowry et al. which is more generally applicable. Anal. Biochem. 83, 346-356 (1977).

87. Proikas-Cezanne, T., Gaugel, A., Frickey, T., Nordheim, A. Rab14 is part of the early endosomal clathrin-coated TGN microdomain. FEBS Lett. 22, 5241-6 (2006).

88. Rahamimoff, R., De Riemer, S., Sakmann, B., Stadler, H., Yakir, N. Ion channels in synaptic vesicles from Torpedo electric organ. Proc Natl Acad Sci 85, 5310-4 (1988).

89. Reimer, R. J., Fon, E. A. and Edwards, R. H. Vesicular neurotransmitter transport and the presynaptic regulation of quantal size. Curr. Opin. Neurobiol. 8, 405-412 (1998).

90. Rizo, J. and Südhof, T. C. Snares and Munc18 in synaptic vesicle fusion. Nat. Rev. Neurosci. 3, 641-653 (2002).

91. Roth, G. and Dicke, U. Evolution of the brain and intelligence. Trends Cogn Sci. 9, 250-7 (2005).

92. Schäger, H. and von Jagow, G. Tricine-sodium dodecyl sulfate-polyacrylamide gel electrophoresis for the separation of proteins in the range from 1 to $100 \mathrm{kDa}$. Anal Biochem 166, 368-379 (1987).

93. Schalk, I., Zeng, K., Wu, S.K., Stura, E.A., Matteson, J., Huang, M., Tandon, A., Wilson, I.A. and Balch, W.E. Structure and mutational analysis of Rab GDPdissociation inhibitor. Nature 381, $42-48$ (1996).

94. Schenck, S., Wojcik, S., Brose, N., Takamori, S. A chloride conductance in VGLUT1 underlies maximal glutamate loading into synaptic vesicles. Nat Neurosci. 2, 2156-62 (2009).

95. Schiavo, G. et al. Tetanus and botulinum-B neurotoxins block neurotransmitter release by proteolytic cleavage of synaptobrevin. Nature 359, 832-835 (1992).

96. Schlüter, O., Khvotchev, M., Jahn, R., Südhof, T. Localization versus function of Rab3 proteins. Evidence for a common regulatory role in controlling fusion. $J$ Biol Chem. 277, 40919-29 (2002).

97. Schütte, C., Hatsuzawa, K., Margittai, M., Stein, A., Riedel, D., Küster, P., König, M., Seidel, C., Jahn, R. Determinants of liposome fusion mediated by synaptic SNARE proteins. Proc. Natl. Acad. Sci. 101, 2858-2863 (2004).

98. Sjöstrand, F. The ultrastructure of retinal rod synapses of guinea pig eye. J. Appl. Physiol. 24, 1422 (1953). 
99. Soldati, T., Shapiro, A., Svejstrup, A., Pfeffer, S. Membrane targeting of the small GTPase Rab9 is accompanied by nucleotide exchange. Nature 369, 76-8 (1994).

100. Söllner, T., Bennett, M. K., Whiteheart, S. W., Scheller, R. H., Rothman, J. E. A protein assembly-disassembly pathway in vitro that may correspond to sequential steps of synaptic vesicle docking, activation, and fusion. Cell 75, 409-418 (1993).

101. Stadler, H., Whittaker, V. P. Identification of vesiculin as a glycosaminoglycan. Brain Res. 153, 408-13 (1978).

102. Südhof T. C. The synaptic vesicle cycle: a cascade of protein-protein interactions. 375, 645-53 (1995).

103. Südhof, T. C. The synaptic vesicle cycle. Annu. Rev. Neurosci. 27, 509-547 (2004).

104. Sun, S., Xie, X., Stone, D. K. Isolation and reconstitution of the dicyclohexylcarbodiimide-sensitive proton pore of the clathrin-coated vesicle proton translocating complex. J Biol Chem. 262, 14790-4 (1987).

105. Sutton, R., Fasshauer, D., Jahn, R., Brunger, A. Crystal structure of a SNARE complex involved in synaptic exocytosis at 2.4 A resolution. Nature 395, 347-53 (1998).

106. Takamori, S., Riedel, D, Jahn, R. Immunoisolation of GABA-specific synaptic vesicles defines a functionally distinct subset of synaptic vesicles. J. Neurosci. 20, 4904-4911 (2000).

107. Takamori, S., Rhee, J. S., Rosenmund, C., Jahn, R. Identification of a vesicular glutamate transporter that defines a glutamatergic phenotype in neurons. Nature 407, 189-194 (2000).

108. Takamori, S. et al. Molecular anatomy of a trafficking organelle. Cell 127, 831-846 (2006).

109. Tong, J., Borbat, P. P., Freed, J. H. and Shin, Y. K. A scissors mechanism for stimulation of SNARE-mediated lipid mixing by cholesterol. Proc. Natl. Acad. Sci. 106, 5141-5146 (2009).

110. Towbin, H., Staehelin, T., Gordon, J. Electrophoretic transfer of proteins from polyacrylamide gels to nitrocellulose sheets: Procedure and some applications. Proc Natl Acad Sci 76, 4350-4354 (1979).

111. Trimble, W., Cowan, D., Scheller, R. VAMP-1: a synaptic vesicle-associated integral membrane protein. Proc Natl Acad Sci 85, 4538-4542 (1988). 
112. Ueda, T., Greengard, P., Berzins, K., Cohen, R., Blomberg, F., Grab, D., Siekevitz, P. Subcellular distribution in cerebral cortex of two proteins phosphorylated by a cAMPdependent protein kinase. J Cell Biol. 83, 308-19 (1979).

113. Ullrich, O. et al. Rab GDP dissociation inhibitor as a general regulator for the membrane association of rab proteins. J. Biol. Chem. 268, 18143-18150 (1993).

114. Verrier, S. E. et al. Members of a mammalian SNARE complex interact in the endoplasmic reticulum in vivo and are found in COPI vesicles Eur. J. Cell Biol. 87, 863-878 (2008).

115. Walch-Solimena, C., Blasi, J., Edelmann, L., Chapman, E. R., Fischer von Mollard, G., Jahn, R. The t-SNARE syntaxin 1 and SNAP-25 are present on organelles that participate in synaptic vesicle recycling. J. of cell Biol. 128, 637-645 (1995).

116. Wang, S., Moriyama, Y., Mandel, M., et al. Cloning of cDNA encoding a 32-kDa protein. An accessory polypeptide of the $\mathrm{H}$-ATPase from chromaffin granules. $J$. Biol. Chem. 263, 17638-42 (1988).

117. Weber, T., Zemelman, B.V., McNew, J.A., Westermann, B., Gmachl, M., Parlati, F., Söllner, T.H., and Rothman, J.E. SNAREpins: Minimal machinery for membrane fusion. Cell 92, 759-772 (1988).

118. Weimbs, T., Low, S. H., Chapin, S. J., Mostov, K. E., Bucher, P., Hofmann, K. A conserved domain is present in different families of vesicular fusion proteins: a new superfamily. Proc. Natl. Acad. Sci. 94, 3046-3051 (1997).

119. Whittaker, V. P., Michaelson, I. A., Kirkland, R. J. The separation of synaptic vesicles from nerve-ending particles ('synaptosomes'). Biochem. J. 90, 293-303 (1964).

120. Whittaker, V. P., Essman, W. B., Dowe, G. H. C. The isolation of pure cholinergic synaptic vesicles from the electric organs of elasmobranch fish of the family torpedinidae. Biochem. J. 128, 833-846 (1972).

121. Wiedemann, B. and Franke, W.W. Identification and localisation of synaptophysin: An integral membrane glycoprotein of $\mathrm{Mw} 38,000$ characteristic of presynaptic vesicles. Cell 41, 1017-1028 (1985).

122. Wingert, F. Biometrische Analyse der Wachstumsfunktionen von Hirnteilen und Körpergewicht der Albinomaus. J. Hirnforsch. 11,133-97 (1969).

123. Wu, S.K., Zeng, K., Wilson, I.A. \& Balch, W.E. Structural insights into the function of Rab GDI superfamily. Trends Biochem. Sci. 21, 472-476 (1996). 
124. Xie, X. S, Stone, D. K. Partial resolution and reconstitution of the subunits of the clathrin-coated vesicle proton ATPase responsible for $\mathrm{Ca} 2+$-activated ATP hydrolysis. J. Biol. Chem. 263, 9859-67 (1988).

125. Xu, T., Rammner, B., Margittai, M., Artalejo, A. R., Neher, E., Jahn, R. Inhibition of SNARE complex assembly differentially affects kinetic components of exocytosis. Cell 99, 713-722 (1999).

126. Zimmermann, H., Denston, C.R. Separation of synaptic vesicles of different functional states from the cholinergic synapses of the Torpedo electric organ. Neuroscience 2, 715-30 (1977).

127. Zimmermann, H., Whittaker, V. P. Effect of electrical stimulation on the yiel and composition of synaptic vesicles from the cholinergic synapses of the electric organ of Torpedo: A combined biochemical, electrophysical and morphological study. J. of Neurochem. 22, 435-450 (1974). 


\section{List of Publications}

Ahmed S, Holt M, Riedel D, Jahn R, `An Improved Method for Small-Scale Isolation of Synaptic Vesicles from Mammalian Brain` (accepted Nature protocols)

Another manuscript is in preparation 


\section{Acknowledgements}

I am grateful to my supervisor, Professor Reinhard Jahn, for giving me the opportunity to perform my Ph.D. in his laboratory and for his support and guidance.

I am also thankful to Dr Matthew Holt for his involvement in my work and for his advice and support during my Ph.D. He guided me with patience in my first scientific steps.

I am thankful to all my colleagues at the Department of Neurobiology for their help and enjoyable time in the lab especially to Emilio, Geert and Yaj. I am grateful to Gottfried Mieskes for his help in solving technical problems and Dietmar Riedel for the introduction into electron microscopy.

I am thankful to my committee member Professor Nils Brose for his time and support.

I look to my family with deep fondness and gratitude for their constant support and prayers. 


\section{Curriculum vitae}

\section{Personal information}

Name: $\quad$ Saheeb Ahmed

Date of birth: $20^{\text {th }}$ of September, 1981

Place of birth: Sargodha, Pakistan

Nationality: German

\section{Education}

2007 - Present:

Ph.D. student of the Georg-August-Universität, Göttingen, Germany at the Department of Neurobiology, Max-Planck Institute for Biophysical Chemistry, Göttingen, Germany

2006 - 2007:

Diploma thesis at the Department of Neurobiology, MaxPlanck Institute for Biophysical Chemistry, Göttingen, Germany

2002 - 2007:

Diploma degree in Biology at the Georg-August-Universität, Göttingen, Germany 